\title{
Environmental Influences on Neuroticism in Adulthood: A Systematic Review
}

Bertus F. Jeronimus, Harriëtte Riese, Johan Ormel.

University of Groningen, University Medical Centre Groningen, Interdisciplinary Center Psychopathology and Emotion regulation (ICPE), The Netherlands.

Cite as:

Jeronimus, B.F., Riese, H., Ormel, J. (2015). Environmental influences on neuroticism in adulthood: A systematic review. In book: Environmental influences on neuroticism: A story about emotional (in) stability. Chapter 4, page 75-131. B.F. Jeronimus. PhD thesis. University of Groningen, Groningen. Ridderprint B.V., the Netherlands, ISBN: 978-94-6299035-7. Doi:10.13140/2.1.3452.2407

This version might not exactly replicate the final version published in the book.

It is not the copy of record. 


\section{Abstract}

Behavioral-genetic studies show substantial non-genetic influences on variance of neuroticism within a population. Longitudinal studies show a small but steady drop in testretest correlations with increasing time intervals. This suggest environmental effects on neuroticism, but a systematic overview of which environmental determinants account for change in neuroticism is lacking. We review (specific or unique) environmental influences that modify the neuroticism setpoint in adulthood and therewith individual life trajectories. Results are interpreted in light of the so-called 'mixed model' in which within-person changes in neuroticism are subdivided over short term perturbations around the setpoint of neuroticism versus more persistent changes in the setpoint itself. To account for genetic confounding and shared environmental influences studies of monozygotic (MZ) twin pairs discordant for neuroticism and longitudinal studies that report on environmental factors that predict within-individual change in neuroticism are reviewed. Our results indicate that the neuroticism setpoint is consistently touched by experiences that affect central aspects of one's identity and status, mainly role transitions as partner (marriage/divorce) and employee (job loss/promotion). Especially interpersonal stress, conflict, and major events that were unpredictable, uncontrollable, unexpected, undesirable, and 'off time' from a life history perspective were followed by changes in neuroticism that persisted more than six months, which suggest setpoint change. Most change after severe SLEs persisted over a decade. Long-term and detailed studies are required to elucidate the details of the 'mixed model' of change in neuroticism. An understanding of the specifics of the events that lead to persistent changes in neuroticism may enable us to craft prevention strategies to tackle the vulnerability for mental disorders inherent in high neuroticism, rather than to wait for their manifestation. 


\section{Introduction}

"After fixing upon some particular class of persons of similar age, sex, and social condition, we have to find out what common incidents in their lives are most apt to make them betray their character." $\quad$ Francis Galton, Measurement of Character (Galton, 1884).

"By changing the inner attitudes of our minds, we may change the outer aspects of our lives. ” William James (1842-1910; James, 1890)

In this paper we review environmental influences on neuroticism, a broad superordinatedimension of behavioural variation in all major theories of temperament and personality. The core of neuroticism is to perceive the world as threatening, and to experience various negative emotions including anxiety, fear, sadness, anger, frustration, irritability, loneliness, worry, self-consciousness, dissatisfaction, hostility, guilt, shyness, distress, self-reproach, and reduced self-confidence (John et al., 2008; McCrae et al., 2008; Widiger, 2009; Jeronimus, 2015). High neuroticism is among the strongest predictors of physical and mental health problems (Hong et al., 2014; Kotov et al., 2010; Ormel et al., 2013), and forecasts important life outcomes such as occupational attainment, divorce, and mortality (Caspi et al., 2005; Chapman et al., 2010; Krueger et al., 2000; Mroczek et al., 2007; Ozer et al., 2006; Roberts et al., 2007). The total economic costs of high neuroticism to society have been estimated at twice that of the common mental disorders combined (Cuijpers et al., 2010).

\section{Environmental influences}

Historical nature-versus-nurture debates of neuroticism have given way to the convention that both are important. Studying genetically identical (MZ) twins reared together and apart indicate that about half of the variance in neuroticism does not root in genetic factors (Briley et al., 2014; Eaves et al., 1989, 1999; Flint, 2004; Jardine et al., 1984; Keller et al., 2005; Laceulle et al., 2013; Lake et al., 2000; McGue et al., 1993; Pilia et al., 2006; Rettew et al., 2006; Tambs et al., 1991; Viken et al., 1994). Longitudinal studies show that the intraindividual temporal stability of neuroticism, as indexed by test-retest correlations, drops steadily over increasing intervals to plateau between $r=.30$ to .50 after 40 years (Billstedt et al., 2013; Briley et al., 2014; Conley, 1985; Fraley et al., 2005; Ormel et al., 2000, 2013; Roberts et al., 2000; Wray et al., 2007). Moreover, substantial intra-individual changes in neuroticism have been observed along the lifespan (Fraley et al., 2005; Helson et al., 2002; Mroczek et al., 2006; Roberts et al., 2000, 2006, 2008). Though neuroticism is of clear importance to societal health (Barlow et al., 2014; Hong et al., 2014; Lahey, 2009; Ormel et al., 2013), remarkably little is known about environmental influences that underlay individual differences and change in neuroticism (Jeronimus et al., 2014; Ormel et al., 2012; Roberts et al., 2008). This paper aims to fill this gap with a review of experiential influences that modify adult neuroticism, but this aim is muddled by person-environment correlation.

\section{Person-environment Correlation}

With age we become mutually accommodated with the changing environment in which we live and grow (Caspi et al., 2005; Kendler et al., 2007; Neyer et al., 2014). For example, we 
select a spouse, friends, vocation, or hobby (or not), and select ourselves into specific situations, but avoid others, a constellation of choices that tend to intensify the propensities that drove us up there in the first place (Caspi et al., 1990, 2005; Dawkins, 1982; Fraley et al., 2005; Jaenike et al., 1991; Johnson, 2007; Kendler et al., 1997, 2007; Rutter, 2012; Shiner et al., 2002). Twin studies show that $20-80 \%$ of the individual differences in various measures of our environment - from social support to life stress - is driven by genetic differences (Bemmels et al., 2008; Dawkins, 1982; Kendler et al., 1997, 2007; Power et al., 2013; Vinkhuyzen et al., 2009). A substantial part of this variance is mediated by neuroticism (Fergusson et al., 1987; Kandler et al., 2012; Power et al., 2013; Saudino et al., 1997), and many behavioural genetic and longitudinal studies show mutual reciprocity between neuroticism and life stress (Finn et al., 2013; Jeronimus et al., 2013, 2014; Kandler et al., 2012; Middeldorp et al., 2008; Riese et al., 2014). Both environmental influences on neuroticism and the rank-order between individuals become increasingly stable along the lifespan, which suggests that increasing gene-environment correlations ( $r \mathrm{GE}$ ) stabilize both our environment and personality (Bleidorn et al., 2014; Briley et al., 2014; Ferguson, 2010; Kandler et al., 2010; McGue et al., 1993; Roberts et al., 2000, 2006; Viken et al., 1994; Wray et al., 2007; Wrzus et al., 2013).

Our environment also changes in pace with a biosocial life script that is manifest in the occurrence, timing, sequencing, duration, and interaction of many social processes and normative life events along our life span (Arnett, 2004; Bleidorn et al., 2013;

Bronfenbrenner, 2005; Ferguson, 2010; Jeronimus et al., 2014; Kandler et al., 2012; Mills, 2000; Neyer et al., 2014; Sameroff, 2010; Wrzus et al., 2013) ${ }^{1}$. For example, we live and grow in a social convoy that escorts us as fellow travelers through time, with our family, spouse, and friends at the core, and acquaintances, neighbors and colleaguesare at the periphery (Antonucci et al., 1987; Carstensen, 2006; Wrzus et al., 2013). This social convoy reaches its maximum size during young adulthood, followed by a shrinkage with age (Carstensen, 2006; Wrzus et al., 2013). These social processes influence the kind of events we experience, part of their impact, and how we regulate our emotions (Antonucci et al., 1987; Arnett, 2004; Carstensen, 2006; Wrzus et al., 2013).

Most positive life events (PLEs) occur during young adulthood (age 20-45), for example, because PLEs tend to relate to the acquisition of social roles, e.g. go live on one's own, graduation, a new friend, a first job, promotion, falling in love, marriage, or giving birth (Berntsen et al., 2011; Masuda et al., 1978; Mills, 2000; Neyer et al., 2014; Rubin et al., 2009). The associated social role changes and pressures drive a maturational mean-level decrease in neuroticism of about $d=0.80$ between age 10 and 40 (Bleidorn et al., 2013; Caspi

\footnotetext{
${ }^{1}$ This has been described in terms of the Red Queen Personality Principle (Jeronimus, 2015), after the Red Queen in Lewis Carroll's book 'Through the Looking Glass' who describes her country as a place where 'it takes all the running you can do, to keep in the same place" (Carroll, 1871). Leigh van Valen used this metaphor to explain that organisms have to continually change and adapt to compete with co-evolving species in order to retain their ecological niche and pace within an increasingly deteriorating environment (van Valen, 1973). In analogy, our development must keep pace with our changing environment and bioecological clock that shapes the fabric of our personal atmosphere (Jeronimus et al., 2014). For example, we have to co-develop with our aging birth-cohort to keep our rank-order the same (Roberts et al., 2000, 2006), as many peers and friends simultaneously experience the same life changes, e.g. graduation, a first job and partner, or children (Arnett, 2004; Friedman et al., 2011). In Germany the mean ages (statistical norm) for a first job is $21.2(S D=4.9)$, birth of a child (31.1, $S D=6.7)$, marriage ( $34.2, S D=10.2)$, separation from partner $(35.6, S D=11.2)$, children leaving home ( 49.7 , $S D=7.7)$, death of spouse $(65.9, S D=10.3)$, see (Neyer et al., 2014; Specht et al., 2011).
} 
et al., 1993; Durbin et al., 2014; Lodi-Smith et al., 2007; Roberts et al., 2006). Negative life events (NLEs), in contrast, tend to be "unscripted" or refer to deviations from the normative timing and sequencing of the biosocial life script, e.g. divorce, widowhood, or unemployment (Lodi-Smith et al., 2007; Neyer et al., 2014; Roberts et al., 2005; Rook et al., 1989; Rubin et al., 2009) ${ }^{2}$. Consequently, NLEs tend to be more uniformly distributed over the life cycle, although their incidence tends to increase slightly from midlife onwards (Berntsen et al., 2011; Masuda et al., 1978; Rubin et al., 2009).

\section{The current study}

A strict demarcation between the individual and the environment is largely based on statistical methodology (Beam et al., 2013; Dawkins, 1982; Johnson et al., 2015; Lewontin, 2000; Ridley, 2003; Roberts et al., 2008). When we aspire to review environmental influences on neuroticism we have to rule out genetic confounding of environmental influences. The best approach seems the application of a neuroticism-discordant monozygotic (MZ) twin design, which has the extraordinary advantage of a control person with a virtually identical DNA sequence. MZ-twins grew up together in the same family environments, tend to share most peers, and share most indirect genetic effects, resulting in close to parallel lives. As a result, most within-MZ-twin pair differences in neuroticism are due to unique environmental influences (Boomsma et al., 2002; Charney, 2012; Fraga et al., 2005; Loehlin, 1992; Plomin et al., 2001). Hence, a review of studies on MZ-twin-pairs discordant for neuroticism seems the best approach to study environments that elicit change in neuroticism, as this design inherently controls for most genetic confounding.

Unfortunately, as we will show, the literature with regard to neuroticism-discordant MZ-twin pairs is strikingly limited. This review therefore additionally includes studies with, a methodologically less strong, within-person longitudinal design to evaluate developmental patterns. However, in population samples, genetic and environmental variance cannot be disentangled and results may be influenced by selection effects or selective subject attrition and, in particular when the time interval between measurement waves is short, be confounded by reciprocal influences or measurement of concurrent relations (potential test-retest carryover effects). As a notable advantage, the repeated measurements in a longitudinal study, however, enable the observation of the temporal order of experiences. Moreover, time quantifies the rate of intra-individual change. In addition, longitudinal studies have the benefit of excluding time-invariant unobserved individual differences, as individuals serve as their own controls. However, the many longitudinal studies on personality (see for a bibliometric portrait (Allik, 2013)) force us to limit ourselves to specific topics.

In this review we focus on longitudinal studies of major PLEs and NLEs i.e. timediscrete transitions that bring about a major change in social, economic or financial status, sources of affection, or social roles (Holmes et al., 1967; Luhmann et al., 2014). Such natural noxious circumstances or events place a stress (burden or strain) upon individuals that tax

\footnotetext{
${ }^{2}$ Departures from these norms may not only stressful because of (prescribed) social norms and pressures, but also because they are unexpected, which impedes anticipatory rehearsal and coping (Mills, 2000; Neugarten, 1979; Rook et al., 1989). Moreover, individuals who are "off time" cannot benefit from the social and institutional structures that smooth the way for those who are "on time" (Caspi et al., 1989; Elder Jr., 1975), e.g. support from peers with similar experiences. Finally, some constraints increase with age, e.g. stigmatization is stronger for singles of age 40 than age 25 (Morris et al., 2007).
} 
their psychological capacities to adapt (Cassel, 1976; Jeronimus et al., 2014; McCrae, 1990). While most life events shall result in short-term state fluctuations of negative affect $(<6$ months), some major events or social role modifications can change the setpoint (or personal average) of the neuroticism density distribution (Fleeson, 2001; Jeronimus et al., 2014; Riese et al., 2014). This regulation mechanism has been called the mixed model of change in neuroticism, and has been described in detail before (see Jeronimus et al., 2015; Ormel et al., 2012). In this review we focus on studies with a span of at least one year such that our events occurred on average at least 6 months before follow-up, in order to explore the long-term dynamics of setpoint change ( $c f$. Jeronimus et al., 2014).

We also focus on experiences that took place in the three core systems in which we are embedded: our nuclear family, social network, and occupational life (Bronfenbrenner, 2005; Jeronimus et al., 2014). These systems are characterized by regulated patterned activities, social roles, and interpersonal relationships, and form the enduring environments that become most colored by recurrent person-environment interactions (Bronfenbrenner, 2005; D. Nettle, 2007). Moreover, the age-graded enactment in these social roles as partner, parent and employee are theorized to drive the mentioned mean-level decrease in neuroticism between age 20 and 40 , estimated at $d=0.20$ per decade (Roberts et al., 2006, 2008) ${ }^{3}$. These choices mean, however, that changes in neuroticism after childhood abuse and adversities before age 18 (Caspi et al., 2011; Jeronimus et al., 2013; Seery et al., 2010), effects of diet, hobbies and sports (Egan et al., 2003; Goma-I-Freixanet, 1991), daily hassles and uplifts (Kanner et al., 1981), inter-cultural differences (Schmitt et al., 2008), and psychological interventions and medication (Du et al., 2002; Jorm, 1989; Tang et al., 2009), among others, fall outside the scope of this review. In sum, we review major environmental influences that modify the neuroticism setpoint during adulthood, and therewith individual life trajectories.

\section{Method}

\section{MZ-twin approach}

Articles between 1950 and 2015 were searched for in the databases of PsychINFO, PubMed, and the ISI Web of Knowledge. The search strings consisted out of two components, with as first string the keywords 'neuroticism, negative emotionality, negative affectivity, trait anxiety or emotional stability'. The last five keywords were included because these domains are constructs closely related to neuroticism. Trait-anxiety refers to long-term and stable personality construct, defined as the tendency to respond with state-anxiety in the anticipation of threatening situations, akin to neuroticism (Smoller et al., 1998). Negative affectivity roughly corresponds to neuroticism, but is often measured on shorter time scales (Ormel et al., 2012; Watson et al., 1984). If results refer to trait-anxiety or negative affectivity this shall be explicitly noted.

The second component of the search string consisted of the terms ' $\mathrm{MZ}$ twins, monozygote, monozygotic twins or identical twins'. Two reviewers screened the search

\footnotetext{
${ }^{3}$ Known as 'absolute continuity', this reflects the assessment of group averages at certain age-points, which shows normative biosocial-maturational changes when a generation maturates (Mroczek et al., 2006). Notably, closely related primate species show similar age-related maturational decreases in emotionality (King et al., 2005; Weiss et al., 2012).
} 
results. The reviewers first screened the title and abstracts of the papers on inclusion criteria. We aimed at papers about MZ-twin pairs that explain within-pair differences in neuroticism. For this paper we selected papers focusing on determinants of the discordance in neuroticism $(k=5)$. Papers without neuroticism-measures or zygosity determination were excluded $(k=$ $60)$. From the remaining papers about neuroticism-discordant MZ-twins, we extracted the cohort name and its characteristics. We recorded, where possible, the sampling population, recruitment strategy, response rate, the actual or eligible age range of the twins, the mean age (SD) of the twins, the proportion women in the sample and significant inclusion and exclusion criteria used in the studies. We further collected the name of the first author, year of publication, type of neuroticism measure, number of participants, zygosity determination and outcome regarding neuroticism. We also noted the criteria used to determine neuroticism, viz. the name of the measurement instrument, the administration format (self-report, interview, observer ratings) and the number of items of the instrument that was used. Crosslinked searches were made taking the lead from key articles.

\section{Longitudinal studies}

We searched for articles published between 1950 and 2015 in all databases of ISI Web of Knowledge, PubMed, and PsychINFO. The same first search-string was used as with the search for MZ-twin studies (neuroticism, negative emotionality, negative affectivity, trait anxiety or emotional stability), complemented by the terms 'Longitudinal or prospective'. The results were screened with our fourfold a-priori selection criteria: The study (a) had to contain a measurement of neuroticism (or negative emotionality or trait-anxiety) before the experience of interest (e.g., divorce); (b) had to contain another measurement of neuroticism (or negative emotionality, trait-anxiety, emotional stability) after the occurrence of the experience; (c) a minimum follow-up time of 12 months; (d) had to be written in English, Dutch, German or French; (e) needed a minimum sample $(N>150)$ to gain sufficient statistical power. From the selected articles we extracted the sampling population, mean age (SD), proportion women, and significant inclusion and exclusion criteria. The same information as described above for the MZ studies were extracted from the selected articles

\section{Statistics}

The heterogeneity of the outcome measures precluded a formal meta-analysis of the environmental influences on neuroticism. However, in order to improve on comparability, outcomes were converted into standardized difference or change score units Cohen's $d$ (Breaugh, 2003). An effect size $d$ of zero means that both groups are exactly the same, whereas 0.50 indicates that the average person in the group who experienced a particular event scored half a SD on neuroticism above the average control. We used conversion formulas derived from Borenstein (2009) and Peterson (2005). As a heuristic to guide interpretation of findings, the convention is that a $d$ of 0.20 is regarded a small effect, 0.50 as medium, and 0.80 as large (Cohen, 1992). For correlations .10-.29 is considered small, .30.49 medium, and from .50 large (Cohen, 1992). We encountered many studies which did not provide enough information to calculate a Cohen's $d$, and for these studies the review lacks an effect size in the text. 


\section{Reporting}

The information extracted from the selected articles is ordered within four broad themes or foci of empirical inquiry; (a) romantic relationships (relationship initiation, properties, and dissolution); (b) social environments (nuclear family, friends); (c) occupational environments; and (d) major non-normative positive and negative stressful life events. In the result section we introduce each theme with a short outline of known neuroticism-driven selection effects in existing meta-analysis and reviews, followed by the studies we encountered, and a synthesis of each theme. This review is restricted to studies conducted in adults, because parenting effects on neuroticism (in the range of normal family-to-family variation) seem to wash out in late adolescence (Goldsmith et al., 1997; Harris, 2009; Krueger et al., 2003; Plomin et al., 2011; Saudino, 2005), while genetic control over the environment increase with age (Harris, 2009; Krueger et al., 2003; Plomin et al., 2011). The results have been arranged over the topics given in Table 1, but note that our choice for these topics was partly influenced by the availability of literature. Moreover, these topics and the broad themes in which they have been arranged show overlap, especially romantic partnerships and social network.

Table 1.

\begin{tabular}{|c|c|c|c|c|c|}
\hline & Romantic Partnerships & Page & & Occupational Environment & Page \\
\hline A1 & Selection effects & 9 & $\mathrm{C} 1$ & Selection effects & 20 \\
\hline A2 & Relationship initiation & 9 & $\mathrm{C} 2$ & Occupation, status, and salary & 21 \\
\hline A3 & Stable partnered and stable single & 10 & C3 & Occupational Satisfaction & 22 \\
\hline A4 & Relationship properties & 11 & $\mathrm{C} 4$ & Occupational Life & 22 \\
\hline A5 & Relationship dissolution & 13 & $\mathrm{C} 5$ & Person-environment fit & 22 \\
\hline A6 & Widowhood & 14 & C6 & Retirement & 23 \\
\hline \multirow[t]{2}{*}{ A7 } & Conclusion & 14 & $\mathrm{C} 7$ & Conclusion & 23 \\
\hline & Social Network & & & Stressful Life Experiences & \\
\hline B1 & Selection effects & 15 & D1 & Stress generation & 24 \\
\hline B2 & Cohabitation & 15 & D2 & Positive experiences & 25 \\
\hline B3 & Nuclear family & 16 & D3 & Negative experiences and timing & 26 \\
\hline B4 & Reproduction & 17 & D4 & Event chains & 27 \\
\hline B5 & Social networks & 18 & D5 & Clustering & 28 \\
\hline B6 & Conclusion & 19 & D6 & Gender differences & 28 \\
\hline
\end{tabular}

\section{Results}

\section{Search results}

The systematic search for MZ-twin studies yielded 371 potentially relevant papers, of which 218 were unique (59\%). As a next step only the papers handling about environmental influences on neuroticism in MZ-twin pairs were selected. References of original articles and related reviews were hand searched for additional papers. We excluded 213 studies because they did not meet the apriori selection criteria listed above. Finally, five twin studies were included in the review study. The systematic searches of longitudinal studies identified 6592 studies, among which 3960 were unique (60\%). The bibliographical lists of all included 
studies were searched for possible additional studies. Overall 60 longitudinal studies met the criteria and were included in the review study and are presented in Table 3 below.

Table 2. Search results

\begin{tabular}{lrrrr} 
& \multicolumn{2}{c}{ Twin studies } & \multicolumn{2}{c}{ Longitudinal } \\
& Total & Unique & Total & Unique \\
Total & 371 & 218 & 6592 & 3960 \\
Excluded & & 213 & & 3900 \\
Included & & 5 & & 60 \\
\hline
\end{tabular}

\section{Review of Empirical Findings Section A: Romantic relationships}

Romantic relationships are the closest and most important relationships in nature after motherhood (Mund et al., 2014; Neyer et al., 2011). We review the effects of a transition into a romantic partnership or marriage on neuroticism, followed by the effects of different relationship properties, and the impact of relationship dissolution or divorce, respectively. While some of these events expand our social system (e.g., a new relationship) others are characterized by a loss within the system (e.g., death of a spouse or divorce) (Jeronimus et al., 2014; Wrzus et al., 2013). We first provide a short outline of some neuroticism-driven selection effects.

\section{Selection effects (A1)}

The selection of a mate is one of the most salient examples of environmental selection (Caspi et al., 1989). Moreover, divorce, separation, and loss of a spouse are considered the three most stressful life events in adulthood (Holmes et al., 1967; Riese et al., 2014; Sutin et al., 2010). Most variance in divorce risk can be explained by genetic differences, somewhat more for men than women (Jockin et al., 1996; McGue et al., 1992), and high neuroticism predicts a substantial part of this "relationship load" (Buss, 2003), at least more than SES or IQ (Roberts et al., 2007). Neuroticism does this via cognitive and emotional processes that color how individuals perceive and construe their environment (Chan et al., 2007; Finn et al., 2013). In short, individuals high (vs. low) on neuroticism tend to select themselves into marital instability $(d=0.45)$, dissatisfaction $(d=0.35)$, conflict $(d=0.60)$, abuse $(d=1.15)$, and dissolution ( $d=0.35)$ (Buss, 1991, 2003; Karney et al., 1995; Kendler, Gardner et al., 2003). Moreover, high ( $v s$. low) neuroticism predicts both the most common cause of marital dissolution, viz., infidelity ( $d=0.91$ ) (Buss et al., 1997; Schmitt \& Shackelford, 2008; Whisman et al., 2007) ${ }^{4}$; and the third universal cause, maltreatment (Betzig, 1989; Buss, 2003). For example, women who partner with a high ( $v s$. low) neurotic men are four times more likely to be abused (Buss, 2003). In the next paragraphs we explore the influences of factors in the romantic relationship domain on neuroticism.

\footnotetext{
${ }^{4}$ Neuroticism predicts the annual prevalence of infidelity after control for gender, age, race and education $(d=0.91)$, and even after control for marital dissatisfaction, $d=0.59$ (Buss, 2003; Whisman et al., 2007).
} 


\section{Relationship initiation (A2)}

Unfortunately, no twin studies of transitions into romantic partnership or marriage were encountered, nor studies of cohabitation of romantic partners and neuroticism. Most longitudinal studies showed decreases in neuroticism after partnering (Costa et al., 2000; Lehnart et al., 2010; Mroczek et al., 2003; Neyer et al., 2001, 2007; Robins et al., 2002), although not all (Jeronimus et al., 2013; Lüdtke et al., 2011). Studies that focused on young adults showed that single 20 year-olds who partnered over the next decade decreased in neuroticism, $d=0.30$ to 0.50 (Lehnart et al., 2010; Neyer et al., 2001, 2007). This decrease was observed irrespective of the duration of the relationship, gender, age (Lehnart et al., 2010; Neyer et al., 2001, 2007), marital status, whether individuals cohabited with the partner, lived on their own, or still lived with their parents (Neyer, 1999). Middle-aged men (age 39-45) also decreased in neuroticism after marriage in middle-age $(d=0.40)$, compared to controls who did not marry (Costa et al., 2000; Mroczek et al., 2003). Saliently, women did not (Costa et al., 2000). However, divorced men (aged 43-91) who remarried also decreased in neuroticism over the next decade after remarriage $(d=0.50)$, compared to men who did not remarry (Mroczek et al., 2003).

Alas, no information was available for the average rate of adaptation to a new partnership or marriage ("the honeymoon effect"), thus how long the decrease in neuroticism persists. Although it is known that subjective wellbeing is increased for about two years (Lucas et al., 2003). After partnering young adults decreased primarily in terms of negative affectivity (depression/anxiety) rather than emotional reactivity (impulsivity and anger) (Asendorpf et al., 2003; DeYoung et al., 2007; Lehnart et al., 2010). In sum, a new romantic relationship tends to be followed by a decrease in neuroticism, most likely for at least a decade, and at least for men, this effect is not limited to first relationships and young adulthood, but can take place along the life cycle.

\section{Stable partnered and stable single (A3)}

Young adults who were stable single or stable partnered between age 20 and 30 showed fairly stable neuroticism levels (Lehnart et al., 2010; Neyer et al., 2001, 2007). However, young adults who continued their relationship decreased more in neuroticism than their peers who separated, $d=-0.36 v s$. -0.22 (Neyer et al., 2007; Robins et al., 2002). Notably, the latter decrease aligns with the normative decrease in neuroticism (of about $d=0.20$ per decade) between age 20 and 40 (Roberts et al., 2006). Adults who changed partner between age 20 and 30 showed a lower temporal stability in neuroticism $(r=.46 v s . .65)$ and smaller decreases in neuroticism than their stable settled and even stable single peers (Lehnart et al., 2006, 2010; Neyer et al., 2001, 2007; Robins et al., 2002 $)^{5}$. These results suggest that relationship continuers ( $\sim 30 \%$ of the participants) show the stereotypic normative maturational decreases but that changers $(\sim 70 \%)$ follow more differential developmental patterns (Lehnart et al., 2006; Robins et al., 2002).

Arguably, partnership dissolution (and re-partnering) may have different implications for different individuals. While some shall be relieved, others may be frightened (Amato et

\footnotetext{
${ }^{5}$ Notably, in contrast, one four-year study reported equal rank-orders of $r=.58$ (Robins et al., 2002).
} 
al., 2007), and these perceptions may result in either a decrease or increase in neuroticism (Lehnart et al., 2006; Neyer et al., 2014). More differential patterns for changers align with the argument in the introduction that normative experiences facilitate the normative maturational changes in personality (viz., decreases in neuroticism), while non-normative experiences evoke responses in line with previous neuroticism levels, thus more differences in response (Caspi et al., 1993; Neyer et al., 2014). Finally, the larger changes in the stable partnered young adults aligns with the idea of romantic relationships as transaction systems, which show a reset after a change of partner (Fraley et al., 2005; Lehnart et al., 2006; Neyer et al., 2001, 2007a, 2007b).

Partnered individuals decreased most in negative affects like sadness and anxiety but not much in emotional reactivity dimensions such as impulsivity and anger (Asendorpf et al., 2003; DeYoung et al., 2007; Lehnart et al., 2010). Finally, two longitudinal studies observed comparable neuroticism levels for married and unmarried adults from age 20 to 30 (Neyer et al., 2001), or for single and stable cohabiting coupes in their thirties, even in retrospect, when both groups were 15 years old (Möller, 2004). This suggests that relationship-transition effects are transient, and that levels gravitate back to their setpoint over a period of adaptation and reorientation (Mroczek et al., 2003), a homeostatic process, which in previous studies has been called the dynamic equilibrium model (Headey et al., 1989, 2010; Lucas et al., 2003, 2007; Ormel et al., 2012). The reviewed studies are by no means conclusive about the effects of partnering, e.g. stable singles may start to increase in neuroticism when their deviation from the biosocial life script becomes more salient with age (Morris et al., 2007), as implied in our introduction. Moreover, the conflicting studies lacked information about past relationships, while divorces may undo some of the initial benefits of partnering (Betzig, 1989; Friedman et al., 2011), a topic we come to after the next paragraph.

\section{Relationship Properties (A4)}

Neuroticism is for both genders associated with unstable marriages (Kurdek, 1993), and also the strongest personality predictor of marital (dis)satisfaction (Heller et al., 2004). Satisfying partnerships buffer spouses from psychological distress and negative life events, whereas marital distress and instability forecasts negative outcomes over the life course (Buss, 2003; Karney et al., 1995). The pendulum for neuroticism appears to swing under the influence of relationship-properties (Fraley et al., 2005; Lehnart et al., 2006; Neyer et al., 2001): We already concluded that individuals who enter a romantic partnership tend to decrease in neuroticism, but this process is faster in high quality, satisfying, affectionate, and secure relationships (Lehnart et al., 2006; Roberts et al., 2000; Robins et al., 2002; Scollon et al., 2006). Even high dependent individuals decrease in neuroticism after partnering, albeit it takes them more time in their partnership to do so (Lehnart et al., 2006). Furthermore, also individuals who increased in relationship closeness over 8 years decreased in neuroticism, but the decrease of the next 7 years did not reach significance (Mund et al., 2014).

Increases in neuroticism were observed for individuals in unhappy and maladaptive partnerships, especially when they were exposed to repeated negative states (Robins et al., 2002), relationship stress (Zautra et al., 2005), dissatisfaction (Neyer et al., 2001; Roberts et al., 2000; Robins et al., 2002; Scollon et al., 2006), insecurity (Mund et al., 2014; Neyer et al., 2001; Roberts et al., 2000; Robins et al., 2002; Scollon et al., 2006), conflict (Mund et al., 
2014; Robins et al., 2002), abuse ( Robins et al., 2002), and negative sexual experiences (Lüdtke et al., 2011). Moreover, the reported dose-response association ( Robins et al., 2002) between maladaptive relationships and negative affect suggest causality (Rutter, 2000), viz. the disposition towards neurotic distress probably results from recurrent negative states or acts of aggression (Krueger, 1999b; Roberts et al., 2008; Robins et al., 2002). Results also indicate that individuals who reported negative relationship-experiences became (on average) more hostile and irritable (mistrusting/self-critic) than their peers ( Robins et al., 2002). Finally, one study reported that more conflicts with a romantic partner predicted subsequent decreases in neuroticism (Mund et al., 2014).

The reviewed studies indicate enduring dynamics (Caspi et al., 2001), e.g. relationship properties had stronger effects in stable-partnered adults than among relationships changers (Robins et al., 2002), in keeping with the relationship as transaction-system perspective. Moreover, a stable relationship does not mean higher personality stability, e.g. men who had highly satisfied marriages over a 24-year interval between high school and midlife reported more personality change (Clausen et al., 1998), in line with observations that neuroticism levels decrease more in a happy marriages (Lehnart et al., 2006; Roberts et al., 2000; Robins et al., 2002; Scollon et al., 2006). Third, men who married a spouse who was high on traitanxiety tended to increase in negative affect (at all four waves) over 13 years of marriage ( $r=$ .33; Caughlin et al., 2000), which suggests emotional contagion. Surprisingly, the reverse association, viz., between the husbands' level of trait-anxiety at $T_{1}$ and the wives' negative affect 13 years later, was not significant (Caughlin et al., 2000) ${ }^{6}$. Fourth, young adults often reported comparable relationship experiences with different partners, indicative of crossrelationship generalization of neuroticism effects on partner selection and relationship quality (Caspi et al., 1989; Robins et al., 2002) ${ }^{7}$. In sum, it seems likely that highly neurotic young adults select themselves in partnerships that over time lead to relationship insecurity and increased neuroticism (Neyer et al., 2007), in accord with the corresponsive principle.

Virtually all observed effects were bidirectional (correlated change), and pure relationships effects on neuroticism were rare (Lehnart et al., 2006). These results support transactional models of human behavior (Caspi et al., 1989; Endler et al., 1976), and the characteristic tendency of individuals high on neuroticism to select themselves into situations that foster negative affect, via the selection of specific partners ( Buss, 2003), interactionstyles (Caughlin et al., 2000; Gottman et al., 1998) ${ }^{8}$, and conflicts (Bolger et al., 1995; Suls et al., 2005). Furthermore, in 40-60\% of the romantic relationships the partners break-up and renew their relationship at least once, called cyclicality (Dailey et al., 2009). Cycling in cohabiting and marital relationships is associated with more uncertainty and lower relationship satisfaction (Vennum et al., 2014), and cross-sectional with higher neuroticism levels (Lindstrom, 2013), but we encountered no longitudinal study of this phenomenon.

\footnotetext{
${ }^{6}$ This is reminiscent of a study of adults over age 50 which reported a modest boost in health for women wo were partnered to men who were highly neurotic and conscientious, while no benefit for being with highly neurotic and conscientious wives was seen in men (Roberts et al., 2009).

${ }^{7}$ Notably, reports of how individuals experience their partner-relationship seem more characterized by one's own personality than that of the partner ( Neyer et al., 2004).

${ }^{8}$ Five processes reliably predict relationship dissolution: criticism, defensiveness, contempt, belligerence, and stonewalling or listener withdrawal (Gottman et al., 1998).
} 
Finally, the most influential relationship variables on neuroticism were conflict frequency and to a lesser extend also feelings of insecurity (Asendorpf et al., 1998, 2003; Mund et al., 2014; Neyer et al., 2007; Parker et al., 2012).

\section{Relationship Dissolution (A5)}

Dissolution is an eminent aspect of the romantic relationships domain, if only because most marriages end in divorce ( Buss, 2003; Stevenson et al., 2007), or the eventual death of one of the partners. MZ-twin pairs discordant for divorce showed for both genders, higher neuroticism scores for the divorced twin of a pair (2008). One study of male twins reported on higher neuroticism for divorced $v s$. married $(d=0.18)$, single, or widowed counterparts (1984). Moreover, four longitudinal studies reported small increases in neuroticism $(d=0.15)$ after divorce (Clausen et al., 1998; Costa et al., 2000; Jeronimus et al., 2013; Kiernan, 1986). However, another four longitudinal studies observed no effects of dissolution on neuroticism (Neyer et al., 2007; Shiner et al., 2002; Specht et al., 2011) or trait-anxiety (Caughlin et al., 2000). For example, divorce within a six-year span was not associated with change in neuroticism for both genders - though men increased slightly in the depression facet (Costa et al., 2000) - whereas a study of married couples reassessed on neuroticism, 13 years after their divorce, reported no effect of divorce on trait-anxiety nor negativity (Caughlin et al., 2000). Furthermore, divorce predicted decreases in personality stability in women over a 24-year interval (between high school and midlife), but observed no effect of divorces on men (1998).

However, as mentioned, two twin studies (Koskenvuo et al., 1984; 2008), four longitudinal studies (Clausen et al., 1998; Costa et al., 2000; Kelly et al., 1987; Kiernan, 1986), and a meta-analysis of longitudinal studies (Twenge, 2000) ${ }^{9}$ reported associations between divorce and neuroticism (for both genders; Kelly et al., 1987). These differences between these studies suggest that homeostatic processes in the aftermath of divorce mask the (initial) impact of divorce (Suh et al., 1996), perhaps because most subjects passed their most distressing phase before researchers collected their data. This is not unlikely in two-wavesnapshot studies, because then the study length must cover the time course of the underlying causal process to avoid spurious results (Rogosa, 1980; Scollon et al., 2006). Moreover, some may anticipate (and prepare for) a divorce with increases in negative and fights before divorce, which would mask the effects of divorce (Buss, 2003; Kurdek, 1992). In addition, as mentioned, differences in how individuals respond to divorce (e.g., relief vs. fear) may mask effects (Amato et al., 2007; Lehnart et al., 2006), though not so much for the MZ-twins (Koskenvuo, 1984; Middeldorp et al., 2005). Furthermore, some inconsistencies may reflect (gender) differences in the meaning divorce conveys over the lifecycle (Buss, 2003, 2012) ${ }^{10}$.

\footnotetext{
${ }^{9}$ Divorce rates and mean-neuroticism levels a decade later correlated 0.48 for males and 0.39 for females (both $p<.001$ ) over 170 studies and 40192 participants, whereas the reverse association (i.e. between mean-neuroticism and divorce rates 10 years later) was nonsignificant for both genders. This suggests that change in environments (i.e. the divorces) precede the change in neuroticism (Twenge, 2000).

${ }^{10}$ Women remarry increasingly less often with age because sex ratio and mate-value changes favor men, known as the marriage squeeze phenomenon (Buss, 2003, 2012). In addition, 90\% of the single parents are women (Buss, 2012). Furthermore, discord and dissolution are typically perceived as signs of failure (Buss, 2003), and may incur severe cost like loss of extended kinships, essential resources, and missed mating opportunities (Betzig, 1989). The price thereof may increase with age as partners have invested more time and energy, have more to loose, and fewer opportunities to repartner. Such factors may (partly) account for the observation that more divorces associate with less personality stability among
} 
One longitudinal study showed intriguing support for the effects of divorce on neuroticism (1986). Kiernan and colleagues followed a cohort of women from their teens before their marriages - into adulthood. Although divorced women had scored higher on neuroticism as teenagers ( $d=0.27$, thus assortment), they also increased significantly in neuroticism after divorce (till $d=0.63$ ). More importantly, women who scored low on neuroticism at age 16 increased in neuroticism after divorce, and the proportion women who scored low on neuroticism dropped from $36 \%$ to $5 \%$ after a broken marriage (Kiernan, 1986). Notably, these results suggest that the association between neuroticism and divorce is not necessarily a reflection of preexisting psychological problems, but rather of secondary stressors (Lock et al., 2012) in the period around (simultaneous with) a relationship dissolution (Lorenz et al., 1997; Pledge, 1992; Umberson et al., 1993). Note that this interpretation aligns with the diverging effects of divorce for MZ-twins (Koskenvuo et al., $1984 ; 2008)$. Finally, the results were probably attenuated because the consequences of divorce were limited for the disproportional young, wealthy, educated, intelligent and Caucasian samples studied (Löckenhoff et al., 2008; Roberts et al., 2006) ${ }^{11}$.

\section{Widowhood (A6)}

In middle aged men (43 to 90) the death of their spouse predicted both level and rate of change in neuroticism, on average an increase $d=0.72$ ( Mroczek et al., 2003). However, these elevations were followed by an accelerated decrease in neuroticism $(d=0.40)$ over the subsequent decade ( Mroczek et al., 2003). This suggests a homeostatic system, wherein individuals return to their setpoint (Ormel et al., 2012). Moreover, the loss of a spouse is reportedly one of the most stressful experiences in adulthood (Hobson et al., 1998; Holmes et al., 1967) ${ }^{12}$. The observation of adaptation processes to such a stressful event suggests that adaptation to much less severe events is likely, such as those discussed in section D.

\section{Conclusion (A7)}

The studies in the romantic partnership section showed that marriage and partner investments result in decreases in neuroticism, in line with normative developmental patterns. Men who selected a spouse high on neuroticism tended to increase in neuroticism over time (Caughlin et al., 2000), in line with transactional models (Caspi et al., 1989; Endler et al., 1976;

\footnotetext{
women, but not among men (1998). However, emotional stability is also more sexually attractive in men than women (Buss, 1989, 2003, 2006; Watson et al., 2014).

${ }^{11}$ Many factors may moderate the association between divorce and neuroticism, e.g. income (Baltes et al., 1997; Karney et al., 1995; Kiernan, 1986), availability or loss of supportive networks (Buss, 2012; Johnson et al., 2002; Karney et al., 1995; Kiernan, 1986; Mastekaasa, 1994); culture and ethnicity (Dion, 2005; Löckenhoff et al., 2008; Zhao et al., 2006); education (Kiernan, 1986; Löckenhoff et al., 2009b), health, employment, length of marriage, conflict with ex, number and severity of negative experiences, if you initiated the divorce (Amato, 2000; Betzig, 1989; Buss, 2003; Dohrenwend, 2006; Hetherington et al., 2002; Lorenz et al., 1997; Mastekaasa, 1994; Weisberg et al., 2011), individual variables (Hobson et al., 1998; Sutin et al., 2010; e.g. gender and age, Weisberg et al., 2011), and so on. For example, women whose marriages have broken down have on average more children to support (Kiernan, 1986). Moreover, divorced individuals have more often both divorced parents and come from poorer families, which may experience difficulties to cope with the financial and emotional strain their adult children may well engender on them (Kiernan, 1986). Hence, divorce may have repercussions for the wider family group - which may in turn associate with more guilt and distress. Nevertheless, the costs of remaining in an unhappy marriage have been discussed.

${ }^{12}$ Note that the death of a spouse means one cannot win her back (although repartnering is possible), and does not require a reassessment of strategies, which might enable a return to pre-existing neuroticism levels (Buss, 2003).
} 
Magnusson, 1990; Roberts et al., 2008). Results align with the corresponsive principle insofar that life events that are associated with change in neuroticism were often selected for as well. The results suggest that romantic relationships have separate positive and negative dimensions, which associate with decreases or increases in neuroticism, respectively, $c f$. (Diener et al., 1984; Ellis et al., 2000; Hetherington et al., 1992; Jeronimus et al., 2014). Alas, few studies focused on transactions beyond emerging adulthood (age 30), however, while spouses may become ever more important resources for dealing with everyday problems in old age, when social networks shrink. Though it is often argued that most relationship effects are confined to emerging adulthood (Parker et al., 2012; Sturaro et al., 2008), the reviewed studies demonstrate that relationship effects on neuroticism occur along the lifespan (Mund et al., 2014; Reis et al., 2000). It remains largely unknown how and why specific contexts or relationship properties change neuroticism, and the specific rate of adaptation to these events. Finally, the family is not a static institution, thus effects possibly differ over generations, given that within decades marriage rates have fallen, divorce rates have risen, and the defining characteristics of marriage have changed (Pinsof, 2002; Stevenson et al., 2007).

\section{Section B: The Social Network}

Social networks refer to the set of people with whom an individual is directly involved, such as family members, friends and acquaintances, and which are crucial for personality development (Bronfenbrenner, 2005; Wrzus et al., 2013). Aspects of this social network show normative developmental changes (Wrzus et al., 2013), but not much is known about how such changes impact on changes in neuroticism (Finn et al., 2013; Mund et al., 2014), and also the trajectories of these effects are not very well understood (Neyer et al., 2014; Wrzus et al., 2013). In this section we review effects of sibling cohabitation, interactions in the nuclear family, or interactions within our social networks, on change in neuroticism. However, before doing so, we outline some neuroticism-driven selection effects that shape our social network.

\section{Selection effects (B1)}

Twin research indicates that most (40-80\%) human variance in social networks and support is explained by genetic influences (DeScioli et al., 2009; Kendler, 1997; Vinkhuyzen et al., 2009). These effects are probably mediated by personality differences, via which individuals select, evoke, and shape their habitual environments (Neyer et al., 2014; Roberts et al., 2007; Rutter et al., 2002). High neuroticism predicts lower (perceived) social support for both genders (Kendler et al., 1997, 2002; Monroe et al., 1986; Sarason et al., 1986; ten Have et al., 2006), lower family satisfaction ( $r=-.19, p<.01$; Wayne et al., 2004), more problems to get along with relatives and friends $(d=0.28)$, fewer confidants, less interpersonal relationships and social integration (Jeronimus et al., 2013; Kendler 1997, 2003), and more loneliness (Hensley et al., 2012), death, illness, and crises in the core network (Kendler et al., 2003). Little of these effects seem due to reporting bias (Bolger et al., 1991; Kendler et al., 2003). Finally, there seems no neuroticism-driven selection for living arrangement (e.g., with parents, alone, with roommates, or with partner) in young adulthood (Jonkmann et al., 2014), possible effects at other age ranges are not studied yet. In the following we focus on effects of 
cohabitation, and interactions in the nuclear family and social networks, followed by a conclusion.

\section{Cohabitation (B2)}

Twins who cohabited with their co-twin at baseline showed no interindividual change in neuroticism over a six-year interval, while twins who had started to live apart (e.g., left parental home) showed significant divergence in neuroticism levels (Kaprio et al., 1990). Another study showed heritability estimates of neuroticism to be 0.54 among cohabiting male twins, but 0.39 among males who lived apart (Koskenvuo et al., 1984). A lower number of social contact seems to antedate (possibly even causally) the suggested decreased intra-pair similarity for neuroticism (1990). This perspective is supported by a meta-analysis of MZtwin studies (McCartney et al., 1990). Finally, a study of 5000 male MZ-twin pairs indicated that a change in residence for negative reasons tended to associate with higher neuroticism scores (Koskenvuo, 1984).

\section{Nuclear family (B3)}

Prospective studies indicate that changes in interpersonal relationships - such as family ties and peer contacts - associate with changes in neuroticism (Asendorpf et al., 1998; Branje et al., 2004; Bratko et al., 1997; Costa et al., 2000; Kendler et al., 2003; Maiden et al., 2003; Neyer et al., 2001; Roberts et al., 2000; Robins et al., 2002; Rose et al., 1990; Sturaro et al., 2008; van Aken et al., 2006). The nuclear family proved the most influential social context, e.g. young adults (age 17-23) who perceived conflict with fathers or mothers often increased in neuroticism $(d=0.60,0.50$, respectively (Sturaro et al., 2008)). Similarly, parents who reported more conflict with their children (Neyer et al., 2001) or adolescents also increased in neuroticism $(d=0.26 \text {; Hutteman et al., 2014 })^{13}$. One study of middle-class two-parent twochild families showed that perceived change in social support had no effect on the parents or oldest child, and only the youngest child increased in neuroticism (Branje et al., 2004). Arguably, this reflects that decreases in support are most threatening to a child that is more dependent (Buss, 2012; Geary et al., 2000, 2001). In accord, changed support from father or mother between age 17 and 23 was unrelated to change in neuroticism among young adults (Sturaro et al., 2008) ${ }^{14}$.

The stress of having a newborn baby associated with increases in neuroticism of $d=$ 0.56 (Hutteman et al., 2014), especially for parents who already had high levels of neuroticism (Jokela et al., 2009). Also parents who became more insecure with their children increased in neuroticism (Neyer et al., 2001), just as women with negative motheringexperiences (Paris et al., 2002) ${ }^{15}$. In contrast, positive mothering-experiences associated with decreases in neuroticism (Paris et al., 2002), just as increased security with family members (Neyer et al., 2007). Increases in neuroticism associated also with more dissatisfaction with

\footnotetext{
${ }^{13}$ This may be interpreted in terms of potential fitness costs (Neyer et al., 2011; Trivers, 1972). Notably, perceived parenting self-efficacy was not associated with changes in neuroticism (Hutteman et al., 2014).

${ }^{14}$ It remains unknown whether the adolescents lived with their parents or independent over this period.

${ }^{15}$ Women with negative mothering-experiences tended to increase in vulnerability, viz., hypersensitivity, fearfulness and dependence (Paris et al., 2002). However, this is a reciprocal effect, because neuroticism also predicts more insecurity (Mund et al., 2014).
} 
one's interpersonal network (Roberts et al., 2000; Robins et al., 2002), abusive interpersonal relationships (Roberts et al., 2000; Robins et al., 2002), and perceived declines of family and social life over time (Costa et al., 2000). Such declines in contact predicted increases in the facet traits anxiety, depression, and vulnerability for stress (Costa et al., 2000). Young women exhibited an accelerated increase in emotional stability (decrease in neuroticism) when they moved out of their parental home (Specht et al., 2011). This effect was not observed among men (Specht et al., 2011). Albeit independent living is a rite of passage to adult status (Arnett, 2004), this observation may reflect 'daughter guarding', because daughters tend to experience more constraint in the parental home (Perilloux et al., 2008).

Finally, a division of 1000 twin-pairs in quartiles based on increasing levels of family dysfunction (negative emotional tone, e.g. support and anger) showed that both the mean and variance of neuroticism increased steadily with more family dysfunction (Kendler et al., 2003), and accounted for about 3\% of the variation in neuroticism (Kendler et al., 2003). Notably, the increase in neuroticism was approximately the same in twins with low versus high genetic liability for high neuroticism (Kendler et al., 2003), indicating environmental canalization, viz., with or without a genetic predisposition, all obtain high scores. This process has also has been observed for high levels of parental conflict (Krueger et al., 2008). Similar processes underlie the observation that neuroticism is more heritable in individuals without religious upbringing (Willemsen et al., 2007), another example of how heritability differs over different environmental contexts (Kendler et al., 2007; Krueger et al., 2008; McCartney et al., 1990; Turkheimer et al., 2003), which stresses prudence about inheritance (Belsky, 1997; Flint, 2004; Keller et al., 2010; Rende et al., 1993; Wolfensberger et al., 2008), and support a sociogenomic perspective on personality development (Briley et al., 2014; Roberts et al., 2008).

\section{Reproduction (B4)}

Becoming a parent is often cited as the most important turning point in one's life, particularly among women (Rönkä et al., 2003). One study showed no change (vs. controls) in neuroticism for individuals who transitioned to parental status over a four-year interval (2001). This may seems counterintuitive, and in discord with social investment predictions (Roberts et al., 2005), but fits the notion that decreases in neuroticism after partnering aid the rearing of a child, before it is born (Buss, 2003; A. Caspi et al., 1990; Inkeles et al., 1963). Perhaps the decrease in neuroticism due to investment is balanced by an increase due to stress of a child. Moreover, lack of change may also reflect a homeostatic process, when neuroticism scores that deviated from the setpoint had already returned to baseline due too low frequent neuroticism measurements. It may also be that young adults who became parent do not show the normative decrease that their peers show (because parenthood may also be stressful), which would manifest in rank-order stabilities (Luhmann et al., 2014; J. Ormel et al., 2012). Lastly, there was no relation between the number of children an individual begets and personality stability over time (Clausen et al., 1998), which does not support the idea that young parents fail to change.

Nevertheless, in a 9-year follow-up study was found that high (vs. low) emotional individuals were less likely have a second and third child (Jokela et al., 2011). And interestingly, individuals who were high ( $v s$. low) on emotionality at baseline and got two or 
more children increased in emotionality over 9 years (from $d=0.13$ to $d=0.36$ ), while emotional stable individuals in similar conditions did not (Jokela et al., 2011). Over these 9 years individuals who had no children remained relatively stable on emotionality, while individuals who had one or more children increased in emotionality (Jokela et al., 2011). Finally, high neuroticism associates with childbirth complications (Johnston et al., 2012), whereas giving birth to a pre-term child increases maternal trait-anxiety measured at 14 days and at 14 months postpartum (Kersting et al., 2004) ${ }^{16}$. Pre-term birth appears to represent a long-term difficulty for the parent, which is an ongoing environmental influence (Jeronimus et al., 2014). In sum, results suggest that the distress associated with childbirth is larger in individuals high on neuroticism before pregnancy (Jokela et al., 2011).

\section{Social networks (B5)}

Most human functioning is socially situated. The neuroticism setpoint must thus be socially embedded. The social convoy that travels with us in time is broader than parents, siblings and spouses, and also contains our friends, acquaintances, and neighbours, albeit these contacts tend to fluctuate more (Antonucci et al., 1987; Wrzus et al., 2013), and decrease in number and importance with age (Carstensen, 2006; Wrzus et al., 2013). Studies about the influence of broader social networks on neuroticism were scarce. Decreases in neuroticism were reported when peer contacts increased between age 18 to 30 (Neyer et al., 2007), or after befriending new people (Jeronimus et al., 2013), but in another study no effect was found (Mund et al., 2014). Insecurity in the presence of peers showed a correlated change with neuroticism (Mund et al., 2014; Neyer et al., 2007). Nevertheless, young adults' perceived conflict with best friends or peers (Sturaro et al., 2008) or changed support from best friend (Sturaro et al., 2008) were unrelated to change in neuroticism. In another study no effect was reported of changes in number of conflicts, quality of contacts with peers, or closeness with friends on change in neuroticism (Mund et al., 2014). Third, all associations between relationship variables and neuroticism were non-significant in an 18-month longitudinal study of first-year students (Asendorpf et al., 1998). However, elderly women who reported declines in social support between age 74-80 (fewer available friends, visits, and social contacts) increased in neuroticism over this six year period (Maiden et al., 2003). One large study reported increases in neuroticism one year after the break-up of a longstanding relationship with a friend or relative $(d=0.20)$, or after serious problems with a close friend, family member or neighbour ( $d=0.14$; Jeronimus et al., 2013). Furthermore, individuals who cared for elderly chronically ill family members decreased in anger and anxiety over two years (arguably an emotional adaptation), albeit guilt and depression persisted (1990). Even so, caregivers who placed their family member in a nursing home decreased also significantly in guilt, when periods just prior and after placement (8 months apart) were compared (1990).

\footnotetext{
${ }^{16}$ Mothers $(N=50)$ of children with a very low birth weight $(<1500$ grams $)$ and/or birth before 32 completed gestational weeks v.s. a control group of mothers $(N=30)$ of term infants born around the 40th gestational week with an average birth weight of 3500 grams; all spontaneous pregnancies (Kersting et al., 2004). Conversely, pre-term born children or children with low birth weight score themselves higher on neuroticism, shyness, and inhibition as emerging adults (Allin et al., 2006; Schmidt et al., 2008), even after control for age and SES (Allin et al., 2006).
} 


\section{Conclusion (B6)}

Changes in neuroticism associated most with problems in the proximal social network, especially in terms of deteriorating ties. Moreover, perceived conflict and perceived deterioration of family life associated more with change in neuroticism than changes in perceived support (Costa et al., 2000; Kendler et al., 2003; Sturaro et al., 2008). This suit of results is in keeping with conceptions of neuroticism as sensitivity to threat and punishment (DeYoung, 2010) and the notion that threats to belongingness or dissolution of social bonds are the primary sources of negative affect (Baumeister et al., 1995; Leary, 1990). However, neuroticism levels appear to be largely unaffected by social relationships beyond family life (Asendorpf et al., 2003; Branje et al., 2004; Mund et al., 2014; Sturaro et al., 2008), and although all studies were restricted to young adults (Asendorpf et al., 1998; Sturaro et al., $2008)^{17}$, this observation aligns with the literature (Neyer et al., 2011).

Theoretically, it may seem likely that neuroticism has a stronger influence on relationship quality than vice versa ( $c f$. extended phenotype): Not only has neuroticism higher stability over time - resulting in persistent and cumulative effects on our social networks, relationship experiences are also likely to have more time-limited effects (Asendorpf et al., 1998; Neyer et al., 2001, 2004), to fluctuate more, and to cancel each other out (Asendorpf et al., 1998; Sturaro et al., 2008). It has therefore been noted that relationship properties and broad traits like neuroticism have a different level of abstraction which results in unfair comparisons, which leads to a preponderance of personality effects (Mund et al., 2014; Neyer et al., 2001). Indeed, in line therewith the authors of a 15-year follow-up study on the facet level of neuroticism reported the effects of facet traits on relationship effects and vice versa to be equally likely (Mund et al., 2014).

An important limitation of the reviewed studies was that mainly samples of young adults were assessed during developmental stages on which important changes in friendshipstatus occur (Oswald et al., 2003), such as when they start a study, which happens in encapsulated environment that are utterly atypical from the social environments of the population as a whole (Herrnstein et al., 1996). It remains therefore unknown if these findings generalize to adults in midlife. This is, however, an important issue, because social networks change over the life cycle, e.g. with age individuals report fewer conflicts, a decline in the number of friends, and less contact with family and friends in general (Neyer et al., 2007; Wrzus et al., 2013). Moreover, social networks differ along the time course (Field et al., 1991; Haan et al., 1986; Helson et al., 1987; Mroczek et al., 2003; Scollon et al., 2006; Stewart et al., 1998), and have a socioeconomic gradient (Costa et al., 2001; Herrnstein et al., 1996; Hofstede et al., 2004; Lynn et al., 1995; Schmitt et al., 2007, 2008; Turkheimer et al., 2003). Furthermore, social networks tend to have a gender-specific make-up, as women tend to have more kin and fewer co-workers in their social networks than men do (Buss, 2012; Kanazawa et al., 2009; Vigil, 2007), and to report fewer conflicts and fewer close friends, but more intimate dyads, prefer smaller groups, experience marriage and family as more central than men do, and profit more from partner support (Buss, 2003, 2012; Darwin, 1872; Neyer

\footnotetext{
${ }^{17}$ Asendorpf and colleagues (1998) concluded that "whether students' peer network grew quickly or slowly, whether they experienced increasing or decreasing conflict with parents or peers, whether they fell in love or not, whether their perception of available support from parents or peers increased or decreased had no effect on their neuroticism score."
} 
et al., 2007; Taylor et al., 2000; Vigil, 2007). Third, women seem more affected on their neuroticism score by stressful events in their proximal network (e.g. death of a loved one, problems getting along) than men, and report more events (Jeronimus et al., 2013; Kessler et al., 1984; Sutin et al., 2010). However, not one study accounted for gender difference in what counts as social capital (Buss, 2012; Kanazawa et al., 2009). In sum, the social network section showed that the vast majority of environmental influences on neuroticism take place within the proximal family. Given the patchy nature of the available data, this is unsurprising, and many questions are not addressed.

\section{Section C: Occupational environments}

Besides from their social relationships most humans also derive their identity from their professional relationships in their occupational environments (Verhaeghe, 2013). Most likely because most awake hours between age 20 and 65 are spend in occupational environments, which, compared to the social and romantic environments, is characterized by more formalized behavior, roles and routines (Rothbart, 2011). The occupational environment provides many resources, in terms of status, behavioral confirmation, stimulation, and money, and therewith access to activities and endowments (Lindenberg, 1996; Wrzus et al., 2013).

\section{Selection effects $(\mathrm{C} 1)$}

Normative development into adulthood, such as graduation and economic independence, associate with emotional stability (Arnett, 2004; Helson et al., 2002; McCrae et al., 1999; Neugarten et al., 1965; Roberts et al., 2005), as well does social investments in the occupational environment ( $n=5188, k=24, r=.11, d=0.22$; Lodi-Smith et al., 2007). However, such associations in the occupational system are easily confounded, because neuroticism is inversely associated with socioeconomic status (SES which refers to social class and educational attainment, e.g. $25^{\text {th }} v s .75^{\text {th }}$ SES percentile, $d=0.21$; Chapman et al., 2010) ${ }^{18}$. Moreover, high (vs. low) neuroticism levels forecast specific job-environments (Costa et al., 1984; Kohn et al., 1973; Koskenvuo et al., 1984; Zhao et al., 2006), downward mobility, job-loss, and lower academic achievement, lower income, occupational prestige, job-satisfaction (Caspi, 1987, 1989; De Neve et al., 2012; Friedman et al., 2011; Jeronimus et al., 2013; Judge et al., 2007; Kendler et al., 2003; O. Reis et al., 2011; Roberts et al., 2003; Shiner et al., 2012; Sutin et al., 2009), and less growth in cognitive achievement ( $r=-.18$ over 68 years, $\mathrm{R}^{2}=1 \%$ after correction for gender and prior ability; Ackerman et al., 1997; Gow et al., 2005).

Most studies, also twin studies, reported negative associations between neuroticism and intelligence ( $r=-10$ to .15; Ackerman et al., 1997; Austin et al., 2002; Bartels et al., 2012), but some find no association (Colom et al., 2009). Furthermore, both high SES individuals and higher educated individuals report more job satisfaction and more problems at - and worries about - their job (Kasl, 1973; Sutin et al., 2010). Finally, a meta-analysis of longitudinal student samples showed no association between economic conditions and change

\footnotetext{
${ }^{18}$ For example, over a 10 -year interval SES explained about $8 \%$ of the mortality risk associated with neuroticism, but neuroticism 11\% for SES (Chapman et al., 2010).
} 
in trait-anxiety after control for social connectedness and threat (Twenge, 2000). In sum, effects in the occupational environment are difficult to interpret in isolation, because they are markedly shaped by neuroticism-driven selection effects. In adults higher neuroticism associated over two years with a lower likelihood to finish formal education or a course (Jeronimus et al., 2013). In the following section we explore influences in the occupational environment that associate with stability and change in neuroticism.

\section{Occupation, Status, and Salary (C2)}

The first study of 5000 male twin pairs reported differences in neuroticism levels in different occupations (Koskenvuo, 1984), arguably a selection effect. Unemployed twins reported higher neuroticism scores $(d=0.15)$, just as twins who worked at night or shiftwork schedules $(d=0.10)^{19}$. Moreover, vocations and neuroticism lay on a continuum from low-neurotic farmers and upper-professionals $(d=-0.16)$ via sedentary occupations to higher scores for twins with heavy physical occupations (in the mines or industry, $d=0.07$ ). Neuroticism weakly associated inversely with income $(d=0.08)$ and level of education $(d=0.12)$, such that the difference in neuroticism between twins educated to secondary school versus higher educated twins (university) was $d=0.15$ (1984). The twin studies thus indicate that neuroticism levels can (partly) be predicted by unemployment, status, income, and education (Alfonsi et al., 2011; Buss, 2012; ten Have et al., 2006).

A two-year study reported decreases in neuroticism $(d=0.20)$ after a new job and for young adults who obtained promotion or more prestigious occupations (Jeronimus et al., 2013; Roberts et al., 2003; Sutin et al., 2009), especially in alienation, angry hostility, and vulnerability to stress (Roberts et al., 2003; Sutin et al., 2009). Moreover, increases in salary associated with accelerated decreases in neuroticism, especially in angry hostility, depression, and impulsiveness (Sutin et al., 2009). Fourth, young adults who achieved financial security between age 18 to 26 experienced an accelerated decrease in negative affect, markedly in stress reaction and alienation, compared to peers who were unable to do so (Roberts et al., 2003). Notably, the relationship between higher income and the decrease neuroticism (Furnham et al., 1986; Sutin et al., 2009) lasted over a 10-year period ( $n=304, d=0.40)$, but post-hoc significance was only observed in a subgroup aged 30 to $40(n=142, d=0.90)$, and not in older individuals ( $\geq 41$ years, $n=162$, age range 41-62; Sutin et al., 2009). Although this are small groups, the results suggest that income-effects overlay with the accelerated decrease in neuroticism for the young adults who became financial independent (Roberts et al., 2003), an "important hurdle to leap" in order to see oneself as an adult (Arnett, 2000). However, individuals who reported decreases in economic status over the life course (vs. no change) increased in neuroticism, and this was also observed during midlife (Costa et al., 2000; Jonassaint et al., 2011).

Occupied women showed more stable personalities than unemployed peers in a 24year follow-up study, after control for other family and occupational variables (Clausen et al., 1998). This latter observation aligns with notions of environment selection as a stabilizing factor for personality development (Caspi et al., 1989; Jeronimus et al., 2014). All

\footnotetext{
${ }^{19}$ These observations overlay with cross-sectional reports of high neuroticism scores among shiftworkers (McLaughlin et al., 2008; Tamagawa et al., 2007).
} 
observations in this paragraph fit the social investment principle (social expectations) and mating preferences. Albeit resources are likely to remain important across the lifespan, strikingly, we encountered only one (supporting) study beyond young adulthood: Elder women who reported more unmet needs over the years between age 74 and 80 (e.g., income, health care, housing, transportation, nutrition and leisure time activities) reported increases in neuroticism (Maiden et al., 2003).

\section{Occupational Satisfaction (C3)}

A study of women reported an association between work satisfaction and a decrease in neuroticism over a 30-year interval (Roberts et al., 2000, 2003). This inverse association between work satisfaction and neuroticism is emphasized by findings from meta-analyses (Bruk-Lee et al., 2009; Judge et al., 2002 $)^{20}$ of longitudinal studies $(d=0.35)$ in both genders, and has been reported for negative affect $(d=0.63)$, trait anger $(d=0.49)$, and trait-anxiety $(d=$ $0.37)^{21}$ as well, see (Bruk-Lee et al., 2009; Connolly et al., 2000). It may be that high neurotic individuals (of both genders) allow their negative moods to affect their job satisfaction (Ilies et al., 2002), in line with their reactivity to and focus on negative stimuli observed in cognitive tasks in lab studies (Chan et al., 2007; Denissen et al., 2008; Rusting et al., 1998).

\section{Occupational Life (C4)}

A study of 5000 male MZ-twin pairs showed that individuals who changed jobs for negative reasons tended to score higher on neuroticism (Koskenvuo, 1984). A longitudinal study (Costa et al., 2000) showed increases in neuroticism after negative changes in the occupational environment (over six years), compared to individuals who reported no change. Similarly, being fired associated with increases in neuroticism $(d=0.30)$ compared to peers who were promoted (Costa et al., 2000). Individuals who lost their job became more anxious, depressed, and vulnerable for stress (Costa et al., 2000). Surprisingly, individuals who reported more work autonomy in their jobs became slightly more alienated, whereas work involvement was not associated with change in neuroticism (Roberts et al., 2003). In a twoyear study of families increases in work stress led to more increases in neuroticism in fathers $\left(\mathrm{R}^{2}=.04\right)$ than mothers $\left(\mathrm{R}^{2}=.01\right)$, and these correlated change suggests dose-responses, viz. the more stress the more emotional instable individuals became (van Aken et al., 2006).

\section{Person-environment fit (C5)}

The neuroticism setpoint captures a balance between the person and his environment (see Jeronimus, 2015, chapter 10), such as the fit with the characteristics of a given job or organization (Roberts et al., 2004), as outlined in the previous paragraph. Young adults who felt growing fit with their work environment decreased in neuroticism over four years

\footnotetext{
${ }^{20}$ Cross-sectional over 24 studies and 9183 individuals; longitudinal over 6 studies and 1799 individuals (Bruk-Lee et al., 2009).

${ }^{21}$ Cross-sectional over 46 studies and 12834 individuals; longitudinal over 6 studies and 905 individuals, from 2 weeks to 7 years (Bruk-Lee et al., 2009).
} 
(Lüdtke et al., 2011), and $d=0.28$ (Roberts et al., 2004) ${ }^{22}$. Students who reported positive interactions with their university and positive feelings about their grades at $T_{2}$ decreased in neuroticism between age 18 (at $T_{1}$ ) and 22 (Robins et al., 2005). In contrast, indicators of low fit, such as counter-productive work behaviors (e.g. norm-violations, deviant or unsafe behaviors, absenteeism, conflict with colleagues, stealing, feigning sickness to take days off, and doing drugs at work), associated with increases in neuroticism (Sackett, 2002; Salgado, 2002) and negative emotionality between age 18 and 26 (Roberts et al., 2006), especially in stress reaction and aggression ( $d=0.37,0.47$, respectively), but decreased in harm avoidance $(d=0.20)$ (Roberts et al., 2006). These behaviors are the functional opposite of social investment, and the observed increase in neuroticism is in line with investment predictions (Lodi-Smith et al., 2007; Morizot et al., 2003).

\section{Retirement (C6)}

The journey from working to retiring is one of life's great transitions, often regarded to be a SLE, which requires adaptation (Bossé et al., 1991; Reis et al., 1993). About 30\% of the elder males report retirement problems (Bossé et al., 1991), and it was therefore surprising that two longitudinal studies found no effect of a retirement transition on neuroticism (Löckenhoff et al., 2009a; Mroczek et al., 2003) ${ }^{23}$. One study reported increases in trait-anxiety in the months before retirement, but not thereafter (Theriault, 1994), thus short-term fluctuations. Retirement satisfaction associated with emotion-related aspects of neuroticism like depression and vulnerability, however, associated with different stress-coping strategies (Löckenhoff et al., 2009a). Though we should be warily with only four studies available, it is salient that retirement-related loss of work roles and declines in activity were unrelated to changes in neuroticism, while unemployment stands out as a major life change and antedated increases in neuroticism (Costa et al., 2000; Koskenvuo et al., 1984). When people are forced to retire, unexpected or involuntarily, the effect on neuroticism may be comparable.

Arguably, retirement has less resource-related consequences, and its effects on status and behavioral confirmation may be easier to substitute (e.g., with more affection or other activities), because retirement is a normative part of our social script, and is perhaps the second longest anticipated event (after death).

\section{Conclusion (C7)}

Young adults who increased in prestige (status), financial security, and satisfaction associated with their occupational environment showed accelerations of the normative decrease in neuroticism (Clausen et al., 1990; Costa et al., 2000; Lüdtke et al., 2011; Roberts et al., 2000, 2003; Sutin et al., 2009). Perhaps because most studies focused on young adults (age 20 to 30) positive changes were more influential than negative changes in the occupational environment. This balance may be different for older individuals, and increases in neuroticism after decreases in economic status were also observed during midlife (Costa et

\footnotetext{
${ }^{22}$ At least for Alpha fit defined as the match between the subjective values and desires of the person and a consensus judgment of resources provided by the environment. This was not so for Beta fit, that is, subjective resources of the environment as perceived by the person (Roberts et al., 2004).

${ }^{23}$ This was supported by one study of 200 men, excluded because there was no follow-up neuroticism measure, which showed that baseline neuroticism was not predictive for problems in the following transition year (Bossé et al., 1991).
} 
al., 2000; Jonassaint et al., 2011). More long-term effects have time to capture the association between wealth and the incidence of negative life events along the lifespan (Vines et al., 2009). Nevertheless, aspects of our occupational environment, in terms of status or satisfaction, predicted changes in neuroticism over 10 to 30 years in multiple studies (Clausen et al., 1998; Roberts et al., 2000, 2003; Sutin et al., 2009).

In the population studies occupational experiences and neuroticism were reciprocal over time, but the effects on neuroticism seem smaller than vice versa (Sutin et al., 2010). This is in line with the corresponsive principle. This selection hypothesis is supported by the small differences in neuroticism between event-discordant MZ-twins, compared to the larger effects reported in the population studies. The twin studies, most robust against selection, indicated that neuroticism levels can (partly) be predicted by unemployment, status, income, and education (Alfonsi et al., 2011; Buss, 2012; ten Have et al., 2006).

It has been noted that occupational troubles and income loss are more stressful for men than women (Kessler et al., 1984; Lucas et al., 2004; Sutin et al., 2010). Neuroticism was inversely associated with social status for men (Anderson et al., 2001; Brody, 2000). This gender difference has to be established in younger samples, in which men are not the natural breadwinners. Nevertheless, such gender differences align with theories in which men strive for occupational status, power, and resources as mating budgets to successfully attract the women most men prefer (Baumeister et al., 2004; Buss, 1989; Darwin, 1872; Miller et al., 2008; Pinker, 2002; Trivers, 1972). Finally, retirement stood out as having no effect on neuroticism, while unemployment consistently predicted increases in neuroticism. Perhaps because retirement is normative, and as such does not signal something about our social position.

\section{Section D: Stressful Life Events}

One potent way to study the temporal dynamics of neuroticism is to focus on stressful life events (SLEs), which are able to alter developmental trajectories (Costa et al., 2000; Löckenhoff et al., 2009b; Lüdtke et al., 2011; Mroczek et al., 2003). We defined SLEs as time-discrete transitions that bring about a major change in social, economic, or financial status, sources of affection, or social roles.

\section{Stress Generation (D1)}

Up to half of the individual variance in SLE occurrences can be explained by genetic differences (Bemmels et al., 2008; Billig et al., 1996; Headey et al., 1989; Hershberger et al., 1995; Kendler et al., 1999, 2007; McAdams et al., 2013; Plomin et al., 1990; Power et al., 2013; Riese et al., 2014; Saudino et al., 1997; Sobolewski et al., 2001; Thapar et al., 1996; Wierzbicki, 1989) ${ }^{24}$. These selection/evocation effects seem relatively stable along the

\footnotetext{
${ }^{24}$ Notably, most of these "one-snapshot studies" are even likely to underestimate the genetic contributions (Kendler et al., 2007); see also (Foley et al., 1996; Kendler, 1997). See for absence (Bemmels et al., 2008; Jeronimus et al., 2014; Kendler et al., 1999) versus presence (Jeronimus et al., 2015; Plomin et al., 1990) of personality effects on exogenous SLEs. Bemmels et al. (2008) reported that environments not shared by siblings explained 33\% of the variance of endogenous SLEs and 57\% of the exogenous SLEs. One study reported that up to $30 \%$ of the variance in SLE-exposure could be explained by neuroticism and social disadvantage (Fergusson et al., 1987).
} 
lifespan (Andrews, 1981; Briley et al., 2014; Van Os et al., 1999; Woods et al., 1982), and explain more variance for PLEs ( 50\%) compared to NLEs ( 40\%) (Kandler et al., 2012; Kendler, 2001; Plomin et al., 1990), and unsurprisingly, more for endogenous (controllable or self-caused, 30-50\%) than exogenous life events (uncontrollable or chance-events, 0-25\%), see (Bemmels et al., 2008; Billig et al., 1996; Headey et al., 1989; Hershberger et al., 1995; Kandler et al., 2012; Kendler et al., 1999, 2007; Plomin et al., 1990; Power et al., 2013; Saudino et al., 1997; Sobolewski et al., 2001; Thapar et al., 1996; Wierzbicki, 1989) ${ }^{25}$. Neuroticism is observed to mediate part of this association, and the prevalence of many specific SLEs increases along the neuroticism-continuum (Headey et al., 1989; Jeronimus et al., 2013, 2014; Lüdtke et al., 2011; Magnus et al., 1993; Poulton et al., 1992; Specht et al., 2011; Vaidya et al., 2002) vs. (Löckenhoff et al., 2009b). For example, individuals from the highest quartile of neuroticism report three times more interpersonal-SLEs than those in the lowest quartile (Fergusson et al., 1987; Poulton et al., 1992; Specht et al., 2011; Van Os et al., 1999), and this association remains after adjustment for mental health (van Os et al., 2001). While most studies report prospective associations between neuroticism and the subsequent occurrence of dependent and independent NLEs ( $d=0.20$ to 0.50$)$ or difficulties $(d=0.32)$ (Fergusson et al., 1987; Grov et al., 2009; Jeronimus et al., 2013, 2014; Kendler et al., 2002, 2003; Lüdtke et al., 2011; Magnus et al., 1993; Poulton et al., 1992; Specht et al., 2011; Vaidya et al., 2002; Van Os et al., 1999, 2001), this is not the case for PLEs (Jeronimus et al., 2013; Lüdtke et al., 2011; Magnus et al., 1993; Specht et al., 2011; Vaidya et al., 2002).

Selection effects are not observed for all specific SLEs, probably because they differ in their controllability (Kandler et al., 2012; Specht et al., 2011) ${ }^{26}$. It may also be that other predictors have an (potentially stronger) impact than personality, albeit it remains unknown which that might be (Roberts et al., 2007; Specht et al., 2011). Albeit most SLEs are likely to have relatively time specific effects, stress often begets further stress, forming event chains (Goodyer et al., 1987; Hammen, 2003), which were discussed in section D4. In sum, individuals high on neuroticism conduct their lives in ways that (unwittingly) encourage interpersonal stress.

\section{Positive Experiences (D2)}

Most studies only assessed negative (stressful) events. Studies in which both NLEs and PLEs were measured showed decreases in neuroticism after PLEs (Jeronimus et al., 2013, 2014; Kuepper et al., 2012; Lüdtke et al., 2011; Paris et al., 2002). For example, $d=0.23$ over one year (Jeronimus et al., 2013), and $d=0.50$ over a 4-year period (Lüdtke et al., 2011).

Moreover, when our personal surroundings change for the better our neuroticism seems to decrease $(d=0.25)$, and this effect lasted more than four years (Jeronimus et al., 2014). One two-year study reported even a slightly stronger effect for PLEs than NLEs on neuroticism ( $n=2981, d=0.23$ vs. 0.19; Jeronimus et al., 2013). However, two other studies found no

\footnotetext{
${ }^{25}$ Though the tendency to report SLEs has a heritable component as well (Kendler et al., 2007; Thapar et al., 1996), little of the observed association between neuroticism and SLEs seems due to reporting bias (Kandler et al., 2012; Kendler et al., 2003).

${ }^{26}$ PLEs that are rated as uncontrollable seem rare (e.g. lottery win), and most PLEs are rated as controllable (Kandler et al., 2012; Mandel et al., 1996; Wright et al., 1985). This is supported by the general stronger genetic influences on PLEs than on NLEs (Kandler et al., 2012).
} 
effect of PLE-aggregates on neuroticism (Jeronimus et al., 2014; Specht et al., 2011), although one observed effects of positive life changes (Jeronimus et al., 2014). Relative increases in the number of PLEs, however, are associated with decreases in neuroticism (Kuepper et al., 2012). Reports of specific PLEs that associate with a decrease in neuroticism are remarkably scarce (beyond those already discussed, e.g. a new romantic partner and promotion at work). Students who reported PLEs during a travel abroad decreased in neuroticism (Andrews et al., 1993; Lüdtke et al., 2011): their trait-anxiety increased over the first six months abroad, but was followed by a marked decrease until 12 months, at the end of their travels (Andrews et al., 1993). Individuals who felt they learned a lesson from an experienced life event also reported a decreased in neuroticism, especially in the depression facet of neuroticism (Lüdtke et al., 2011). Finally, whereas NLEs are nearly always undesirable, PLEs may vary widely in their desirability (Zautra et al., 2005).

\section{Negative experiences and timing effects (D3)}

Population studies show that up to $90 \%$ of the participants report a significant SLE over the past decade (Sutin et al., 2010). For example, 25\% witnessed an accident, and 50\% experienced the death of a close other (Löckenhoff et al., 2009b; Sutin et al., 2010). Moreover, individuals who experienced an extreme SLE tended to increase in neuroticism $(d=0.30)$ at threefold the normative rate of change in midlife (Löckenhoff et al., 2009b; Terracciano et al., 2005) ${ }^{27}$. Adults who reported an 'extreme horrifying or frightening event' over the two years prior to follow-up $\left(T_{2}, 25 \%\right.$ or $\left.n=115\right)$ tended to increase in neuroticism, especially in two specific neuroticism facets, viz., angry hostility and depression (N3, Löckenhoff et al., 2009b)). However, an 8-year follow-up study in individuals in their midlife (age 42 to 50) observed no change in mean-level neuroticism for those who experienced a severe trauma (vs. controls), though their trait stability was lower (Ogle et al., 2014). A third of participants reported that they were still not adjusted to changes resulting from a SLE that they experienced over the past two years (Löckenhoff et al., 2009b). This self-reported adjustment associated with higher educational levels $(d=0.50)$, but, interestingly, not with $T_{1}$ personality (Löckenhoff et al., 2009b).

Most longitudinal studies with aggregated NLE measures show that their incidence predicts increases in neuroticism (Jeronimus et al., 2013; Laceulle et al., 2015; Kuepper et al., 2012; Lüdtke et al., 2011; Paris et al., 2002; Riese et al., 2014). However, increases in negative affect three months later $(d=0.63$; Jeronimus et al., 2013; Suh, 1996) are not the lasting changes we conceive of as change in the setpoint of neuroticism (Jeronimus et al., 2013, 2014; Ormel et al., 2012; Riese et al., 2014). Some studies observed increases in neuroticism 12 months after the SLE-occurrence (Jeronimus et al., 2013) or even after four years $(d=0.60$; Lüdtke et al., 2011), but other studies failed to observe changes in neuroticism at 6 to 36 months follow-up (Jeronimus et al., 2014; Suh, 1996). These inconsistencies are probably due to the specifics of the SLEs, because some of the SLEs that occurred more than four years before $T_{2}$ did associate with higher negative affect (Suh, 1996): the death of a close family member, parental divorce and abortion $(d=0.43)$. Arguably

\footnotetext{
${ }^{27}$ Three $t$-score points instead of the average of one (a $t$-score has a mean of 50 and SD of 10).
} 
these are more personal and severe SLEs (Jeronimus et al., 2014; Suh, 1996). In a 16-year five-wave study life event aggregates had no (persistent) effect on neuroticism, while longterm difficulties and deteriorated life quality predicted lasting ( $>13.5$ years) increases in neuroticism (Jeronimus et al., 2014). Moreover, changed life quality and endogenous longterm difficulties accounted for up to $10 \%$ of the observed individual change in neuroticism (Jeronimus et al., 2014).

Individuals who described a life event as a turning point in their life, or construed the event as negative or mixed positive/negative, tended to increase in neuroticism as well (Lüdtke et al., 2011). Generally death and dying of significant others are the most potent of all NLEs in adulthood (Hobson et al., 1998; Holmes et al., 1967; Sutin et al., 2010), and most frequently mentioned (Berntsen et al., 2011). Health-care issues come second, e.g. (life threatening) illness and injury, which seem to increase in incidence over the life course (Berntsen et al., 2011; Hobson et al., 1998; Lüdtke et al., 2011). Their relevance to neuroticism has been indicated by exposure-discordant MZ-twins (Middeldorp, 2008). Finally, the third most potent SLEs are contacts with the criminal justice system, followed by financial issues (Hobson et al., 1998; Lüdtke et al., 2011). In sum, neuroticism seems most sensitive to the type of SLEs that can be categorized as traumas as described in the DSM-V for post-traumatic stress disorders (American Psychiatric Association, 2013): first-hand exposure, witness, or confrontation with actual or threatened death, serious injury, or sexual violence, or a threat to the physical integrity of self or others (close family member or friend).

\section{Event Chains (D4)}

Besides their independent effect, PLEs and NLEs are also part of so called event chains, e.g. unemployment (or divorce) may lead to serious financial problems, which leads to a move to more affordable housing (in a poorer neighbourhood), and a decrease in PLEs. Although single events generally have frequencies below 10\% (Costa et al., 2000), NLE-scores tend to associate over time ( $r>.20$ over 7 years; Van Os et al., 1999). Most studies are pretty bad suited to address such interrelations. Moreover, long-term difficulties predicted positive life changes 9-years later ( $r=.19$; de Graaf et al., 2002), and PLEs and NLEs show complementary longitudinal relationships ( $r>$.30; de Graaf et al., 2002; Magnus et al., 1993; Overbeek et al., 2010), e.g. divorce and marriage. In addition, one study of students reported a positive association ( $r=.26$ ) between baseline neuroticism and the individual rate of change, indicating that high-neurotic individuals increased more in neuroticism (over 4 years) after an event than their low-neurotic peers (Lüdtke et al., 2011), although women appeared to change less than men did (Lüdtke et al., 2011). However, another study in adult twins did not observe an effect of baseline neuroticism (Riese et al., 2014) ${ }^{28}$.

We evaluate our surroundings constantly for simply feeling good or bad, roughly because positive affects permit approach of incentives, and negative affects motivate avoidance of threats (Carver, 2005; Harmon-Jones et al., 2011; Kahneman, 2011; Nettle, 2007, 2010; Panksepp et al., 2012). Though positive and negative life changes are inversely related with each other (e.g., $r=-.49$; Jeronimus et al., 2014), positive and negative life events

\footnotetext{
${ }^{28}$ One study over 5 months, and therefore not included in this review, showed no effect of baseline neuroticism on the posttraumatic stress response after a severe stressful event (Engelhard et al., 2009)
} 
are moderately associated within individuals, $r=.11$ to .47 (Jeronimus et al., 2013, 2014; Kandler et al., 2012). Individuals differ in how many life events they experience, both positive and negative (Jeronimus et al., 2013, 2014; Laceulle et al., 2015). Moreover, we seem to be more variant in our responses to aggregates of PLEs than to NLEs (Garland et al., 2010; Zautra et al., 2005), which is often explained with the 'broaden-and-build theory' of positive emotions (Fredrickson, 1998; Garland et al., 2010). PLEs are proposed to broaden individual's behavioral and thought repertoire (via positive affect) which leads to greater affective complexity (Fredrickson, 1998, 2003; Garland et al., 2010; Isen, 1987; Zautra et al., 2005) and resilience (Cohn et al., 2009; Shiner et al., 2012). Ancestral responses to NLEs have probably been more constrained (Panksepp et al., 2012).

Depending on conditions, NLEs and PLEs may be reciprocally, nonreciprocal, or independently activated (Cacioppo et al., 1999), e.g. (relatively) unrelated during times of low stress, but associated in high stress contexts, when individuals process negative information at the expense of positive information (Zautra et al., 2005). PLEs may also buffer for the impact of NLEs on neuroticism (Baumeister et al., 2001; Dohrenwend, 1978, 2006; Fredrickson, 1998; Garland et al., 2010; Rutter, 1987). After control for the opposite valence, negative affect is reported to be influenced by both PLEs and NLEs (1996). Likewise, after control for the opposite valence of life events and change in symptoms of depression and anxiety PLEs may be more predictive for change in neuroticism than NLEs (Jeronimus et al., 2013).

\section{Clustering (D5)}

The common clustering on valence (PLEs/NLEs) has its drawbacks. Traumatic experiences (accidents, an angry tiger) may be clustered with less severe events (going to the dentist, having your paper rejected), or ambiguous and divergent experiences (Costa et al., 2000; Kessler et al., 1984; Löckenhoff et al., 2009b; Magnus et al., 1993; Monroe, 2008; Rauthmann et al., 2014; Specht et al., 2011; Vaidya et al., 2002). Moreover, it is rather arbitrary; other researchers cluster on categories, like single events, collective events, network events, occupational, financial or health events (Sutin et al., 2010). In addition, some LEs may confound with symptoms of psychopathology (Grant et al., 2004), such as conflicts with others, or worries about one's life situation. Arguably, changes in habits of sleeping or eating, or sexual difficulties, which are reported to associate with change in neuroticism (Lüdtke et al., 2011; Sutin et al., 2011), might be better conceptualized as (early) symptoms of illness (e.g. depression) than as life events. Moreover, their relation with stress is often bidirectional (McEwen, 2008), e.g. sleep deprivation elates negative affect in response to mild stressors ( $d=0.50$ to 0.90 ; Minkel et al., 2012), and increases in impulsivity associate with increases in eating (Sutin et al., 2011). The same yields for increases in doctor visits across college which tend to be accompanied by an increase $(d=0.82)$ in neuroticism (Robins, 2005).

\section{Gender Differences in SLEs (D6)}

Life event inventories tend to represent typical male experiences best, and often lack experiences such as abortion or rape (Buss, 2003; Kessler et al., 1984), albeit studies who do 
so report comparable results (Lüdtke et al., 2011). However, gender differences should be bore in mind when interpreting evidence about sex differences in exposure, as most gender divergence in distress scores may be explained by differential response rather than differential exposure, e.g. stronger female reactivity (Kessler et al., 1984). Moreover, studies often find no gender differences in the report of specific life events (Maciejewski et al., 2001; Paykel, 1991), though some do (Breslau et al., 1995; Kessler et al., 1984; Specht et al., 2011). However, when asked to report the most important SLE over the past decade, women tend to report network events (problems with close other), whereas men are more likely to report problems with their own health or trouble at work (Breslau et al., 1995; Hobson et al., 1998; Sutin et al., 2010), which, as discussed, appear to align with their reproductive aspirations.

\section{Discussion}

We reviewed the literature for environmental influences on neuroticism, paradoxically one of the most stable aspects of personality and most susceptible to change as well (Shiner et al., 2002; Watson et al., 2003). Most individuals seem able to maintain stable neuroticism equilibria under stable life circumstances, given a normal level of education, a stable social network, a stable partnership, and a satisfying job. Evidently, neuroticism levels change during more turbulent times, when individuals adapt to environmental change and new roles. Our results show that the neuroticism setpoint can and does change over time in response to a wide range of environmental factors, primarily in the context of partner relationships, proximal family, and work properties, and often (but not always) in accord with social investment perspectives. Most observed effect sizes align with the modus in psychology (Meyer et al., 2001; Richard et al., 2003; Roberts et al., 2007). Our results support the literature that characterizes neuroticism as enhanced sensitivity and reactivity to events that are unpredictable, uncontrollable, unexpected, undesirable, and 'off time' from a life history perspective (Barlow et al., 2014; Caspi et al., 1993; Elder, 1994; Jeronimus et al., 2014; Mortimer et al., 1978; Neyer et al., 2014; Sanderman, 1988; Wood et al., 2014) and to interpersonal stress and conflict (social cues), rather than to physical threat (Bolger et al., 1991, 1995; Chan et al., 2007; Denissen et al., 2008; Gross et al., 1998; Gunthert et al., 1999; Kaplan et al., 2005; Martin, 1985; Matthews, 2004; Penke et al., 2007; Roberts et al., 2000, 2003; Ruiz-Caballero et al., 1995; Scarr et al., 1983; Suls et al., 2005) ${ }^{29}$. In the following we reflect upon our results in the light of the mixed model of change in neuroticism, the corresponsive principle, the social investment theory, and revive bioecological systems theory to provide structure to the study of environmental effects.

\section{Mixed Model of Change in Neuroticism}

To discuss environmental effects on neuroticism we distinguish three temporal levels, in terms of hours, weeks, and years. At the most momentary level we experience affective states

\footnotetext{
${ }^{29}$ Most variance in human anxiety revolves around social fears such as being criticized or rejected (Leary et al., 2001; Matthews, 2004) and separation anxiety (Konnor, 2010; Luo et al., 2001). Moreover, removal from the group is universally the primary human punishment (Verhaeghe, 2013). Interestingly, the salience of social exclusion seems to result in shortterm mating strategies in women while social inclusion does this for men (Sacco et al., 2011, 2012).
} 
in response to environmental stimuli (e.g., anger, frustration, fear, sadness) that last for several hours at best (Ekman, 2007; Kahneman, 2011; Panksepp et al., 2012; Russell, 2003; Verduyn et al., 2011; Verduyn et al., 2014). High neuroticism is characterized by more and more persistent negative affect (Buss et al., 1984; Catell et al., 1970; Cloninger, 1986; Digman, 1990; Eysenck, 1958; Goldberg, 1993; John et al., 2008; McCrae et al., 2008; Tellegen, 1985; Watson et al., 2003; Widiger, 2009).

More long-term temperament-like frameworks capture balances (e.g., subjective wellbeing) or consistencies in such affective-emotional expressions across multiple contexts over the months, which form personal density distributions of affective-emotional expression (Fleeson et al., 2009; Panksepp et al., 2012; Schuett et al., 2010; Wolf et al., 2012). At this secondary temporal level we also encounter persistent episodes of mood (Buss, 2012; Jeronimus et al., 2013; Ormel et al., 2012; Williams, 1990), specific symptoms (Ormel et al., 2013), and episodes of anxious or depressive illness (Fleeson, 2001; Jeronimus et al., 2013). Life events that trigger an anxious/depressive episode do this typically within maximal three months (Brilman et al., 2001; Faravelli et al., 2007; Kendler et al., 1999; Suh et al., 1996), and most major depressive episodes recover within three months (Spijker et al., 2002). Moreover, most life event effects on neuroticism have also receded within six months (Jeronimus et al., 2013, 2014; Riese et al., 2014), which led us to review studies that span one year at least.

At a third temporal level we conceptualize neuroticism setpoint change, viz. the person characteristic (trait-like) average of the negative-affective density distribution (Fleeson, 2001; Jeronimus et al., 2013; Ormel et al., 2012; Riese et al., 2014). Some reviewed studies showed event-driven changes in neuroticism that persisted over a decade (Jeronimus et al., 2014; Mroczek et al., 2003; Mund et al., 2014), in line with the mixed model of change in neuroticism (Ormel et al., 2012). It remains unknown how long changes in the neuroticism must persist before we can speak of setpoint change (viz., where do the second and third temporal levels border). For example, the literature suggests that grief or bereavement after the loss of a loved one can persists for up to two years (DSM-5, APA, 2013). In prior work we argued that experience-driven changes in neuroticism that persist for more than 6 months indicate setpoint change (Jeronimus et al., 2014), and based upon this review this position seems reasonable.

Two studies showed that major increases in the neuroticism setpoint measured about two years after a negative environmental change ( $d=0.50$ to $0.70, e . g$. death of a spouse) receded by about $60 \%$ over the next decade (Jeronimus et al., 2014; Mroczek et al., 2003). Furthermore, adaptation seems faster after PLEs than NLEs, e.g. the magnitude of setpoint change in neuroticism after changed life situation was $25 \%$ stronger for increases versus decreases after 4 years, but already $65 \%$ after 6 years (Jeronimus et al., 2014). In sum, we take these results to suggest that changes in neuroticism that persist for 6 months indicate setpoint change, but that setpoint change may decay over years to decades (Luhmann et al., 2014; Riese et al., 2014). Neuroticism setpoint change may serve to balance our inner and outer worlds (the Red Queen Personality Principle), and to adapt to (or cope with) specific changes in our personal environment, and are perhaps followed by slower external adaptation (e.g., via substitution processes; Jeronimus et al., 2014; Ormel et al., 1999). This would enable the neuroticism setpoint to gravitate slowly back (in terms of years) towards the - 
generally more normative - equilibria to which one was accustomed (Jeronimus et al., 2014; Ormel et al., 2012).

\section{Corresponsive Principle}

Neuroticism appears sensitive to "unscripted" events (Hofstede et al., 2004; Rubin et al., 2009). We tend to respond to non-normative events in line with our pre-existing neuroticismlevels (Bolger et al., 1991; Grant, 2010; Hampson, 2012; Ormel et al., 1989; Van Os et al., 1999), resulting in a widening of intrinsic differences via reciprocal causality (Lüdtke et al., 2011; Roberts et al., 2003, 2004; Specht et al., 2011; Sutin et al., 2010). SLE-prevalences follow a neuroticism-continuum (Headey et al., 1989; Jeronimus et al., 2013; Lüdtke et al., 2011; Magnus et al., 1993; Poulton et al., 1992; Specht et al., 2011; Vaidya et al., 2002) such that the quarter with the highest ( $v s$. lowest) neuroticism levels experience up to three times more interpersonal-SLEs (Fergusson et al., 1987; Poulton et al., 1992; Specht et al., 2011; Van Os et al., 1999). Moreover, neuroticism levels moderate the association between SLEs and mental-health problems (Bolger et al., 1991; Grant, 2010; Hampson, 2012; Ormel et al., 1989; Van Os et al., 1999), in line with conceptions of neuroticism as the vulnerability to destabilize when exposed to environmental-stress (Brown et al., 1978; Finlay-Jones et al., 1981; McEwen et al., 1993; Moffitt et al., 2007; Zuckerman, 1999).

Additionally, a twin study observed a neuroticism versus ‘type-of-vocation' gradient that suggests selection forces and higher neuroticism scores for individuals with night and shift work schedules (Koskenvuo, 1984). Finally, high ( $v$ s. low) neurotic adults tend to select themselves in neuroticism-promoting relationships (Buss, 2003; Kiernan, 1986; Neyer et al., 2007), report more distress after childbirth (Jokela et al., 2011), and more relationship dissolution (Lehnart et al., 2006; Neyer et al., 2014), which lead to more neuroticism.

We use the concept of severe trauma to outline a few additional points with regard to the corresponsive principle. Severe trauma associates with higher neuroticism scores along the lifespan (Jeronimus et al., 2013; Ogle et al., 2014), but childhood trauma seems more predictive for high neuroticism in midlife than severe trauma in midlife (age 42-50), despite the recency of the latter (Ogle et al., 2014). The corresponsive principle holds that autocatalytic processes (selection and evocation effects) magnify pre-existing differences in neuroticism, accumulations that could explain heightened neuroticism at midlife (Caspi et al., 2005; Roberts et al., 2005a, 2005b; Laceulle et al., 2015). However, children and adolescents also have a more flexible neuroticism setpoint (Briley et al., 2014; Ferguson, 2010; Roberts et al., 2000) because they live in less stable personal atmosphere (Bleidorn et al., 2014; Kandler et al., 2010; M. McGue et al., 1993; Roberts et al., 2000; Viken et al., 1994; Wray et al., 2007; Wrzus et al., 2013), which aligns with the corresponsive principle. Third, severe trauma may impact less at midlife, because by then individuals tend to be more emotional stable - thus less reactive (Bolger et al., 1991; Grant, 2010; Hampson, 2012; Ormel et al., 1989; Van Os et al., 1999), in line with the corresponsive principle.

The corresponsive principle functions as a kind of "verbal magic" (Boag, 2011) that is difficult to falsify and applies (post-hoc) to most observations, but not all (Jeronimus et al., 2013; Riese et al., 2014; Spinhoven et al., 2014). For example, one large twin study observed no stronger impact of SLEs on neuroticism for individuals who were high (vs. low) on neuroticism at baseline (Riese et al., 2014). One two-year population study ( $n=2981)$ 
observed that childhood trauma amplified the decrease in neuroticism after PLEs but dampened increases in neuroticism after NLEs (Jeronimus et al., 2013), in contradiction to the corresponsive principle. Finally, accumulating gene-environment correlations, also known as the Dickens-Flynn effect (Beam et al., 2013; Flynn, 2009), affect most personality traits and other traits alike, and may also magnify cultural phenomena (Gladwell, 2008; Jeronimus et al., 2015). For example, in one 3-year study blacks were more often exposed to physical assault than whites (Breslau et al., 1995). It remains therefore unknown how and why people develop as they do, and more specific theories than the corresponsive principle seem required to explain changes in neuroticism in response to specific environmental influences, both in terms of mechanisms and timing.

\section{Social Investment Theory}

The social investment hypothesis holds that age-graded social roles drive functional personality maturation via associated societal expectations and contingencies (such as becoming a reliable partner, a nurturing parent, or a cooperative colleague) and promote a reward structure that facilitates emotional stability (Bleidorn et al., 2013; Caspi et al., 2006; Lodi-Smith et al., 2007; Roberts et al., 2003, 2005, 2008; Wood et al., 2014). In this review we observed (accelerated) decreases in neuroticism for individuals who transited into a (romantic) partner role, at least for men also in midlife, and after remarriage (Costa et al., 2000; Lehnart et al., 2010; Mroczek et al., 2003; Mund et al., 2014; Neyer et al., 2001, 2007; Robins et al., 2002). The increase in negative affect (depression/anxiety) rather than emotional reactivity (impulsivity and anger) (Asendorpf et al., 2003; DeYoung et al., 2007; Lehnart et al., 2010) is reminiscent of changes that have been observed for elevations in social rank (Gilbert, 2000), which support the notion of partnering as a rite to adult status (Arnett, 2004;D. M. Buss, 2012).

Young adults in stable relations $(\sim 30 \%)$ showed stereotypic normative decreases in neuroticism while those who changed partners $(\sim 70 \%)$ followed more differential developmental patterns (Lehnart et al., 2006; Robins et al., 2002). However, we found no support for decreases in neuroticism after young adults begot a child (Neyer, 2001), while partner hood seems paramount to functional maturation (Buss, 2003; Caspi et al., 1990; Inkeles et al., 1963). Begetting a child is an exception to the general rule, perhaps because it is an epitome of anticipation (extremely "scripted" and often planned), which enables coping and environmental adaptation. It has been noted that pre-conceptions of a future identity (rather than direct experience) may change personality in anticipation of future roles (Neyer et al., 2014; Wood et al., 2006a, 2006b), a rather complex intrapsychic influence.

Alternatively, the stress of becoming a parent may counterbalance the decrease due to social investment. In the occupational domain we observed (accelerated) decreases in neuroticism for young adults who became financially independent (Roberts et al., 2003; Sutin et al., 2009), increased in occupational status (Jonassaint et al., 2011; Roberts et al., 2003; Sutin et al., 2009), or experienced growing fit with their environment (Lüdtke et al., 2011; Roberts et al., 2004; Robins et al., 2005). Salient was the absence of retirement-driven effects on neuroticism (Löckenhoff et al., 2009a; Mroczek et al., 2003), perhaps because retirement is the second longest anticipated event (after death). 
The social investment hypothesis implies that individuals who develop in accordance with their sociocultural tide ('assimilation') benefit while the minority that cannot keep pace with the cultural life script (or swim against the current) "pay a price" (see the introduction). Individuals who report or show low fit with their environment (e.g., dismissal; Costa et al., 2000), and behaviours that are functional opposites of (social) investment, e.g. counterproductive work behaviors (Roberts et al., 2006; Sackett, 2002; Salgado, 2002), unemployment (Costa et al., 2000; Koskenvuo et al., 1984), or breaking the law (Morizot et al., 2003), indeed associate with (relative) increases in neuroticism (this review).

Furthermore, transitional events (e.g., a first romantic partner, a first job, becoming a parent) are predict changes in neuroticism (Bleidorn et al., 2013; Lodi-Smith et al., 2007), but little is known about what these transitions actually mean for the individual (De Fruyt et al., 2014), e.g. in terms of proximal processes (Bronfenbrenner, 2005), resource availability (Ormel et al., 1999), or functional values (Wood et al., 2014). Furthermore, high neuroticism is characterized by more awareness of - and sensitivity to - normative comparisons (Gibbons et al., 1999; Jonkmann et al., 2012; VanderZee et al., 1996). Finally, cross-cultural studies showed that individuals in Pakistan, China, Guatemala and Brazil transit at a much younger age into the labor force than their peers in Canada, Australia or the Netherlands (the timing of their biosocial life script), and also show the normative decrease in neuroticism $(d=0.20$ per decade) at an earlier age (Bleidorn et al., 2013; McCrae et al., 1999; Roberts et al., 2006), which can be seen as support for social investment as a prime drive behind the normative decrease in neuroticism.

\section{Environments}

Many social events are instantaneously reflected in the structure of our personal environment, e.g. entrance events expand our personal atmosphere (or Metasystem) with a new romantic relationship, job, or friends. In each of these systems we play a specific role (as friend, employee, and partner/parent) and experience enduring patterned interactions with our surroundings (Bleidorn et al., 2013; Jeronimus et al., 2014; Neyer et al., 2014). Exit events, in contrast, contract the personal atmosphere, and tend to associate with increases in neuroticism (e.g., divorce, death of a spouse, end of a friendship, or dismissal/unemployment). Moreover, each microsystem can be touched by "unscripted" more stochastic experiences, e.g. accidents, disease, and the like, events that associate with change in neuroticism. The derivation of a taxonomy for environmental influences (just as we did for personality) is an old problem that psychologists still struggle to solve (Rauthmann et al., 2014). Capturing the complex effects of multiple environmental factors on neuroticism is a daunting enterprise because we seek to understand them by the analysis of components that can only be understood in relation to the whole (Bronfenbrenner, 2005; Lewontin, 2000; Mischel, 1968; Sameroff, 2010; Bos et al., 2016).

One promising framework to structure environmental influences on neuroticism is bioecological systems theory (Bronfenbrenner, 2005), conceptualized as a framework of interconnected nested systems. The sum of the family system, occupational system, and social systems of which we are part forms our personal atmosphere (Mesosystem), which in turn is shaped by a Chrono system (outlined below). For example, reactions to normative events tend to be more scripted, but the content and timing of this script shall vary along 
sociohistorical contexts (Arnett, 2004; Dumont, 2010; Neyer et al., 2014; Wiesner-Hanks, 2006). Culture can be seen as an extra-somatic means of human adaptation to our ecological niche, called characteristic adaptations (Cramer et al., 2012; Fleeson, 2001, 2009; Larsen et al., 2013; Lehmann et al., 2013; McCrae, 2013; Wood et al., 2014). With an eye for detail we could discern time-and-space-specific differences in (a) the prominence of specific facet traits and (b) the impact of life events (e.g., parenthood, divorce, change in social support) on the neuroticism setpoint, e.g. for both genders along the life cycle, over generations, or in subcultures (Vines et al., 2009; Wood et al., 2014). A consideration of these differences may deepen our understanding of how neuroticism and our (social) environment interact, and why the strength of neuroticism effects vary across situations, to enhance wellbeing.

\section{The Many Personalities of Neuroticism}

Neuroticism has been described as a "hodgepodge of quite different person-qualities" that makes neuroticism "an over inclusive, easy-to-invoke societally evaluative wastebasket label" (Block, 2010; Ormel et al., 2004). Our current taxonomies suffice to classify, integrate, and guide personality research, but lack a theoretical or empirical foundation to determine the exact facets that make up the neuroticism trait space (Caspi et al., 2011; Dumont, 2010; Larsen et al., 2013; McCrae, 2013; Roberts et al., 2006). Consequently, theorists disagree whether angry-hostility, aggression, irritability, impulsivity, inferiority, or dependency are core aspects of neuroticism (Caspi et al., 2006; Ormel et al., 2012; Pervin et al., 1999). The wondrous variety of measures and labels akin to neuroticism seem to boil down to three clusters in the neuroticism trait space: an anxiety-withdrawal cluster ("Fear"), a depressionunhappiness-distress cluster ("Grief/Sad"), and a vulnerability-stress-reactivity (“Anger") cluster (Barlow et al., 2014; Caspi et al., 2011; DeYoung et al., 2007, 2010; Fox et al., 2005; Panksepp et al., 2012; Pervin et al., 1999; Rothbart et al., 2007). The fact that similar clusters have been distinguished for psychopathology, e.g. fear, anxious-misery (inhibition), and externalizing clusters, respectively, is taken as support (Jeronimus et al., 2015; Krueger, 1999a; Lahey et al., 2012) . $^{30}$.

The anxiety and depression clusters of neuroticism refer to the stable (lifelong) tendency to experience negative affect or aversive mood states including anxiety, depression, fear, anger, contempt, disgust, guilt, irritability, nervousness, distress, impulsivity, and unpleasurable engagement (Costa et al., 1987, 1992; Ormel et al., 2003, 2012, 2013; Watson et al., 1984). Both domains merge in a neuroticism setpoint and personal density distribution of negative affect, with the specific emotions and behaviors variable over individuals, theories, and cultures (Block, 2010; Ireland et al., 2014). There are differences as well (see also Jeronimus, 2015), e.g. sadness is marked by negative valance and low arousal, while anxiety is marked by negative valance and high arousal (Russell, 2003). Negative affectivity has been described as the more cognitive component of neuroticism, which decreases when young

\footnotetext{
${ }^{30}$ Or in the tripartite model, Anxious Arousal, Anhedonic Depression, and General Distress (Clark et al., 1991; Shankman et al., 2003; Wardenaar et al., 2014). Notably, Fear, Grief/Sad, and Anger also make up the mammalian negative-affective super factor (Panksepp et al., 2012). Another large twin study showed that covariance between internalizing and externalizing clusters disappears after accounting for genetic and environmental influences shared in common with neuroticism and novelty seeking (Hink et al., 2013).
} 
adults find themselves a romantic partner (Asendorpf et al., 2003; DeYoung et al., 2007; Lehnart et al., 2010).

Emotional reactivity (impulsivity and anger), in contrast, decreases after young adults obtain promotion or more prestigious occupations (Roberts et al., 2003; Sutin et al., 2009). This emotional reactivity or volatility cluster of neuroticism refers to the tendency to be easily upset (Block, 2010; DeYoung et al., 2007) and to destabilize after exposure to environmental stress (Ackerman, 1997; Bolger et al., 1991; Brown et al., 1978; Buss et al., 2004; Finlay-Jones et al., 1981; Gross et al., 1998; McEwen et al., 1993; Moffitt et al., 2007; Zuckerman, 1999) ${ }^{31}$. This emotional instability results in heightened sensitivity to environmental factors (a low threshold of arousal) and unexpected, intense, and rapid changes in emotion, thus the amplitude of the personal density distribution (Buss, 2011; Cole et al., 2009; Rettew et al., 2005; Tellegen, 1985) ${ }^{32}$. Reactivity is often operationalized as individual differences in the thresholds of reaction, latency, intensity, peak-intensity, duration, and recovery of negative affects/emotions (Buss, 2011; Panksepp et al., 2012; Rettew et al., 2005; Rothbart, 2011). The neurotic volatility cluster may underlie the consistent associations between neuroticism, mood variability (Eysenck, 1981; Larsen, 1987; Murray et al., 2002; Murray et al., 2002; Williams, 1990, 1993), and mood disorders (Kotov et al., 2010; Lahey, 2009; Ormel et al., 2013; Jeronimus et al., 2016).

Finally, frustration/anger versus anxiety/depression also differ in the type of behaviours they motivate, e.g. approach versus avoidance (Carver et al., 1994, 2006, 2009; Jeronimus et al., 2015, 2016). Anger and anxiety are also mediated by different neurological substrates (Panksepp et al., 2012) and have different implications for development and psychopathology (Frick, 2004; Hill, 2011; Reynolds et al., 2001). Finally, facet traits can also differ in their sensitivity to environmental influences (Bleidorn et al., 2009; Mund et al., 2014). To conclude, the three clusters in the neuroticism concept may explain why neuroticism is both one of the most stable aspects of personality and most susceptible to change as well (Shiner et al., 2002; Watson et al., 2003), and the sensitivity to environments is inherent in the conceptualization of neuroticism.

\section{Limitations}

This review was limited by the range of available studies (also accounting for many inconsistencies), while measure-heterogeneity precluded formal meta-analyses.

Consequently, this review became a qualitative synthesis of the relevant, representative, and evidence-based literature, and relied on the scarce MZ-twin studies, and criteria of consistency of the association, temporal order, and evidence of dose-response (correlated change) mechanisms. In the following we outline some challenging issues of measurement in terms of content, methods, and informants.

\footnotetext{
${ }^{31} C f$. the allostatic load model (McEwen et al., 1993; Monroe, 2008) and a sense of being out of control as a common feature of anxiety and fear (Mogg et al., 1998).

${ }^{32}$ High neuroticism is characterized by more intense experience of negative emotions (such as fearful and sad), but the volatility facet of neuroticism also results in more extreme positive feelings (such as enjoyment; Ng, 2009; Weibel et al., 2011).
} 


\section{Ipsative stability}

Within this review we ignored changes in the stability in the configuration of other traits within the individual (ipsative stability), while there may be dynamic interactions between them (DeYoung et al., 2002; Digman, 1997). We can only claim that neuroticism is uniquely related to the studied experiences if neuroticism is studied together with all other dimensions of personality. Life event occurrences are influenced by all traits, e.g. more extraverted, agreeable, and conscientious individuals tend to report more PLEs (Vaidya et al., 2002). Second, after a SLE (with high event centrality) people tend to show a small (temporary) increase in neuroticism, but also in openness to experience and conscientiousness (Boals et al., 2014). Third, there are indications for synergistic effects between high neuroticism and high conscientiousness that result in good health behaviours (Friedman et al., 2011; Lee et al., 2006; Roberts et al., 2009). Though we acknowledge that typological approaches result in important information loss (Costa et al., 2002), perhaps traits configurations form "personality chords" (e.g. high neuroticism, conscientiousness, and agreeableness), which seem to render one vulnerable or resilient to specific events (Becker, 1999; Caspi et al., 2011; DeYoung et al., 2002; Wille et al., 2013) ${ }^{33}$, or disorders (Decuyper et al., 2009; Laceulle et al., 2014).

\section{Methodological concerns}

We observed methodological concerns, e.g. attrition was often associated with higher neuroticism levels (Jeronimus et al., 2013; Scollon et al., 2006), and rather high in relationship studies (Karney et al., 1995). Second, the relative small sample sizes may partly explain the lack of separate models for both genders or failure to account for the divergent meanings events (being married/remarried/divorced/single, but also work and social network) may have for men and women (Buss, 2003; Friedman et al., 2011; Kanazawa et al., 2009; Vigil, 2007). Third, many longitudinal studies lean on associations or cross-lagged paths (Freedman, 1987; Rogosa, 1980), which conceal the magnitude of the reciprocity (socialization vs. selection), e.g. the bidirectionality between neuroticism and divorce (Costa et al., 1994; Neyer et al., 2001) ${ }^{34}$. In addition, most cross-lagged panel models and latent growth curve models do not allow changes in one domain (neuroticism or environmental factors) to predict changes in the other domain, thus do not study dynamic transactions directly (Mund et al., 2014).

Furthermore, it is often observed that neuroticism effects on the environment are stronger than vice versa (Jeronimus et al., 2014). This led some to argue that comparisons between neuroticism (as a broad domain) and environmental variables are unfair (Neyer et al., 2001), and that facet traits are a more equal measurement level (Mund et al., 2014). Fourth, all studies lacked a life-span perspective, and most had few measurement occasions over small spans (two-wave snapshots), which foreclose reflections on short-and long-term

\footnotetext{
${ }^{33}$ For example, some proposed an Alpha trait (or "chord") to maintain stability, that captures emotional stability, agreeableness, and conscientiousness, and a Beta trait as tendency toward exploration and growth, with extraversion and openness (Becker, 1999; Caspi et al., 2011; DeYoung et al., 2002).

${ }^{34}$ In one study the authors therefore remained puzzled whether change in neuroticism "resulted from the interaction with (or nurturing by) a partner" or whether a transition into a partnership was a "characteristic adaptation" of intrinsic personality change (Costa et al., 1994; Neyer et al., 2001).
} 
temporal dynamics (Biesanz et al., 2003), while earlier experience may form a dynamic moderator or have sequelae (Friedman et al., 2011; Luhmann et al., 2009). Life records capture the natural history of the person as no other data can, and are highly reliable due to aggregation of observations over a long period (Caspi et al., 1989; Friedman et al., 2011). Finally, we may have encountered the 'file-drawer problem' because we found remarkably few studies with negative findings (no effect; Ferguson et al., 2012; Ioannidis, 2005; Simmons et al., 2011).

\section{Instruments and tools}

Important statistical tools like correlated change require large sample sizes in order to have sufficient statistical power, especially after control for $T_{1}$-values and Bonferroni adjustment, but may proof to be crucial tools to uncover mechanisms behind intra-individual change (Hertzog et al., 2003; Scollon et al., 2006). Furthermore, twin studies at least controlled for most confounding due to genetic factors and shared experiences (Riese et al., 2014). In virtually all studies personality was assessed with self-report instruments (Mund et al., $2014)^{35}$, a strategy that is especially problematic for self-report life events (often with Likertscales), because retrospection inherently incorporates response components, such as cognition and appraisal (Lazarus et al., 1985; Monroe, 2008), and item interpretation or recall (Dohrenwend, 2006; Schwarz, 2007).

Interview-based methods are therefore the gold standard for assessing life stress (Dohrenwend, 2006; Hammen, 2005; Monroe, 2008; Paykel, 2001), and data indeed suggests worrisome discrepancies between interviews and self-report (Duggal et al., 2000; Lewinsohn et al., 2003). Interviews are an incomplete solution, however, if only for the demands of time and cost, and few (<2\%) studies therefore use interviews (Grant et al., 2004). In addition, interviews may be less likely to elicit embarrassing or consequential information, such as physical or sexual abuse (Singleton et al., 1993). Similarly, interviews about marital satisfaction may result in social desirability or self-presentation biases (Kelly et al., 1987; Robins et al., 2002). Even so, interviews would probably have broadened our knowledge (Jeronimus et al., 2014), just as more dyadic analyses would (Finn et al., 2013; Mund et al., 2014). Finally, it is tempting to argue for experiments to establish causality, but hitherto it is unethical to expose random individuals to divorce or pregnancy, and allowed stressors are unrepresentative of the life stresses that people encounter in the real world (either in intensity or duration). Furthermore, only specific people shall participate in experiments, while both experimenters and subjects shall know it's an experiment.

\section{Therapy}

The review did not focus on the context of therapy, although this provides one of the best opportunities to study the possibility of change in neuroticism (see chapter 10). Within therapy environmental influences are clearly defined and controlled, making intervention

\footnotetext{
${ }^{35}$ Albeit these are reliable measures they assessed only perceptions of the subject, thus reflect 'beliefs' of the participants, which are surely consequential, but not nessecerily accurate. Studies should more often be dyadic. None of the studies included used behavioral observation (either 'live' or videotape) or informants, while this has been implemented before (Borkenau et al., 2001; Hirschmüller et al., 2014).
} 
studies "a window into the organization of a system and the processes associated with transition" (Hayes et al., 2007). Given that neuroticism is a risk factor for - or may reflect subtreshold levels of - developing psychological disorders (Fanous et al., 2007; Jeronimus et al., 2016; Kendler et al., 2010; Kotov et al., 2010; Malouff et al., 2005; Ormel et al., 2001, 2013), a reasonable aim for clinicians developing prevention strategies may be to influence neuroticism, as decreases in neuroticism may improve resilience and health (Barlow et al., 2014; Jeronimus et al., 2013; Lahey, 2009). Prior work has shown that interventions treating high neuroticism are feasible (De Fruyt et al., 2006; Glinski et al., 2010; Jorm, 1989; Nelis et al., 2011; Quilty et al., 2008; Tang et al., 2009; Zinbarg et al., 2008), both psychological and pharmacological ( $d=0.40$ to 1.25 ). We feel this complex topic deserves a review for itself.

\section{Psychometrics}

Neuroticism measures are constructed via standard psychometric procedures, including high test-retest reliability, and focus on static aspects of neuroticism, not change (Hertzog et al., 2003; Mroczek et al., 2003). Hence, responses in terms of 'general feelings' are less sensitive to intraindividual variability, and likely to underestimate trait change. Furthermore, most questionnaires discriminate good at the most disturbed high end of the neuroticism continuum, but rather poorly at the emotional stability side (Jorm et al., 1990). One solution may be additional observation studies of real-life trait-relevant situations that make people show their personality (Gosling et al., 2003; Hirschmüller et al., 2014; Rauthmann et al., $2014)^{36}$, as Galton argued (Galton, 1884). Another solution may be to focus were possible on changes in the relevant facets (Ferguson, 2010; Mund et al., 2014). Third, we should study the differences between personality instruments and those used to gauge mental health (Ormel et al., 2014; Jeronimus et al., 2016). Moreover, the review would have been more informative if studies used personality measures with known scale properties (e.g. ratio scales). In addition, we hope for more cross-cultural evidence, because virtually all samples were western, educated, industrialized, rich, and democratic (WEIRD) populations (Henrich et al., 2010), and a five factor structure seems less robust in non-educated individuals, e.g. Bolivian forager-horticulturalist (Gurven et al., 2013).

\section{Conclusion}

We reviewed environmental factors that foster stability and change in neuroticism. The key message is that neuroticism setpoint levels are consistently touched by normative experiences that affect core aspects of one's identity and status, mainly role transitions as partner (marriage/divorce) and employee (dismissal/promotion). The neuroticism setpoint was most responsive to major interpersonal stressors that were unpredictable, uncontrollable, unexpected, undesirable, and 'off time' from a life history perspective. The magnitude of the observed effects range at the modal within psychological research. Increases in the neuroticism setpoint about two years after a major SLE were followed by a $60 \%$ decrease in size over the subsequent decade, which we take to suggest that the neuroticism setpoint has its own temporal dynamics. We propose that changes in neuroticism that persist over six

\footnotetext{
${ }^{36}$ And use experience sampling strategies (e.g., van der Krieke et al., 2015, 2016).
} 
months indicate setpoint change. Nevertheless, more lifespan studies and detailed dissections of environmental factors are required to understand the dynamics of setpoint change in neuroticism: paradoxically both one of the most stable and changeable personality traits. 


\section{References}

Ackerman, P. L. (1997). Personality, self-concept, interests, and intelligence: Which construct doesn't fit? Journal of Personality, 65(2), 171-204. doi:10.1111/j.14676494.1997.tb00952.x

Ackerman, P. L., \& Heggestad, E. D. (1997). Intelligence, personality, and interests: Evidence for overlapping traits. Psychological Bulletin, 121(2), 219-245. doi:10.1037/0033-2909.121.2.219

Alfonsi, G., Conway, M., \& Pushkar, D. (2011). The lower subjective social status of neurotic individuals: Multiple pathways through occupational prestige, income, and illness. Journal of Personality, 79(3), 619-642. doi:10.1111/j.1467-6494.2011.00684.x

Allik, J. (2013). Personality psychology in the first decade of the new millennium: A bibliometric portrait. European Journal of Personality, 27(1), 5-14. doi:10.1002/per.1843

Allin, M., Rooney, M., Cuddy, M., Wyatt, J., Walshe, M., Rifkin, L., \& Murray, R. (2006). Personality in young adults who are born preterm. Pediatrics, 117(2), 309-316. doi:10.1542/peds.2005-0539

Amato, P. R. (2000). The consequences of divorce for adults and children. Journal of Marriage and Family, 62(4), 1269-1287. doi:10.1111/j.1741-3737.2000.01269.x

Amato, P. R., \& Hohmann-Marriott, B. (2007). A comparison of high- and low-distress marriages that end in divorce. Journal of Marriage and Family, 69(3), 621-638. doi:10.1111/j.1741-3737.2007.00396.x

American Psychiatric Association. (2013). Diagnostic and statistical manual of mental disorders (Fifth ed., DSM-5) American Psychiatric Association.

Anderson, C., John, O., Keltner, D., \& Kring, A. (2001). Who attains social status? effects of personality and physical attractiveness in social groups. Journal of Personality and Social Psychology, 81(1), 116-132. doi:10.1037/0022-3514.81.1.116

Andrews, G., Page, A. C., \& Neilson, M. (1993). Sending your teenagers away - controlled stress decreases neurotic vulnerability. Archives of General Psychiatry, 50(7), 585-589.

Andrews, G. (1981). A prospective study of life events and psychological symptoms. Psychological Medicine: A Journal of Research in Psychiatry and the Allied Sciences, 11(4), 795-801. doi:10.1017/S0033291700041295

Antonucci, T. C., \& Akiyama, H. (1987). Social networks in adult life and a preliminary examination of the convoy model. Journal of Gerontology, 42(5), 519-527. doi:10.1093/geronj/42.5.519

Arnett, J. J. (2000). Emerging adulthood: A theory of development from the late teens through the twenties. American Psychologist, 55(5), 469-480. doi:10.1037/0003066X.55.5.469 
Arnett, J. J. (2004). Emerging adulthood: The winding road from the late teens through the twenties. New York, NY US: Oxford University Press.

Asendorpf, J. B., \& Wilpers, S. (1998). Personality effects on social relationships. Journal of Personality and Social Psychology, 74(6), 1531-1544.

Asendorpf, J. B., \& Van Aken, M. A. G. (2003). Personality?relationship transaction in adolescence: Core versus surface personality characteristics. Journal of Personality, 71(4), 629-666. doi:10.1111/1467-6494.7104005

Austin, E., Deary, I., Whiteman, M., Fowkes, F., Pedersen, N., Rabbitt, P., . . McInnes, L. (2002). Relationships between ability and personality: Does intelligence contribute positively to personal and social adjustment? Personality and Individual Differences, 32(8), 1391-1411. doi:10.1016/S0191-8869(01)00129-5

Baltes, M., \& Lang, F. (1997). Everyday functioning and successful aging: The impact of resources. Psychology and Aging, 12(3), 433-443. doi:10.1037/0882-7974.12.3.433

Barlow, D. H., Sauer-Zavala, S., Carl, J. R., Bullis, J. R., \& Ellard, K. K. (2014). The nature, diagnosis, and treatment of neuroticism: Back to the future. Clinical Psychological Science, 2(3), 344-65. doi:10.1177/2167702613505532

Bartels, M., van Weegen, F. I., van Beijsterveldt, C. E. M., Carlier, M., Polderman, T. J. C., Hoekstra, R. A., \& Boomsma, D. I. (2012). The five factor model of personality and intelligence: A twin study on the relationship between the two constructs. Personality and Individual Differences, 53(4), 368-373. doi: 10.1016/j.paid.2012.02.007

Baumeister, R. F., \& Leary, M. R. (1995). The need to belong - desire for interpersonal attachments as a fundamental human-motivation. Psychological Bulletin, 117(3), 497529. doi:10.1037/0033-2909.117.3.497

Baumeister, R., \& Vohs, K. (2004). Sexual economics: Sex as female resource for social exchange in heterosexual interactions. Personality and Social Psychology Review, 8(4), 339-363. doi:10.1207/s15327957pspr0804_2

Baumeister, R. F., Bratslavsky, E., Finkenauer, C., \& Vohs, K. D. (2001). Bad is stronger than good. Review of General Psychology, 5(4), 323-370. doi:10.1037/10892680.5.4.323

Beam, C. R., \& Turkheimer, E. (2013). Phenotype-environment correlations in longitudinal twin models. Development and Psychopathology, 25(1), 7-16. doi: $10.1017 /$ S0954579412000867

Becker, P. (1999). Beyond the big five. Personality and Individual Differences, 26(3), 511530. doi:10.1016/S0191-8869(98)00168-8

Belsky, J. (1997). Variation in susceptibility to environmental influence: An evolutionary argument. Psychological Inquiry, 8(3), 182-186. doi:10.1207/s15327965pli0803_3

Bemmels, H. R., Burt, S. A., Legrand, L. N., Iacono, W. G., \& McGue, M. (2008). The heritability of life events: An adolescent twin and adoption study. Twin Research and Human Genetics, 11(3), 257-265. doi:10.1375/twin.11.3.257 
Berntsen, D., Rubin, D. C., \& Siegler, I. C. (2011). Two versions of life: Emotionally negative and positive life events have different roles in the organization of life story and identity. Emotion, 11(5), 1190-1201. doi:10.1037/a0024940

Betzig, L. (1989). Causes of conjugal dissolution - a cross-cultural-study. Current Anthropology, 30(5), 654-676. doi:10.1086/203798

Biesanz, J., West, S., \& Kwok, O. (2003). Personality over time: Methodological approaches to the study of short-term and long-term development and change. Journal of Personality, 71(6), 905-941. doi:10.1111/1467-6494.7106002

Billig, J., Hershberger, S., Iacono, W., \& McGue, M. (1996). Life events and personality in late adolescence: Genetic and environmental relations. Behavior Genetics, 26(6), 543554. doi:10.1007/BF02361227

Billstedt, E., Skoog, I., Duberstein, P., Marlow, T., Hällström, T., André, M., . . W Waern, M. (2013). A 37-year prospective study of neuroticism and extraversion in women followed from mid-life to late life. Acta Psychiatrica Scandinavica, 129(35), 43. doi:10.1111/acps.12093

Bleidorn, W., Klimstra, T. A., Denissen, J. J. A., Rentfrow, P. J., Potter, J., \& Gosling, S. D. (2013). Personality maturation around the world - A cross-cultural examination of the social investment theory. Psychological Science, 24(12), 2530. doi:10.1177/0956797613498396

Bleidorn, W., Kandler, C., \& Caspi, A. (2014). The behavioural genetics of personality development in adulthood?classic, contemporary, and future trends. European Journal of Personality, 28(3), 244-255. doi:10.1002/per.1957

Bleidorn, W., Kandler, C., Riemann, R., Angleitner, A., \& Spinath, F. M. (2009). Patterns and sources of adult personality development: Growth curve analyses of the NEO PI-R scales in a longitudinal twin study. Journal of Personality and Social Psychology, 97(1), 142-155. doi:10.1037/a0015434

Block, J. (2010). The five-factor framing of personality and beyond: Some ruminations. Psychological Inquiry: An International Journal for the Advancement of Psychological Theory, 21(1), 2.

Boag, S. (2011). Explanation in personality psychology: "verbal magic" and the five-factor model. Philosophical Psychology, 24(2), 223-243. doi:10.1080/09515089.2010.548319

Boals, A., Southard-Dobbs, S., \& Blumenthal, H. (2014). Adverse events in emerging adulthood are associated with increases in neuroticism. Journal of Personality, , n/a-n/a. doi:10.1111/jopy.12095

Bolger, N., \& Schilling, E. A. (1991). Personality and the problems of everyday life: The role of neuroticism in exposure and reactivity to daily stressors. Journal of Personality, $59(3), 355$.

Bolger, N., \& Zuckerman, A. (1995). A framework for studying personality in the stress process. Journal of Personality and Social Psychology, 69(5), 890-902. doi:10.1037/0022-3514.69.5.890 
Boomsma, D., Busjahn, A., \& Peltonen, L. (2002). Classical twin studies and beyond. Nature Reviews Genetics, 3(11), 872-882. doi:10.1038/nrg932

Borenstein, M., Hedges, L. V., Higgins, J. P. T., \& Rothstein, H. R. (2009). Introduction to meta-analysis. United Kingdom: John Wiley \& Sons Ltd.

Borkenau, P., Riemann, R., Angleitner, A., \& Spinath, F. M. (2001). Genetic and environmental influences on observed personality: Evidence from the german observational study of adult twins. Journal of Personality and Social Psychology, 80(4), 655-668. doi:10.1037//0022-3514.80.4.655

Bos, E.H., van der Meulen, L., Wichers, M., Jeronimus, B.F. (2016). A primrose path? Moderating effects of age and gender in the association between green space and mental health. International journal of environmental research and public health, 13(5), 492. doi:10.3390/ijerph13050492

Bossé, R., Aldwin, C. M., Levenson, M. R., \& Workman-Daniels, K. (1991). How stressful is retirement? findings from the normative aging study. Journal of Gerontology, 46(1), P9P14. doi:10.1093/geronj/46.1.P9

Branje, S., van Lieshout, C., \& van Aken, M. (2004). Relations between big five personality characteristics and perceived support in adolescents' families. Journal of Personality and Social Psychology, 86(4), 615-628. doi:10.1037/0022-3514.86.4.615

Bratko, D., \& Marusic, I. (1997). Family study of the big five personality dimensions. Personality and Individual Differences, 23(3), 365-369.

Breaugh, J. A. (2003). Effect size estimation: Factors to consider and mistakes to avoid. Journal of Management, 29(1), 79-97. doi:10.1177/014920630302900106

Breslau, N., Davis, G. C., \& Andreski, P. (1995). Risk factors for PTSD-related traumatic events: A prospective analysis. The American Journal of Psychiatry, 152(4), 529-535.

Briley, D. A., \& Tucker-Drob, E. (2014). Genetic and environmental continuity in personality development: A meta-analysis. Psychological Bulletin, 140(5), 1303-1331. doi:10.1037/a0037091

Brilman, E., \& Ormel, J. (2001). Life events, difficulties and onset of depressive episodes in later life. Psychological Medicine, 31(05), 859. doi:10.1017/S0033291701004019

Brody, L. R. (2000). The socialization of gender differences in emotional expression: Display rules, infant temperament, and differentiation. In A. Fischer (Ed.), Gender and emotion: Social psychological perspectives (pp. 24). Cambridge, UK.: Cambridge University Press.

Bronfenbrenner, U. (Ed.). (2005). Making human beings human: Biological perspectives on human development. London: Sage Publications, Inc.

Brown, G. W., \& Harris, T. (1978). The social origins of depression. London: Tavistock Publications. 
Bruk-Lee, V., Khoury, H. A., Nixon, A. E., Goh, A., \& Spector, P. E. (2009). Replicating and extending past Personality/Job satisfaction meta-analyses. Human Performance, 22(2), 156-189. doi:10.1080/08959280902743709

Buss, A. H. (2011). Pathways to individuality: Evolution and development of personality traits. Washington, DC: American Psychological Association. doi:10.1037/a0026164

Buss, A. H., \& Plomin, R. (1984). Temperament: Early developing personality traits. Hillsdale, N.J.: L. Erlbaum Associates.

Buss, D., \& Larsen, R. (2004). Personality psychology: Domains of knowledge about human nature (2nd ed.) McGraw-Hill.

Buss, D. M. (1989). Sex-differences in human mate preferences - evolutionary hypothesis tested in 37 cultures. Behavioral and Brain Sciences, 12(1), 1-14.

Buss, D. M. (2003). The evolution of desire (2nd ed.). New York, USA.: Basic Books.

Buss, D. M. (2012). Evolutionary psychology (4th ed.). Boston, MA.: Pearson.

Buss, D. M. (1991). Conflict in married-couples - personality predictors of anger and upset. Journal of Personality, 59(4), 663-688.

Buss, D. M. (2006). The evolutionary genetics of personality: Does mutation load signal relationship load? Behavioral and Brain Sciences, 29(4), 409.

Buss, D. M., \& Shackelford, T. K. (1997). Susceptibility to infidelity in the first year of marriage. Journal of Research in Personality, 31(2), 193. doi:10.1006/jrpe.1997.2175"

Cacioppo, J., Gardner, W., \& Berntson, G. (1999). The affect system has parallel and integrative processing components: Form follows function. Journal of Personality and Social Psychology, 76(5), 839-855. doi:10.1037/0022-3514.76.5.839

Carroll, L. (1871). Through the looking glass. London: Macmillan.

Carstensen, L. (2006). The influence of a sense of time on human development. Science, 312(5782), 1913-1915. doi:10.1126/science.1127488

Carver, C. S. (2005). Impulse and constraint: Perspectives from personality psychology, convergence with theory in other areas, and potential for integration. Personality and Social Psychology Review, 9(4), 312-333. doi:10.1207/s15327957pspr0904_2

Carver, C. S. (2006). Approach, avoidance, and the self-regulation of affect and action. Motivation and Emotion, 30(2), 105-110. doi:10.1007/s11031-006-9044-7

Carver, C. S., \& Harmon-Jones, E. (2009). Anger is an approach-related affect: Evidence and implications. Psychological Bulletin, 135(2), 183-204. doi:10.1037/a0013965

Carver, C. S., \& White, T. L. (1994). Behavioral inhibition, behavioral activation, and affective responses to impending reward and punishment: The BIS/BAS scales. Journal of Personality and Social Psychology, 67(2), 319-333. doi:10.1037/0022-3514.67.2.319 
Caspi, A. (1987). Personality in the life course. Journal of Personality and Social Psychology, 53(6), 1203-1213. doi:10.1037/0022-3514.53.6.1203

Caspi, A., \& Bem, D. J. (1990). Personality continuity and change across the life course. . In L. A. Pervin (Ed.), Handbook of personality: Theory and research (pp. 549-575). New York: Guilford.

Caspi, A., Roberts, B. W., \& Shiner, R. L. (2005). Personality development: Stability and change . Annual Review of Psychology, 56(1), 453-484. doi:10.1146/annurev.psych.55.090902.141913

Caspi, A., \& Shiner, R. (2006). Personality development. In N. Eisenberg (Ed.), Handbook of child psychology (Vol. 3 ed., pp. 300). Hobokon, New Jersey: John Wiley \& Sons, Inc.

Caspi, A., \& Shiner, R. (2011). Temperament and personality. In M. Rutter, D. Bishop, D. Pine, S. Scott, J. Stevenson, E. Taylor \& A. Thapar (Eds.), Rutter's child and adolescent psychiatry (5th ed., pp. 182). Malden, Massachusetts, USA: Blackwell Publishing Limited.

Caspi, A., Bem, D. J., \& Elder, G. H. (1989). Continuities and consequences of interactional styles across the life course. Journal of Personality, 57(2), 375-406. doi:10.1111/j.14676494.1989.tb00487.x

Caspi, A., \& Roberts, B. (2001). Personality development across the life course: The argument for change and continuity. Psychological Inquiry, 12(2), 49-66. doi:10.1207/S15327965PLI1202_01

Caspi, A., \& Moffitt, T. E. (1993). When do individual differences matter? A paradoxical theory of personality coherence. Psychological Inquiry, 4(4), pp. 247-271.

Cassel, J. (1976). Contribution of social-environment to host-resistance - 4th wade hampton frost lecture. American Journal of Epidemiology, 104(2), 107-123.

Catell, R., Eber, H., \& Tatsuoka, M. (1970). Handbook for the sixteen personality questionnaire (16PF) Champaign, I1: Institute for Personality and Ability Testing.

Caughlin, J., Huston, T., \& Houts, R. (2000). How does personality matter in marriage? an examination of trait anxiety, interpersonal negativity, and marital satisfaction. Journal of Personality and Social Psychology, 78(2), 326-336. doi:10.1037//0022-3514.78.2.326

Chan, S. W. Y., Goodwin, G. M., \& Harmer, C. J. (2007). Highly neurotic never-depressed students have negative biases in information processing. Psychological Medicine, 37(9), 1281-1291. doi:10.1017/S0033291707000669

Chapman, B. P., Fiscella, K., Kawachi, I., \& Duberstein, P. R. (2010). Personality, socioeconomic status, and all-cause mortality in the united states. American Journal of Epidemiology, 171(1), 83-92. doi:10.1093/aje/kwp323

Charney, E. (2012). Behavior genetics and post genomics. Behavioral and Brain Sciences, 35(5), 331-58. doi:10.1017/S0140525X11002226 
Clark, L. A., \& Watson, D. (1991). Tripartite model of anxiety and depression - psychometric evidence and taxonomic implications. Journal of Abnormal Psychology, 100(3), 316336.

Clausen, J. A., \& Gilens, M. (1990). Personality and labor-force participation across the life course - a longitudinal-study of women careers. Sociological Forum, 5(4), 595-618.

Clausen, J., \& Jones, C. (1998). Predicting personality stability across the life span: The role of competence and work and family commitments. Journal of Adult Development, 5(2), 73-83. doi:10.1023/A:1023038410560

Cloninger, C. R. (1986). A unified biosocial theory of personality and its role in the development of anxiety-states. Psychiatric Developments, 4(3), 167-226.

Cohen, J. (1992). A power primer. Psychological Bulletin, 112(1), 155.

Cohn, M. A., Fredrickson, B. L., Brown, S. L., Mikels, J. A., \& Conway, A. M. (2009). Happiness unpacked: Positive emotions increase life satisfaction by building resilience. Emotion, 9(3), 361-368. doi:10.1037/a0015952

Cole, P. M., Llera, S. J., \& Pemberton, C. K. (2009). Emotional instability, poor emotional awareness, and the development of borderline personality. Development and Psychopathology, 21(Special Issue 04), 1293. doi:10.1017/S0954579409990162

Colom, R., \& Angeles Quiroga, M. (2009). Neuroticism, intelligence, and intra-individual variability in elementary cognitive tasks: Testing the mental noise hypothesis. Psicothema, 21(3), 403-408.

Conley, J. J. (1985). Longitudinal stability of personality-traits - a multitrait-multimethodmultioccasion analysis. Journal of Personality and Social Psychology, 49(5), 1266-1282. doi:10.1037/0022-3514.49.5.1266

Connolly, J., \& Viswesvaran, C. (2000). The role of affectivity in job satisfaction: A metaanalysis. Personality and Individual Differences, 29(2), 265-281. doi:10.1016/S01918869(99)00192-0

Costa, P. T., jr, \& McCrae, R. R. (1994). Set like plaster: Evidence for the stability of adult personality. In T. F. Hetherton, \& J. L. Weinberger (Eds.), Can personality change? (pp. 21-40). Washington, D.C.: American Psychological Association.

Costa, P. T., Herbst, J. H., McCrae, R. R., \& Siegler, I. C. (2000). Personality at midlife: Stability, intrinsic maturation, and response to life events. Assessment, 7(4), 365-378. doi:10.1177/107319110000700405

Costa, P. T., \& McCrae, R. R. (1992). The five-factor model of personality and its relevance to personality disorders. Journal of Personality Disorders, 6(4), 343-359.

Costa, P. T., McCrae, R. R., \& Holland, J. L. (1984). Personality and vocational interests in an adult sample. Journal of Applied Psychology, 69(3), 390-400. doi:10.1037//00219010.69.3.390 
Costa, P. T., Herbst, J. H., McCrae, R. R., Samuels, J., \& Ozer, D. J. (2002). The replicability and utility of three personality types. European Journal of Personality, 16(S1), S73-S87. doi:10.1002/per.448

Costa, P. T., \& McCrae, R. R. (1987). Neuroticism, somatic complaints, and disease: Is the bark worse than the bite? Journal of Personality, 55(2), 299-316. doi:10.1111/j.14676494.1987.tb00438.x

Costa, P., Jr., Terracciano, A., \& McCrae, R. R. (2001). Gender differences in personality traits across cultures: Robust and surprising findings. Journal of Personality and Social Psychology, 81(2), 322-331. doi:10.1037/0022-3514.81.2.322

Cramer, A. O. J., Van der Sluis, S., Noordhof, A., Wichers, M., Geschwind, N., Aggen, S. H., ... Borsboom, D. (2012). Measurable like temperature or mereological like flocking? on the nature of personality traits. European Journal of Personality, 26(4), 451-459. doi:10.1002/per.1879

Cuijpers, P., Smit, F., Penninx, B. W. J. H., de Graaf, R., ten Have, M., \& Beekman, A. T. F. (2010). Economic costs of neuroticism: A population-based study. Arch Gen Psychiatry. 67(10), 1086.

Dailey, R. M., Pfiester, A., Jin, B., Beck, G., \& Clark, G. (2009). On-again/off-again dating relationships: How are they different from other dating relationships? Personal Relationships, 16(1), 23-47. doi:10.1111/j.1475-6811.2009.01208.x

Darwin, C. (1872). The expression of the emotions in man and animals. Great Britain: John Murray.

Dawkins, R. (1982). The extended phenotype - the long reach of the gene (2nd, 2008 ed.). New York: Oxford University Press.

De Fruyt, F., \& De Clercq, B. (2014). Personality and psychopathology: A field in transition. European Journal of Personality, 28(4)

De Fruyt, F., Van Leeuwen, K., Bagby, R. M., Rolland, J., \& Rouillon, F. (2006). Assessing and interpreting personality change and continuity in patients treated for major depression. Psychological Assessment, 18(1), 71-80. doi:10.1037/1040-3590.18.1.71

de Graaf, R., Bijl, R. V., Ravelli, A., Smit, F., \& Vollenbergh, W. A. M. (2002). Predictors of first incidence of DSM-III-R psychiatric disorders in the general population: Findings from the netherlands mental health survey and incidence study. Acta Psychiatrica Scandinavica, 106(4), 303-313. doi:10.1034/j.1600-0447.2002.01397.x

De Neve, J., \& Oswald, A. J. (2012). Estimating the influence of life satisfaction and positive affect on later income using sibling fixed effects. Proceedings of the National Academy of Sciences, 109(49), 19953-19958. doi:10.1073/pnas.1211437109

Decuyper, M., De Pauw, S., De Fruyt, F., De Bolle, M., \& De Clercq, B. J. (2009). A metaanalysis of psychopathy-, antisocial PD- and FFM associations. European Journal of Personality, 23(7), 531-565. doi:10.1002/per.729 
Denissen, J. J. A., \& Penke, L. (2008). Neuroticism predicts reactions to cues of social inclusion. European Journal of Personality, 22(6), 497-517. doi:10.1002/per.682

DeScioli, P., \& Kurzban, R. (2009). The alliance hypothesis for human friendship. Plos One, 4(6), e5802. doi:10.1371/journal.pone.0005802

DeYoung, C., Peterson, J., \& Higgins, D. (2002). Higher-order factors of the big five predict conformity: Are there neuroses of health? Personality and Individual Differences, 33(4), 533-552. doi:10.1016/S0191-8869(01)00171-4

DeYoung, C. G. (2010). Toward a theory of the big five. Psychological Inquiry: An International Journal for the Advancement of Psychological Theory, 21(1), 26.

DeYoung, C. G., Quilty, L. C., \& Peterson, J. B. (2007). Between facets and domains: 10 aspects of the big five. Journal of Personality and Social Psychology, 93(5), 880-896. doi:10.1037/0022-3514.93.5.880

Diener, E., \& Emmons, R. A. (1984). The independence of positive and negative affect. Journal of Personality and Social Psychology, 47(5), 1105-1117. doi:10.1037//00223514.47.5.1105

Digman, J. (1997). Higher-order factors of the big five. Journal of Personality and Social Psychology, 73(6), 1246-1256. doi:10.1037/0022-3514.73.6.1246

Digman, J. M. (1990). Personality structure: Emergence of the five-factor model. Annual Review of Psychology, 41, 417-440.

Dion, K. (2005). Marital status as stimulus variable and subject variable. Psychological Inquiry, 16(2-3), 104-110.

Dohrenwend, B. P. (2006). Inventorying stressful life events as risk factors for psychopathology: Toward resolution of the problem of intracategory variability. Psychological Bulletin, 132(3), 477-495.

Dohrenwend, B. S. (1978). Social stress and community psychology. American Journal of Community Psychology, 6(1), 1-14. doi:10.1007/BF00890095

Du, L., Bakish, D., Ravindran, A., \& Hrdina, P. (2002). Does fluoxetine influence major depression by modifying five-factor personality traits? Journal of Affective Disorders, 71(1-3), 235-241. doi:10.1016/S0165-0327(01)00370-6

Duggal, S., Malkoff-Schwartz, S., Birmaher, B., Anderson, B. P., Matty, M. K., Houck, P. R., ... Frank, E. (2000). Assessment of life stress in adolescents: Self-report versus interview methods. Journal of the American Academy of Child and Adolescent Psychiatry, 39(4), 445-452.

Dumont, F. (2010). A history of personality psychology: Theory, science, and research from hellenism to the twenty-first century. New York: Cambridge University Press.

Durbin, C. E., \& Hicks, B. M. (2014). Personality and psychopathology: A Stagnant Field in need of development. European Journal of Personality, 28(4), 362.

doi:10.1002/per.1962 
Eaves, L., Heath, A., Martin, N., Maes, H., Neale, M., Kendler, K., . . Corey, L. (1999). Comparing the biological and cultural inheritance of personality and social attitudes in the virginia 30,000 study of twins and their relatives. Twin Research, 2(2), 62. doi:PubMed ID: 10480741

Eaves, L. J., Eysenck, H. J., \& Martin, N. G. (1989). Genes, culture and personality: An empirical approach. San Diego, CA US: Academic Press.

Egan, S., \& Stelmack, R. (2003). A personality profile of mount everest climbers. Personality and Individual Differences, 34(8), 1491-1494. doi:10.1016/S0191-8869(02)00130-7

Ekman, P. (2007). Gegrepen door emoties. Nieuwezijds B.V.

Elder, G. H. (1994). Time, human agency, and social-change - perspectives on the lifecourse. Social Psychology Quarterly, 57(1), 4-15.

Elder, G. H.,Jr. (1975). Age differentiation and the life course. Annual Review of Sociology, 1, pp. 165-190.

Ellis, B., \& Malamuth, N. (2000). Love and anger in romantic relationships: A discrete systems model. Journal of Personality, 68(3), 525-556. doi:10.1111/1467-6494.00105

Endler, N. S., \& Magnusson, D. (1976). Toward an interactional psychology of personality. Psychological Bulletin, 83(5), 956-974. doi:10.1037/0033-2909.83.5.956

Engelhard, I. M., van, d. H., \& Lommen, M. J. J. (2009). Individuals high in neuroticism are not more reactive to adverse events. Personality and Individual Differences, 47(7), 697700. doi:10.1016/j.paid.2009.05.031

Eysenck, H. J. (1981). A model for personality. New York: Springer-Verlag.

Eysenck, H. J. (1958). A short questionnaire for the measurement of two dimensions of personality. Journal of Applied Psychology, 42(1), 14-17. doi:10.1037/h0041738

Fanous, A. H., Neale, M. C., Aggen, S. H., \& Kendler, K. S. (2007). A longitudinal study of personality and major depression in a population-based sample of male twins.

Psychological Medicine: A Journal of Research in Psychiatry and the Allied Sciences, 37(8), 1163-1172. doi:10.1017/S0033291707000244

Faravelli, C., Catena, M., Scarpato, A., \& Ricca, V. (2007). Epidemiology of life events: Life events and psychiatric disorders in the sesto fiorentino study. Psychotherapy and Psychosomatics, 76(6), 361-368. doi:10.1159/000107564

Ferguson, C. J. (2010). A meta-analysis of normal and disordered personality across the life span. Journal of Personality and Social Psychology, 98(4), 659-667. doi:10.1037/a0018770

Ferguson, C. J., \& Heene, M. (2012). A vast graveyard of undead theories: Publication bias and psychological Science's aversion to the null. Perspectives on Psychological Science, 7(6), 555-561. doi:10.1177/1745691612459059 
Fergusson, D. M., \& Horwood, L. J. (1987). Vulnerability to life events exposure. Psychological Medicine: A Journal of Research in Psychiatry and the Allied Sciences, 17(3), 739-749. doi:10.1017/S0033291700025976

Field, D., \& Millsap, R. E. (1991). Personality in advanced old-age - continuity or change. Journals of Gerontology, 46(6), P299-P308.

Finlay-Jones, R., \& Brown, G. W. (1981). Types of stressful life event and the onset of anxiety and depressive disorders. Psychological Medicine, 11(4), 803-815.

Finn, C., Mitte, K., \& Neyer, F. J. (2013). The relationship-specific interpretation bias mediates the link between neuroticism and satisfaction in couples. European Journal of Personality, 27(2), 200-212. doi:10.1002/per.1862

Fleeson, W. (2001). Toward a structure- and process-integrated view of personality: Traits as density distributions of states. Journal of Personality and Social Psychology, 80(6), 1011-1027. doi:10.1037//0022-3514.80.6.1011

Fleeson, W., \& Gallagher, P. (2009). The implications of big five standing for the distribution of trait manifestation in behavior: Fifteen experience-sampling studies and a metaanalysis. Journal of Personality and Social Psychology, 97(6), 1097-1114. doi:10.1037/a0016786

Flint, J. (2004). The genetic basis of neuroticism. Neuroscience and Biobehavioral Reviews, 28(3), 307-316. doi:10.1016/j.neubiorev.2004.01.004

Flynn, J. R. (2009). What is intelligence? (2nd ed.). Cambridge: Cambridge University Press.

Foley, D., Neale, M., \& Kendler, K. (1996). A longitudinal study of stressful life events assessed at interview with an epidemiological sample of adult twins: The basis of individual variation in event exposure. Psychological Medicine, 26(6), 1239-1252.

Fox, N., Henderson, H., Marshall, P., Nichols, K., \& Ghera, M. (2005). Behavioral inhibition: Linking biology and behavior within a developmental framework. Annual Review of Psychology, 56, 235-262. doi:10.1146/annurev.psych.55.090902.141532

Fraga, M. F., Ballestar, E., Paz, M. F., Ropero, S., Setien, F., Ballestar, M. L., . . Esteller, M. (2005). Epigenetic differences arise during the lifetime of monozygotic twins.

Proceedings of the National Academy of Sciences of the United States of America, 102(30), 10604-10609. doi:10.1073/pnas.0500398102

Fraley, R. C., \& Roberts, B. W. (2005). Patterns of continuity: A dynamic model for conceptualizing the stability of individual differences in psychological constructs across the life course. Psychological Review, 112(1), 60-74. doi:10.1037/0033-295X.112.1.60

Fredrickson, B. L. (1998). What good are positive emotions? Review of General Psychology, 2(3), 300-319. doi:10.1037/1089-2680.2.3.300

Fredrickson, B. (2003). The value of positive emotions - the emerging science of positive psychology in coming to understand why it's good to feel good. American Scientist, 91(4), 330-335. doi:10.1511/2003.26.865 
Freedman, D. A. (1987). As others see us: A case study in path analysis. Journal of Educational and Behavioral Statistics, 12(2), 101-128. doi:10.3102/10769986012002101

Frick, P. (2004). Integrating research on temperament and childhood psychopathology: Its pitfalls and promise. Journal of Clinical Child and Adolescent Psychology, 33(1), 2-7. doi:10.1207/S15374424JCCP3301_1

Friedman, H. S., \& Martin, L. R. (2011). The longevity project. England: Hudson Street Pers.

Furnham, A., \& Zacherl, M. (1986). Personality and job-satisfaction. Personality and Individual Differences, 7(4), 453-459. doi:10.1016/0191-8869(86)90123-6

Galton, F. (1884). Measurement of character. Fortnightly Review, 36, 179-185.

Garland, E. L., Fredrickson, B., Kring, A. M., Johnson, D. P., Meyer, P. S., \& Penn, D. L. (2010). Upward spirals of positive emotions counter downward spirals of negativity: Insights from the broaden-and-build theory and affective neuroscience on the treatment of emotion dysfunctions and deficits in psychopathology. Clinical Psychology Review, 30(7), 849-864. doi:10.1016/j.cpr.2010.03.002

Geary, D. C., \& Flinn, M. V. (2001). Evolution of human parental behavior and the human family. Parenting-Science and Practice, 1(1-2), 5-61. doi:10.1207/S15327922PAR011\&2_2

Geary, D. (2000). Evolution and proximate expression of human paternal investment. Psychological Bulletin, 126(1), 55-77. doi:10.1037//0033-2909.126.1.55

Gibbons, F., \& Buunk, B. (1999). Individual differences in social comparison: Development of a scale of social comparison orientation. Journal of Personality and Social Psychology, 76(1), 129-142. doi:10.1037/0022-3514.76.1.129

Gilbert, P. (2000). The relationship of shame, social anxiety and depression: The role of the evaluation of social rank. Clinical Psychology \& Psychotherapy, 7(3), 174-189. doi:10.1002/1099-0879(200007)7:3<174::AID-CPP236>3.0.CO;2-U

Gladwell, M. (2008). Outliers: The story of success. USA: Little, Brown and Company.

Glinski, K., \& Page, A. C. (2010). Modifiability of neuroticism, extraversion, and agreeableness by group cognitive behaviour therapy for social anxiety disorder. Behaviour Change, 27(1), 42-52. doi:10.1375/bech.27.1.42Pub

Goldberg, L. R. (1993). The structure of phenotypic personality traits. American Psychologist, 48(1), 26-34. doi:10.1037/0003-066X.48.1.26

Goldsmith, H. H., Buss, K. A., \& Lemery, K. S. (1997). Toddler and childhood temperament: Expanded content, stronger genetic evidence, new evidence for the importance of environment. Developmental Psychology, 33(6), 891-905. doi:10.1037/00121649.33.6.891

Goma-I-Freixanet, M. (1991). Personality profile of subjects engaged in high physical risk sports. Personality and Individual Differences, 12(10), 1087-1093. 
Goodyer, I. M., Kolvin, I., \& Gatzanis, S. (1987). The impact of recent undesirable life events on psychiatric-disorders in childhood and adolescence. British Journal of Psychiatry, 151, 179-184. doi:10.1192/bjp.151.2.179

Gosling, S. D., Kwan, V. S. Y., \& John, O. P. (2003). A dog's got personality: A crossspecies comparative approach to personality judgments in dogs and humans. Journal of Personality and Social Psychology, 85(6), 1161-1169. doi:10.1037/0022-3514.85.6.1161

Gottman, J., Coan, J., Carrere, S., \& Swanson, C. (1998). Predicting marital happiness and stability from newlywed interactions. Journal of Marriage and the Family, 60(1), 5-22. doi:10.2307/353438

Gow, A., Whiteman, M., Pattie, A., \& Deary, I. (2005). The personality-intelligence interface: Insights from an ageing cohort. Personality and Individual Differences, 39(4), 751-761. doi:10.1016/j.paid.2005.01.028

Grant, S. (2010). Neuroticism: The personality risk factor for stress and impaired health and well-being. In R. G. Jackson (Ed.), Psychology of neuroticism and shame (pp. 1-36). New York: Nova Science Publishers.

Grant, K., Compas, B., Thurm, A., McMahon, S., \& Gipson, P. (2004). Stressors and child and adolescent psychopathology: Measurement issues and prospective effects. Journal of Clinical Child and Adolescent Psychology, 33(2), 412-425. doi:10.1207/s15374424jccp3302_23

Gross, J. J., Sutton, S. K., \& Ketelaar, T. (1998). Relations between affect and personality: Support for the affect-level and affective reactivity views. Personality and Social Psychology Bulletin, 24(3), 279-288. doi:10.1177/0146167298243005

Grov, E. K., Fossa, S. D., Bremnes, R. M., Dahl, O., Klepp, O., Wist, E., \& Dahl, A. A. (2009). The personality trait of neuroticism is strongly associated with long-term morbidity in testicular cancer survivors. Acta Oncologica, 48(6), 842-849. doi:10.1080/02841860902795232

Gunthert, K. C., Cohen, L. H., \& Armeli, S. (1999). The role of neuroticism in daily stress and coping. Journal of Personality and Social Psychology, 77(5), 1087-1100. doi:10.1037/0022-3514.77.5.1087

Gurven, M., von Rueden, C., Massenkoff, M., Kaplan, H., \& Lero Vie, M. (2013). How universal is the big five? testing the five-factor model of personality variation among forager-farmers in the bolivian amazon. Journal of Personality and Social Psychology, 104(2), 354-370. doi:10.1037/a0030841

Haan, N., Millsap, R., \& Hartka, E. (1986). As time goes by: Change and stability in personality over fifty years. Psychology and Aging, 1(3), 220-232. doi:10.1037/08827974.1.3.220

Hammen, C. (2003). Social stress and women's risk for recurrent depression. Arch Womens Ment Health, 6(1), 9-13.

Hammen, C. (2005). Stress and depression. Annual Review of Clinical Psychology, 1(1), 293319. doi:10.1146/annurev.clinpsy.1.102803.143938 
Hampson, S. E. (2012). Personality processes: Mechanisms by which personality traits " get outside the skin". Annual Review of Psychology, 63, 315-39. doi:10.1146/annurev-psych120710-100419

Harmon-Jones, E., Harmon-Jones, C., Amodio, D. M., \& Gable, P. A. (2011). Attitudes toward emotions. Journal of Personality and Social Psychology, 101(6), 1332. doi: $10.1037 / \mathrm{a} 0024951$

Harris, J. R. (2009). The nurture assumption: Why children turn out the way they do (2nd ed.). New York, USA.: Free Press, Simon \& Schuster, Inc.

Hayes, A. M., Laurenceau, J., Feldman, G., Strauss, J. L., \& Cardaciotto, L. (2007). Change is not always linear: The study of nonlinear and discontinuous patterns of change in psychotherapy. Clinical Psychology Review, 27(6), 715-723. doi:DOI: 10.1016/j.cpr.2007.01.008

Headey, B. (2010). The set point theory of well-being has serious flaws: On the eve of a scientific revolution? Social Indicators Research, 97(1), 7-21. doi:10.1007/s11205-0099559-x

Headey, B., \& Wearing, A. (1989). Personality, life events, and subjective well-being: Toward a dynamic equilibrium model. Journal of Personality and Social Psychology, 57(4), 731-739. doi:10.1037/0022-3514.57.4.731

Heller, D., Watson, D., \& Ilies, R. (2004). The role of person versus situation in life satisfaction: A critical examination. Psychological Bulletin, 130(4), 574-600. doi:10.1037/0033-2909.130.4.574

Helson, R., Jones, C., \& Kwan, V. S. Y. (2002). Personality change over 40 years of adulthood: Hierarchical linear modeling analyses of two longitudinal samples. Journal of Personality and Social Psychology, 83(3), 752-766. doi:10.1037//0022-3514.83.3.752

Helson, R., Kwan, V., John, O., \& Jones, C. (2002). The growing evidence for personality change in adulthood: Findings from research with personality inventories. Journal of Research in Personality, 36(4), 287-306. doi:10.1016/S0092-6566(02)00010-7

Helson, R., \& Moane, G. (1987). Personality change in women from college to midlife. Journal of Personality and Social Psychology, 53(1), 176-186. doi:10.1037/00223514.53.1.176

Henrich, J., Heine, S. J., \& Norenzayan, A. (2010). The weirdest people in the world? Behavioral and Brain Sciences, 33(2-3), 61. doi:10.1017/S0140525X0999152X

Hensley, B., Martin, P., Margrett, J. A., MacDonald, M., Siegler, I. C., Poon, L. W., \& Georgia Centenarian Study. (2012). Life events and personality predicting loneliness among centenarians: Findings from the georgia centenarian study. Journal of Psychology, 146(1-2), 173-188. doi:10.1080/00223980.2011.613874

Herrnstein, R. J., \& Murray, C. (1996). The bell curve. New York: Free Press Paperbacks. 
Hershberger, S. L., Billig, J. P., Iacono, W. G., \& McGue, M. (1995). Life events, personality, and psychopathology in late adolescence - genetic and environmentalfactors. Behavior Genetics, 25(3), 270-270.

Hertzog, C., \& Nesselroade, J. R. (2003). Assessing psychological change in adulthood: An overview of methodological issues. Psychology and Aging, 18(4), 639-657. doi:10.1037/0882-7974.18.4.639

Hetherington, E. M., Clingempeel, W. G., Anderson, E. R., Deal, J. E., Hagan, M. S., Hollier, E. A., . . MacCoby, E. E. (1992). Coping with marital transitions: A family systems perspective. Monographs of the Society for Research in Child Development, 57(2-3), 1242. doi:10.2307/1166050

Hetherington, E. M., \& Kelly, J. (2002). For better or for worse: Divorce reconsidered. New York: W.W. Norton.

Hill, J. (2011). Disorders of personality. In M. Rutter, D. Bishop, D. Pine, S. Scott, J. Steverson, E. Taylor \& A. Thapar (Eds.), Rutter's child and adolescent psychiatry (5th ed., ). Massachusets, USA.: Wiley-Blackwell.

Hink, L., Rhee, S., Corley, R., Cosgrove, V., Hewitt, J., Schulz-Heik, R., . . Waldman, I. (2013). Personality dimensions as common and broadband-specific features for internalizing and externalizing disorders. Journal of Abnormal Child Psychology, 41(6), 939-957. doi:10.1007/s10802-013-9730-3

Hirschmüller, S., Egloff, B., Schmukle, S. C., Nestler, S., \& Back, M. D. (2014). Accurate judgments of neuroticism at zero acquaintance: A question of relevance. Journal of Personality, , n/a-n/a. doi:10.1111/jopy.12097

Hobson, C., Kamen, J., Szostek, J., Nethercut, C., Tiedmann, J., \& Wojnarowicz, S. (1998). Stressful life events: A revision and update of the social readjustment rating scale. International Journal of Stress Management, 5(1), 1-23. doi:10.1023/A:1022978019315

Hofstede, G., \& McCrae, R. (2004). Personality and culture revisited: Linking traits and dimensions of culture. Cross-Cultural Research, 38(1), 52-88. doi:10.1177/1069397103259443

Holmes, T. H., \& Rahe, R. H. (1967). Social readjustment rating scale. Journal of Psychosomatic Research, 11(2), 213-218.

Hong, R. Y., \& Cheung, M. W. -. (2014). The structure of cognitive vulnerabilities to depression and anxiety: Evidence for a common core etiologic process based on a metaanalytic review. Clinical Psychological Science, doi:10.1177/2167702614553789

Hutteman, R., Bleidorn, W., Kerestes, G., Brkovic, I., Butkovic, A., \& Denissen, J. J. A. (2014). Reciprocal associations between parenting challenges and parents' personality development in young and middle adulthood. European Journal of Personality, 28(2), 168-179. doi:10.1002/per.1932

Ilies, R., \& Judge, T. A. (2002). Understanding the dynamic relationships among personality, mood, and job satisfaction: A field experience sampling study. Organizational Behavior 
and Human Decision Processes, 89(2), 1119-1139. doi:DOI: 10.1016/S07495978(02)00018-3

Inkeles, A., \& Levinson, D. J. (1963). The personal system and the sociocultural system in large-scale organizations. Sociometry, 26(2), 217-229.

Ioannidis, J. P. A. (2005). Why most published research findings are false. PLoS Med, 2(8), e124.

Ireland, M. E., Hepler, J., Li, H., \& Albarracin, D. (2014). Neuroticism and attitudes toward action in 19 countries. Journal of Personality, early online version, 5 june doi:10.1111/jopy.12099

Isen, A. M. (1987). Positive affect, cognitive-processes, and social-behavior. Advances in Experimental Social Psychology, 20, 203-253. doi:10.1016/S0065-2601(08)60415-3

Jaenike, J., \& Holt, R. D. (1991). Genetic-variation for habitat preference - evidence and explanations. American Naturalist, 137, S67-S90. doi:10.1086/285140

James, W. (1890). The principles of psychology.

Jardine, R., Martin, N. G., \& Henderson, A. S. (1984). Genetic covariation between neuroticism and the symptoms of anxiety and depression. Genetic Epidemiology, 1(2), 89-107.

Jeronimus, B. F. (2015). Environmental influences on neuroticism: A story about emotional (in)stability. Groningen, The Netherlands: University of Groningen. doi:10.13140/2.1.3452.2407

Jeronimus, B. F., Kotov, R., Riese, H., \& Ormel, J. (2016). Neuroticism's prospective association with mental disorders halves after adjustment for baseline symptoms and psychiatric history, but the adjusted association hardly decays with time: A metaanalysis on 59 longitudinal/prospective studies with 443,313 participants. Psychological Medicine, 46(14), 2883-2906. doi:10.1017/S0033291716001653

Jeronimus, B.F., Laceulle, O.M. (2017). Frustration. In: Zeigler-Hill V., Shackelford T. (eds) Encyclopedia of Personality and Individual Differences. Springer, Cham.

Jeronimus, B. F., Ormel, J., Aleman, A., Penninx, B. W. J. H., \& Riese, H. (2013). Negative and positive life events are associated with small but lasting change in neuroticism. Psychological Medicine, 43(11), 2403-2415. doi:10.1017/S0033291713000159

Jeronimus, B.F., Riese, H. (2016). If it ain't broke, don't fix it: Depressive traits are part and parcel of neuroticism revisited. Psychoneuroendocrinology 65, 165. doi:10.1016/j.psyneuen.2015.12.005

Jeronimus, B. F., Riese, H., Oldehinkel, A. J., \& Ormel, J. (2015). Why does frustration predict psychopathology? multiple prospective pathways over adolescence: A TRAILS study. European Journal of Personality, 31(1), 85-103. doi:10.1002/per.2086

Jeronimus, B. F., Riese, H., Sanderman, R., \& Ormel, J. (2014). Mutual reinforcement between neuroticism and life experiences: A five-wave, 16-year study to test reciprocal 
causation. Journal of Personality and Social Psychology, 107(4), 751.

doi:10.1037/a0037009

Jeronimus, B. F., Stavrakakis, N., Veenstra, R., \& Oldehinkel, A. J. (2015). Relative age effects in adolescence: The TRAILS study. PLoS One, 10(6), e0128856.

doi:10.1371/journal.pone.0128856

Jockin, V., McGue, M., \& Lykken, D. (1996). Personality and divorce: A genetic analysis. Journal of Personality and Social Psychology, 71(2), 288-299. doi:10.1037/00223514.71.2.288

John, O. P., Robins, R., \& Pervin, L. A. (2008). Handbook of personality: Theory and research (3rd ed.). New York: Guilford.

Johnson, W., \& Penke, L. (2015). Genetics of social behavior . In Gawronski, B., \& Bodenhausen, G. (Ed.), Theory and explanation in social psychology. (pp. 205). New York: Guilford Press.

Johnson, D., \& Wu, J. (2002). An empirical test of crisis, social selection, and role explanations of the relationship between marital disruption and psychological distress: A pooled time-series analysis of four-wave panel data. Journal of Marriage and Family, 64(1), 211-224. doi:10.1111/j.1741-3737.2002.00211.x

Johnson, W. (2007). Genetic and environmental influences on behavior: Capturing all the interplay. Psychological Review, 114(2), 423-440. doi:10.1037/0033-295X.114.2.423

Johnston, R. G., \& Brown, A. E. (2012). Maternal trait personality and childbirth: The role of extraversion and neuroticism. Midwifery, 2(5), 1244-1250. doi:10.1016/j.midw.2012.08.005

Jokela, M., Alvergne, A., Pollet, T. V., \& Lummaa, V. (2011). Reproductive behavior and personality traits of the five factor model. European Journal of Personality, 25(6), 487500. doi:10.1002/per.822

Jokela, M., Kivimäki, M., Elovainio, M., \& Keltikangas-Järvinen, L. (2009). Personality and having children: A two-way relationship. Journal of Personality and Social Psychology, 96(1), 218-230. doi:10.1037/a0014058

Jonassaint, C., Siegler, I., Barefoot, J., Edwards, C., \& Williams, R. (2011). Low life course socioeconomic status (SES) is associated with negative NEO PI-R personality patterns. International Journal of Behavioral Medicine, 18(1), 13-21. doi:10.1007/s12529-0099069-x

Jonkmann, K., Thoemmes, F., Lüdtke, O., \& Trautwein, U. (2014). Personality traits and living arrangements in young adulthood: Selection and socialization. . Developmental Psychology, 50(3), 683. doi:10.1037/a0034239

Jonkmann, K., Becker, M., Marsh, H. W., Lüdtke, O., \& Trautwein, U. (2012). Personality traits moderate the big-Fish-Little-pond effect of academic self-concept. Learning and Individual Differences, 22(6), 736-746. doi:http://dx.doi.org/10.1016/j.lindif.2012.07.020 
Jorm, A. F. (1989). Modifiability of trait anxiety and neuroticism - a meta-analysis of the literature. Australian and New Zealand Journal of Psychiatry, 23(1), 21-29. doi:10.3109/00048678909062588

Jorm, A. F., \& Duncan-Jones, P. (1990). Neurotic symptoms and subjective well-being in a community sample - different sides of the same coin. Psychological Medicine, 20(3), 647-654.

Judge, T. A., Heller, D., \& Mount, M. K. (2002). Five-factor model of personality and job satisfaction: A meta-analysis. Journal of Applied Psychology, 87(3), 530-541. doi:10.1037//0021.9010.87.3.530

Judge, T. A., \& Hurst, C. (2007). Capitalizing on one's advantages: Role of core selfevaluations. Journal of Applied Psychology, 92(5), 1212-1227. doi:10.1037/00219010.92.5.1212

Kahneman, D. (2011). Thinking, fast and slow. London: Penguin Books.

Kanazawa, S., \& Savage, J. (2009). An evolutionary psychological perspective on social capital. Journal of Economic Psychology, 30(6), 873-883.

doi:10.1016/j.joep.2009.08.002

Kandler, C., Bleidorn, W., Riemann, R., Angleitner, A., \& Spinath, F. M. (2012). Life events as environmental states and genetic traits and the role of personality: A longitudinal twin study. Behavior Genetics, 42(1), 57-72. doi:10.1007/s10519-011-9491-0

Kandler, C., Bleidorn, W., Riemann, R., Spinath, F. M., Thiel, W., \& Angleitner, A. (2010). Sources of cumulative continuity in personality: A longitudinal multiple-rater twin study. Journal of Personality and Social Psychology, 98(6), 995-1008. doi:10.1037/a0019558

Kanner, A. D., Coyne, J. C., Schaefer, C., \& Lazarus, R. S. (1981). Comparison of two modes of stress measurement: Daily hassles and uplifts versus major life events. Journal of Behavioral Medicine, 4(1), 1-39.

Kaplan, H. S., \& Gangestad, S. W. (2005). Life history theory and evolutionary psychology. In D. M. Buss (Ed.), The handbook of evolutionary psychology. (pp. 68-95). Hoboken, NJ US: John Wiley \& Sons Inc.

Kaprio, J., Koskenvuo, M., \& Rose, R. J. (1990). Change in cohabitation and intrapair similarity of monozygotic (MZ) cotwins for alcohol use, extraversion, and neuroticism. Behavior Genetics, 20(2), 265-276. doi:10.1007/BF01067794

Karney, B. R., \& Bradbury, T. N. (1995). The longitudinal course of marital quality and stability - a review of theory, method, and research. Psychological Bulletin, 118(1), 3-34.

Kasl, S. V. (1973). Mental health and work environment: An examination of the evidence. Journal of Occupational Medicine.: Official Publication of the Industrial Medical Association, 15(6), 509-518.

Keller, M. C., Coventry, W. L., Heath, A. C., \& Martin, N. G. (2005). Widespread evidence for non-additive genetic variation in cloninger's and eysenck's personality dimensions 
using a twin plus sibling design. Behavior Genetics, 35(6), 707-721.

doi:10.1007/s10519-005-6041-7

Keller, M. C., Medland, S. E., \& Duncan, L. E. (2010). Are extended twin family designs worth the trouble? A comparison of the bias, precision, and accuracy of parameters estimated in four twin family models. Behavior Genetics, 40(3), 377-393.

doi:10.1007/s10519-009-9320-x

Kelly, E. L., \& Conley, J. J. (1987). Personality and compatibility: A prospective analysis of marital stability and marital satisfaction. Journal of Personality and Social Psychology, 52(1), 27-40. doi:10.1037/0022-3514.52.1.27

Kendler, K. S., Gardner, C. O., \& Prescott, C. A. (2002). Toward a comprehensive developmental model for major depression in women. American Journal of Psychiatry, 159(7), 1133-1145.

Kendler, K. S., Aggen, S. H., Jacobson, K. C., \& Neale, M. C. (2003). Does the level of family dysfunction moderate the impact of genetic factors on the personality trait of neuroticism? Psychological Medicine, 33(5), 817-825. doi:10.1017/S0033291703007840

Kendler, K. S., Gardner, C. O., \& Prescott, C. A. (2003). Personality and the experience of environmental adversity. Psychological Medicine, 33(7), 1193-1202. doi:10.1017/S0033291703008298

Kendler, K. S., Karkowski, L. M., \& Prescott, C. A. (1999). The assessment of dependence in the study of stressful life events: Validation using a twin design. Psychological Medicine, 29(06), 1455.

Kendler, K. S., \& Myers, J. (2010). The genetic and environmental relationship between major depression and the five-factor model of personality. Psychological Medicine, 40(05), 801. doi:10.1017/S0033291709991140

Kendler, K. S., \& Baker, J. H. (2007). Genetic influences on measures of the environment: A systematic review. Psychological Medicine, 37(5), 615-626.

doi:10.1017/S0033291706009524

Kendler, K. (1997). Social support: A genetic-epidemiologic analysis. American Journal of Psychiatry, 154(10), 1398-1404.

Kendler, K. (2001). Twin studies of psychiatric illness - an update. Archives of General Psychiatry, 58(11), 1005-1014. doi:10.1001/archpsyc.58.11.1005

Kendler, K., Karkowski, L., \& Prescott, C. (1999). Causal relationship between stressful life events and the onset of major depression. American Journal of Psychiatry, 156(6), 837841.

Kersting, A., Dorsch, M., Wesselmann, U., Lüdorff, K., Witthaut, J., Ohrmann, P., . . Arolt, V. (2004). Maternal posttraumatic stress response after the birth of a very low-birthweight infant. Journal of Psychosomatic Research, 57(5), 473-476.

doi:10.1016/j.jpsychores.2004.03.011 
Kessler, R. C., \& Mcleod, J. D. (1984). Sex-differences in vulnerability to undesirable life events. American Sociological Review, 49(5), 620-631.

Kiernan, K. E. (1986). Teenage marriage and marital breakdown: A longitudinal-study. Population Studies, 40(1), 35-54.

King, J. E., Weiss, A., \& Farmer, K. H. (2005). A chimpanzee (pan troglodytes) analogue of cross-national generalization of personality structure: Zoological parks and an african sanctuary. Journal of Personality, 73(2), 389-410. doi:10.1111/j.14676494.2005.00313.x

Kohn, M. L., \& Schooler, C. (1973). Occupational experience and psychological functioning - assessment of reciprocal effects. American Sociological Review, 38(1), 97-118.

Konnor, M. (2010). The evolution of childhood. relationships, emotion, mind. Cambridge, Massachusetts, London, England: The Belknap Press of Harvard University Press.

Koskenvuo, M., Langinvainio, H., Kaprio, J., \& Sarna, S. (1984). Health related psychosocial correlates of neuroticism: A study of adult male twins in finland. Acta Geneticae Medicae Et Gemellologiae, 33(2), 307-320.

Kotov, R., Gamez, W., Schmidt, F., \& Watson, D. (2010). Linking "big" personality traits to anxiety, depressive, and substance use disorders: A meta-analysis. Psychological Bulletin, 136(5), 768-821. doi:10.1037/a0020327

Krueger, R. F. (1999a). The structure of common mental disorders. Archives of General Psychiatry, 56(10), 921-926. doi:10.1001/archpsyc.56.10.921

Krueger, R. F. (1999b). Personality traits in late adolescence predict mental disorders in early adulthood: A prospective-epidemiological study. Journal of Personality, 67(1), 39-65.

Krueger, R. F., Markon, K. E., \& Bouchard, T. J. (2003). The extended genotype: The heritability of personality accounts for the heritability of recalled family environments in twins reared apart. Journal of Personality, 71(5), 809-833.

Krueger, R., Caspi, A., \& Moffitt, T. (2000). Epidemiological personology: The unifying role of personality in population-based research on problem behaviors. Journal of Personality, 68(6), 967-998. doi:10.1111/1467-6494.00123

Krueger, R. F., South, S., Johnson, W., \& Iacono, W. (2008). The heritability of personality is not always 50\%: Gene-environment interactions and correlations between personality and parenting. Journal of Personality, 76(6), 1485-1522. doi:10.1111/j.14676494.2008.00529.x

Kuepper, Y., Wielpuetz, C., Alexander, N., Mueller, E., Grant, P., \& Hennig, J. (2012). 5HTTLPR S-allele: A genetic plasticity factor regarding the effects of life events on personality? Genes, Brain and Behavior, 11(6), 643-650. doi:10.1111/j.1601183X.2012.00783.X

Kurdek, L. A. (1993). Predicting marital dissolution - a 5-year prospective longitudinal-study of newlywed couples. Journal of Personality and Social Psychology, 64(2), 221-242. doi:10.1037/0022-3514.64.2.221 
Kurdek, L. A. (1992). Relationship stability and relationship satisfaction in cohabiting gay and lesbian couples: A prospective longitudinal test of the contextual and interdependence models. Journal of Social and Personal Relationships, 9(1), 125-142. doi:10.1177/0265407592091007

Laceulle, O. M., Jeronimus, B. F., Van Aken, M. A. G., \& Ormel, J. (2015). Why not everybody gets their fair share of stress: Adolescent's perceived relationship affection mediates associations between temperament and subsequent stressful social events. European Journal of Personality, 29(2), 125-37. doi:10.1002/per.1989

Laceulle, O. M., Ormel, J., Aggen, S. S. H., Neale, M. C., \& Kendler, K. S. (2013). Genetic and environmental influences on the longitudinal structure of neuroticism: A trait-state approach. Psychological Science, 24(9), 1780-1790. doi:10.1177/0956797613481356

Laceulle, O. M., Ormel, J., Vollebergh, W. A. M., van Aken, M. A. G., \& Nederhof, E. (2014). A test of the vulnerability model: Temperament and temperament change as predictors of future mental disorders? The TRAILS study. Journal of Child Psychology and Psychiatry, 55(3), 227-236. doi:10.1111/jcpp.12141

Lahey, B. B. (2009). Public health significance of neuroticism. American Psychologist, 64(4), 241-256. doi:10.1037/a0015309

Lahey, B. B., Applegate, B., Hakes, J. K., Zald, D. H., Hariri, A. R., \& Rathouz, P. J. (2012). Is there a general factor of prevalent psychopathology during adulthood? Journal of Abnormal Psychology, 121(4), 971-977. doi:10.1037/a0028355

Lake, R. I. E., Eaves, L. J., Maes, H. H. M., Heath, A. C., \& Martin, N. G. (2000). Further evidence against the environmental transmission of individual differences in neuroticism from a collaborative study of 45,850 twins and relatives on two continents. Behavior Genetics, 30(3), 223-233. doi:10.1023/A:1001918408984

Larsen, R. J., \& Buss, D. M. (2013). Personality psychology: Domains of knowledge about human nature. New York: McGraw-Hill.

Larsen, R. J. (1987). The stability of mood variability - a spectral analytic approach to daily mood assessments. Journal of Personality and Social Psychology, 52(6), 1195-1204. doi:10.1037//0022-3514.52.6.1195

Lazarus, R. S., DeLongis, A., Folkman, S., \& Gruen, R. (1985). Stress and adaptational outcomes: The problem of confounded measures. American Psychologist, 40(7), 770779. doi:10.1037/0003-066X.40.7.770

Leary, M. R. (1990). Responses to social exclusion - social anxiety, jealousy, loneliness, depression, and low self-esteem. Journal of Social and Clinical Psychology, 9(2), 221229. doi:10.1521/jscp.1990.9.2.221

Leary, M. R., \& Baumeister, R. F. (2001). The nature and function of self-esteem: Sociometer theory. In M. P. Zanna (Ed.), Advances in experimental social psychology (pp. 1-62) Academic Press. doi:10.1016/S0065-2601(00)80003-9 
Lee, W. E., Wadsworth, M. E. J., \& Hotopf, A. (2006). The protective role of trait anxiety: A longitudinal cohort study. Psychological Medicine, 36(3), 345-351. doi: $10.1017 /$ S0033291705006847

Lehmann, R., Denissen, J. J. A., Allemand, M., \& Penke, L. (2013). Age and gender differences in motivational manifestations of the big five from age 16 to 60 . Developmental Psychology, 49(2), 365-383. doi:10.1037/a0028277

Lehnart, J., \& Neyer, F. J. (2006). Should I stay or should I go? attachment and personality in stable and instable romantic relationships. European Journal of Personality, 20(6), 475495. doi:10.1002/per.606

Lehnart, J., Neyer, F. J., \& Eccles, J. (2010). Long-term effects of social investment: The case of partnering in young adulthood. Journal of Personality, 78(2), 639-670.

doi:10.1111/j.1467-6494.2010.00629.x

Lewinsohn, P., Rohde, P., \& Gau, J. (2003). Comparability of self-report checklist and interview data in the assessment of stressful life events in young adults. Psychological Reports, 93(2), 459-471. doi:10.2466/PR0.93.6.459-471

Lewontin, R. (2000). The triple helix: Gene, organism and environment Harvard University Press.

Lindenberg, S. (1996). Continuities in the theory of social production functions. In $\mathrm{H}$. Ganzeboom, \& S. Lindenberg (Eds.), Verklarende sociologie: Opstellen voor reinhard wippler (). Amsterdam: Thela Thesis.

Lindstrom, R. A. (2013). Cyclicality and the relationship between neuroticism, communication, and relationship satisfaction in cohabiting couples. (Unpublished Master of Science). Kansas State University, Manhattan, Kansas.

Lock, S., Rubin, G. J., Murray, V., Rogers, M. B., Amlôt, R., \& Williams, R. (2012). Secondary stressors and extreme events and disasters: A systematic review of primary research from 2010-2011. PLOS Currents Disasters, 29(4), 2. doi:10.1371/currents.dis.a9b76fed1b2dd5c5bfcfc13c87a2f24f.

Löckenhoff, C. E., Terracciano, A., \& Costa, P. T., Jr. (2009a). Five-factor model personality traits and the retirement transition: Longitudinal and cross-sectional associations. Psychology and Aging, 24(3), 722-728. doi:10.1037/a0015121

Löckenhoff, C. E., Terracciano, A., Patriciu, N. S., Eaton, W. W., \& Costa, P. T., Jr. (2009b). Self-reported extremely adverse life events and longitudinal changes in five-factor model personality traits in an urban sample. Journal of Traumatic Stress, 22(1), 53-59. doi:10.1002/jts.20385

Löckenhoff, C. E., Terracciano, A., Bienvenu, O. J., Patriciu, N. S., Nestadt, G., McCrae, R. R., . . Costa Jr., P. T. (2008). Ethnicity, education, and the temporal stability of personality traits in the east baltimore epidemiologic catchment area study. Journal of Research in Personality, 42(3), 577-598. doi:DOI: 10.1016/j.jrp.2007.09.004

Lodi-Smith, J., \& Roberts, B. W. (2007). Social investment and personality: A meta-analysis of the relationship of personality traits to investment in work, family, religion, and 
volunteerism. Personality and Social Psychology Review, 11(1), 68-86.

doi:10.1177/1088868306294590

Loehlin, J. C. (1992). Genes and environment in personality development. Thousand Oaks, CA US: Sage Publications, Inc.

Lorenz, F. O., Simons, R. L., Rand, D. C., Elder, G. H.,Jr., Johnson, C., \& Chao, W. (1997). Married and recently divorced mothers' stressful events and distress: Tracing change across time. Journal of Marriage and Family, 59(1), pp. 219-232.

Lucas, R. E., Clark, A. E., Georgellis, Y., \& Diener, E. (2003). Reexamining adaptation and the set point model of happiness: Reactions to changes in marital status. Journal of Personality and Social Psychology, 84(3), 527-539. doi:10.1037/0022-3514.84.3.527

Lucas, R. E., Clark, A. E., Georgellis, Y., \& Diener, E. (2004). Unemployment alters the set point for life satisfaction. Psychological Science, 15(1), 8-13.

Lucas, R. E. (2007). Adaptation and the set-point model of subjective well-being. Current Directions in Psychological Science, 16(2), 75-79. doi:10.1111/j.14678721.2007.00479.x

Lüdtke, O., Roberts, B. W., Trautwein, U., \& Nagy, G. (2011). A random walk down university avenue: Life paths, life events, and personality trait change at the transition to university life. Journal of Personality and Social Psychology, 101(3), 620-637. doi:10.1037/a0023743

Luhmann, M., \& Eid, M. (2009). Does it really feel the same? changes in life satisfaction following repeated life events. Journal of Personality and Social Psychology, 97(2), 363-381. doi:10.1037/a0015809

Luhmann, M., Orth, U., Specht, J., Kandler, C., \& Lucas, R. E. (2014). Studying changes in life circumstances and personality: It's about time. European Journal of Personality, 28(3), 256-266. doi:10.1002/per.1951

Luo, Z., Crompton, A., \& Sun, A. (2001). A new mammaliaform from the early jurassic and evolution of mammalian characteristics. Science, 292(5521), 1535-1540.

doi:10.1126/science. 1058476

Lynn, R., \& Martin, T. (1995). National differences for thirty-seven nations in extraversion, neuroticism, psychoticism and economic, demographic and other correlates. Personality and Individual Differences, 19(3), 403-406. doi:10.1016/0191-8869(95)00054-A

Maciejewski, P. K., Prigerson, H. G., \& Mazure, C. M. (2001). Sex differences in eventrelated risk for major depression. Psychological Medicine, 31(4), 593-604.

Magnus, K., Diener, E., Fujita, F., \& Payot, W. (1993). Extraversion and neuroticism as predictors fo objective life events: A longitudinal analysis. Journal of Personality and Social Psychology, 65(5), 1046-1053. doi:10.1037/0022-3514.65.5.1046

Magnusson, D. (1990). Personality development from an interactional perspective. Handbook of personality: Theory and research (pp. 193). New York, NY, US: Guilford Press. 
Maiden, R., Peterson, S., Caya, M., \& Hayslip, B. (2003). Personality changes in the old-old: A longitudinal study. Journal of Adult Development, 10(1), 31-39.

doi:10.1023/A:1020786719959

Malouff, J. M., Thorsteinsson, E. B., \& Schutte, N. S. (2005). The relationship between the five-factor model of personality and symptoms of clinical disorders: A meta-analysis. Journal of Psychopathology and Behavioral Assessment, 27(2), 101-114. doi:10.1007/s10862-005-5384-y

Mandel, D. R., \& Lehman, D. R. (1996). Counterfactual thinking and ascriptions of cause and preventability. Journal of Personality and Social Psychology, 71(3), 450-463. doi:10.1037/0022-3514.71.3.450

Martin, M. (1985). Neuroticism as predisposition toward depression - a cognitive mechanism. Personality and Individual Differences, 6(3), 353-365. doi:10.1016/01918869(85)90060-1

Mastekaasa, A. (1994). The subjective well-being of the previously married - the importance of unmarried cohabitation and time since widowhood or divorce. Social Forces, 73(2), 665-692. doi:10.2307/2579825

Masuda, M., \& Holmes, T. H. (1978). Life events: Perceptions and frequencies. Psychosomatic Medicine, 40(3), 236-261.

Matthews, G. (2004). Neuroticism from the top down: Psychophysiology and negative emotionality. In R. M. Stelmack (Ed.), On the psychobiology of personality: Essays in honor of marvin zuckerman (pp. 249-266). New York: Elsevier Science.

McAdams, T., Gregory, A., \& Eley, T. (2013). Genes of experience: Explaining the heritability of putative environmental variables through their association with behavioural and emotional traits. Behavior Genetics, 43(4), 314-328.

doi:10.1007/s10519-013-9591-0

McCartney, K., Harris, M. J., \& Bernieri, F. (1990). Growing up and growing apart - a developmental metaanalysis of twin studies. Psychological Bulletin, 107(2), 226-237. doi:10.1037/0033-2909.107.2.226

McCrae, R. R., \& Costa, P. T., Jr. (2008). The five-factor theory of personality. In L. A. Pervin (Ed.), Handbook of personality psychology: Theory and research (3rd ed., pp. 159-181). New York, US: Guilford Press.

McCrae, R. R. (1990). Controlling neuroticism in the measurement of stress. Stress Medicine, 6(3), 237-241. doi:10.1002/smi.2460060309

McCrae, R. R. (2013). Exploring trait assessment of samples, persons, and cultures. Journal of Personality Assessment, 95(6), 556-570. doi:10.1080/00223891.2013.821075

McCrae, R. R., Costa, P. T., de Lima, M. P., Simões, A., Ostendorf, F., Angleitner, A., . . Piedmont, R. L. (1999). Age differences in personality across the adult life span: Parallels in five cultures. Developmental Psychology, 35(2), 466-477. doi:10.1037/00121649.35.2.466 
McEwen, B. S., \& Stellar, E. (1993). Stress and the individual - mechanisms leading to disease. Archives of Internal Medicine, 153(18), 2093-2101.

doi:10.1001/archinte.153.18.2093

McEwen, B. S. (2008). Central effects of stress hormones in health and disease:

Understanding the protective and damaging effects of stress and stress mediators.

European Journal of Pharmacology, 583(2-3), 174-185.

doi:10.1016/j.ejphar.2007.11.07t

McGue, M., \& Lykken, D. T. (1992). Genetic influence on risk of divorce. Psychological Science, 3(6), 368-373. doi:10.1111/j.1467-9280.1992.tb00049.x

McGue, M., Bacon, S., \& Lykken, D. T. (1993). Personality stability and change in early adulthood: A behavioral genetic analysis. Developmental Psychology, 29(1), 96-109. doi:10.1037/0012-1649.29.1.96

McLaughlin, C., Bowman, M. L., Bradley, C. L., \& Mistlberger, R. E. (2008). A prospective study of seasonal variation in shift-work tolerance. Chronobiology International, 25(23), 455-470. doi:10.1080/07420520802118269

Meyer, G., Finn, S., Eyde, L., Kay, G., Moreland, K., Dies, R., .. . Reed, G. (2001). Psychological testing and psychological assessment - A review of evidence and issues. American Psychologist, 56(2), 128-165. doi:10.1037//0003-066X.56.2.128

Middeldorp, C. M., Cath, D. C., Beem, A. L., Willemsen, G., \& Boomsma, D. I. (2008). Life events, anxious depression and personality: A prospective and genetic study. Psychological Medicine, 38(11), 1557-1565. doi:10.1017/S0033291708002985

Middeldorp, C., Cath, D., Vink, J., \& Boomsma, D. (2005). Twin and genetic effects on life events. Twin Research and Human Genetics, 8(3), 224-231.

doi:10.1375/1832427054253130

Miller, A. S., \& Kanazawa, S. (2008). Why beautiful people have more daughters. New York, USA: Penguin Group.

Mills, M. (2000). Providing space for time: The impact of temporality on life course research. Time \& Society, 9(1), 91-127. doi:10.1177/0961463X00009001006

Minkel, J. D., Banks, S., Htaik, O., Moreta, M. C., Jones, C. W., McGlinchey, E. L., . . Dinges, D. F. (2012). Sleep deprivation and stressors: Evidence for elevated negative affect in response to mild stressors when sleep deprived. Emotion, 12(5), 1015-20. doi:10.1037/a0026871

Mischel, W. (1968). Personality and assessment. New York: Wiley.

Moffitt, T. E., Caspi, A., Harrington, H., Milne, B. J., Melchior, M., Goldberg, D., \& Poulton, R. (2007). Generalized anxiety disorder and depression: Childhood risk factors in a birth cohort followed to age 32. Psychological Medicine, 37(3), 441-452.

doi:10.1017/S0033291706009640 
Mogg, K., \& Bradley, B. P. (1998). A cognitive-motivational analysis of anxiety. Behaviour Research and Therapy, 36(9), 809-848. doi:http://dx.doi.org/10.1016/S00057967(98)00063-1

Möller, K. (2004). The longitudinal and concurrent role of neuroticism for partner relationships. Scandinavian Journal of Psychology, 45(1), 79-83. doi:10.1111/j.14679450.2004.00381.x

Monroe, S. M. (2008). Modern approaches to conceptualizing and measuring human life stress. Annual Review of Clinical Psychology, 4, 33-52. doi:10.1146/annurev.clinpsy.4.022007.141207

Monroe, S. M., \& Steiner, S. C. (1986). Social support and psychopathology: Interrelations with preexisting disorder, stress, and personality. Journal of Abnormal Psychology, 95(1), 29.

Morizot, J., \& Le Blanc, M. (2003). Continuity and change in personality traits from adolescence to midlife: A 25-year longitudinal study comparing representative and adjudicated men. Journal of Personality, 71(5), 705-755.

Morris, W. L., Sinclair, S., \& DePaulo, B. M. (2007). No shelter for singles: The perceived legitimacy of marital status discrimination. Group Processes \& Intergroup Relations, 10(4), 457-470. doi:10.1177/1368430207081535

Mortimer, J. T., \& Simmons, R. G. (1978). Adult socialization. Annual Review of Sociology, 4, pp. 421-454.

Mroczek, D. K., \& Spiro, A. (2003). Modeling intraindividual change in personality traits: Findings from the normative aging study. The Journals of Gerontology: Series B: Psychological Sciences and Social Sciences, 58B(3), 153-165.

Mroczek, D. K., \& Spiro, A. I. (2007). Personality change influences mortality in older men. Psychological Science, 18(5), 371-376.

Mroczek, D. K., Almeida, D. M., Spiro, A., \& Pafford, C. (2006). Modeling intraindividual stability and change in personality. In D. K. Mroczek T. D. Little (Ed.), Handbook of personality development (pp. 163-180). Mahwah, NJ, US: Lawrence Erlbaum Associates Publishers.

Mund, M., \& Neyer, F. J. (2014). Treating personality-relationship transactions with respect: Narrow facets, advanced models, and extended time frames. Journal of Personality and Social Psychology, 107(2), 352.

Murray, G., Allen, N. B., \& Trinder, J. (2002). Longitudinal investigation of mood variability and the ffm: Neuroticism predicts variability in extended states of positive and negative affect. Personality and Individual Differences, 33(8), 1217-1228. doi:10.1016/S01918869(01)00217-3

Nelis, D., Kotsou, I., Quoidbach, J., Hansenne, M., Weytens, F., Dupuis, P., \& Mikolajczak, M. (2011). Increasing emotional competence improves psychological and physical wellbeing, social relationships, and employability. Emotion, 11(2), 354-366.

doi:10.1037/a0021554 
Nettle, D. (2007). Personality: What makes you the way you are. New York: Oxford University Press.

Nettle, D., \& Penke, L. (2010). Personality: Bridging the literatures from human psychology and behavioural ecology. Philosophical Transactions of the Royal Society B-Biological Sciences, 365(1560), 4043-4050. doi:10.1098/rstb.2010.0061

Neugarten, B. L. (1979). Time, age, and the life-cycle. American Journal of Psychiatry, 136(7), 887-894.

Neugarten, B. L., Moore, J. W., \& Lowe, J. C. (1965). Age norms, age constraints, and adult socialization. American Journal of Sociology, 70(6), 710-717. doi:10.1086/223965

Neyer, F. J. (1999). Die persönlichkeit junger erwachsener in verschiedenen lebensformen. Kölner Zeitschrift Für Soziologie Und Socialpsychologie, 51, 491-508.

Neyer, F. J., \& Lehnart, J. (2007). Relationships matter in personality development: Evidence from an 8-year longitudinal study across young adulthood. Journal of Personality, 75(3), 535-568. doi:10.1111/j.1467-6494.2007.00448.x

Neyer, F. J., \& Voigt, D. (2004). Personality and social network effects on romantic relationships: A dyadic approach. European Journal of Personality, 18(4), 279-299. doi:10.1002/per.519

Neyer, F. J., \& Asendorpf, J. B. (2001). Personality-relationship transaction in young adulthood. Journal of Personality and Social Psychology, 81(6), 1190-1204. doi:10.1037/0022-3514.81.6.1190

Neyer, F. J., Mund, M., Zimmermann, J., \& Wrzus, C. (2014). Personality-relationship transactions revisited. Journal of Personality, 82(6), 539-50. doi:10.1111/jopy.12063

Neyer, F. J., Wrzus, C., Wagner, J., \& Lang, F. R. (2011). Principles of relationship differentiation. European Psychologist, 16(4), 267-277. doi:10.1027/1016-9040/a000055

$\mathrm{Ng}, \mathrm{W}$. (2009). Clarifying the relation between neuroticism and positive emotions. Personality and Individual Differences, 47(1), 69-72. doi:DOI: 10.1016/j.paid.2009.01.049

Ogle, C. M., Rubin, D. C., \& Siegler, I. C. (2014). Changes in neuroticism following trauma exposure. Journal of Personality, 82(2), 93-102. doi:10.1111/jopy.12037

Ormel, J., Jeronimus, B. F., Kotov, R., Riese, H., Bos, E. E., Hankin, B., \& Rosmalen, J. G. M. (2013). Neuroticism and common mental disorders: Meaning and utility of a Complex relationship. Clinical Psychology Review, 33(5), 686-697.

Ormel, J., Laceulle, O. M., \& Jeronimus, B. F. (2014). Why personality and psychopathology are correlated: A developmental perspective is a first step but more is needed. European Journal of Personality, 28(4), 396-398.

Ormel, J., Rosmalen, J., \& Farmer, A. (2004). Neuroticism: A non-informative marker of vulnerability to psychopathology. Social Psychiatry and Psychiatric Epidemiology, 39(11), 906-912. doi:10.1007/s00127-004-0873-y 
Ormel, J., Lindenberg, S., Steverink, N., \& Verbrugge, L. M. (1999). Subjective well-being and social production functions. Social Indicators Research, 46(1), 61-90.

doi:10.1023/A:1006907811502

Ormel, J., Oldehinkel, A. J., \& Brilman, E. I. (2001). The interplay and etiological continuity of neuroticism, difficulties, and life events in the etiology of major and subsyndromal, first and recurrent depressive episodes in later life. The American Journal of Psychiatry, 158(6), 885-891. doi:10.1176/appi.ajp.158.987.885

Ormel, J., Riese, H., \& Rosmalen, J. G. M. (2012). Interpreting neuroticism scores across the adult life course: Immutable or experience-dependent set points of negative affect? Clinical Psychology Review, 32(1), 71-79. doi:10.1016/j.cpr.2011.10.004

Ormel, J., \& Rijsdijk, F. V. (2000). Continuing change in neuroticism during adulthood: Structural modelling of a 16-year, 5-wave community study. Personality and Individual Differences, 28(3), 461-478. doi:10.1016/S0191-8869(99)00112-9

Ormel, J., Stewart, R., \& Sanderman, R. (1989). Personality as modifier of the life changedistress relationship: A longitudinal modelling approach. Social Psychiatry and Psychiatric Epidemiology, 24(4), 187-195. doi:10.1007/BF02351820

Oswald, D., \& Clark, E. (2003). Best friends forever?: High school best friendships and the transition to college. Personal Relationships, 10(2), 187-196. doi:10.1111/14756811.00045

Overbeek, G., Vermulst, A., de Graaf, R., ten Have, M., Engels, R., \& Scholte, R. (2010). Positive life events and mood disorders longitudinal evidence for an erratic lifecourse hypothesis. Journal of Psychiatric Research, 44(15), 1095-1100. doi:10.1016/j.jpsychires.2010.03.019

Ozer, D. J., \& Benet-Martínez, V. (2006). Personality and the prediction of consequential outcomes. Annual Review of Psychology, 57(1), 401-421.

Panksepp, J., \& Biven, L. (2012). The archaeology of mind: Neuroevolutionary origins of human emotions. New York: Norton \& Company.

Paris, R., \& Helson, R. (2002). Early mothering experience and personality change. Journal of Family Psychology, 16(2), 172-185. doi:10.1037//0893-3200.16.2.172

Parker, P. D., Luedtke, O., Trautwein, U., \& Roberts, B. W. (2012). Personality and relationship quality during the transition from high school to early adulthood. Journal of Personality, 80(4), 1061-1089. doi:10.1111/j.1467-6494.2012.00766.x

Paykel, E. S. (1991). Depression in women. British Journal of Psychiatry, 158, 22-29.

Paykel, E. S. (2001). The evolution of life events research in psychiatry. Journal of Affective Disorders, 62(3), 141-149. doi:DOI: 10.1016/S0165-0327(00)00174-9

Penke, L., Denissen, J. J. A., \& Miller, G. F. (2007). Evolution, genes, and inter-disciplinary personality research. European Journal of Personality, 21(5), 639-665.

doi:10.1002/per.657 
Perilloux, C., Fleischman, D. S., \& Buss, D. M. (2008). The daughter-guarding hypothesis: Parental influence on, and emotional reactions to, offspring's mating behavior. Evolutionary Psychology, 6(2), 217-233.

Pervin, L. A., \& John, O. P. (1999). Handbook of personality: Theory and research. . New York, NY.: Guilford Press.

Peterson, R. A., \& Brown, S. P. (2005). On the use of beta coefficients in meta-analysis. Journal of Applied Psychology, 90(1), 175-181. doi:10.1037/0021-9010.90.1.175

Pilia, G., Chen, W., Scuteri, A., Orrú, M., Albai, G., Dei, M., . . Schlessinger, D. (2006). Heritability of cardiovascular and personality traits in 6,148 sardinians. PLoS Genet, 2(8), e132.

Pinker, S. (2002). The blank slate. . New York, USA.: Penguin Group.

Pinsof, W. M. (2002). The death of "till death us do part": The transformation of pairbonding in the 20th century. [ ] Family Process, 41(2), 135-157. doi:10.1111/j.15455300.2002.41202.x

Pledge, D. S. (1992). Marital separation divorce - a review of individual-responses to a major life stressor. Journal of Divorce \& Remarriage, 17(3-4), 151-181.

Plomin, R., Asbury, K., \& Dunn, J. (2001). Why are children in the same family so different? nonshared environment a decade later. Canadian Journal of Psychiatry, 46(3), 225-233.

Plomin, R., \& Daniels, D. (2011). Why are children in the same family so different from one another? International Journal of Epidemiology, 40(3), 563-582. doi:10.1093/ije/dyq148

Plomin, R., Lichtenstein, P., Pedersen, N. L., McClearn, G. E., \& Nesselroade, J. R. (1990). Genetic influence on life events during the last half of the life span. Psychology and Aging, 5(1), 25-30. doi:10.1037/0882-7974.5.1.25

Poulton, R. G., \& Andrews, G. (1992). Personality as a cause of adverse life events. Acta Psychiatrica Scandinavica, 85(1), 35-38.

Power, R. A., Wingenbach, T., Cohen-Woods, S., Uher, R., Ng, M. Y., Butler, A. W., . . McGuffin, P. (2013). Estimating the heritability of reporting stressful life events captured by common genetic variants. Psychological Medicine, 43(9), 1965. doi:10.1017/S0033291712002589

Quilty, L. C., De Fruyt, F., Rolland, J., Kennedy, S. H., Rouillon, P. F., \& Bagby, R. M. (2008). Dimensional personality traits and treatment outcome in patients with major depressive disorder. Journal of Affective Disorders, 108(3), 241-250. doi:DOI: 10.1016/j.jad.2007.10.022

Rabins, P. V., Fitting, M. D., Eastham, J., \& Zabora, J. (1990). Emotional adaptation over time in care-givers for chronically ill elderly people. Age and Ageing, 19(3), 185-190.

Rauthmann, J. F., Gallardo-Pujol, D., Guillaume, E. M., Todd, E., Nave, C. S., Sherman, R. A., . . F Funder, D. C. (2014). The situational eight DIAMONDS: A taxonomy of major 
dimensions of situation characteristics. Journal of Personality and Social Psychology, 107(4), 677-718. doi:10.1037/a0037250

Realo, A., van der Most, P. J., Allik, J., Esko, T., Jeronimus, B. F., Kööts-Ausmees, L., . . . Ormel, J. (2016). SNP-based heritability estimates of common and specific variance in self- and informant-reported neuroticism scales. Journal of Personality, 85(6), 906-919. doi:10.1111/jopy.12297

Reis, H., Collins, W., \& Berscheid, E. (2000). The relationship context of human behavior and development. Psychological Bulletin, 126(6), 844-872. doi:10.1037//00332909.126.6.844

Reis, M., \& Gold, D. P. (1993). Retirement, personality, and life satisfaction: A review and two models. Journal of Applied Gerontology, 12(2), 261-282.

doi:10.1177/073346489301200209

Reis, O., Dörnte, M., \& von der Lippe, H. (2011). Neuroticism, social support, and the timing of first parenthood: A prospective study. Personality and Individual Differences, 50(3), 381-386. doi:DOI: 10.1016/j.paid.2010.10.028

Rende, R. D., Plomin, R., Reiss, D., \& Hetherington, E. M. (1993). Genetic and environmental influences on depressive symptomatology in adolescence: Individual differences and extreme scores. Journal of Child Psychology and Psychiatry, 34(8), 1387-1398. doi:10.1111/j.1469-7610.1993.tb02097.x

Rettew, D. C., Vink, J. M., Willemsen, G., Doyle, A., Hudziak, J. J., \& Boomsma, D. I. (2006). The genetic architecture of neuroticism in 3301 dutch adolescent twins as a function of age and sex: A study from the dutch twin register. Twin Research and Human Genetics, 9(1), 24-29. doi:10.1375/twin.9.1.24

Rettew, D., \& McKee, L. (2005). Temperament and its role in developmental psychopathology. Harvard Review of Psychiatry, 13(1), 14-27. doi:10.1080/10673220590923146

Reynolds, S., \& Clark, L. (2001). Predicting dimensions of personality disorder from domains and facets of the five-factor model. Journal of Personality, 69(2), 199-222. doi:10.1111/1467-6494.00142

Richard, F. D., Bond Jr., C. F., \& Stokes-Zoota, J. (2003). One hundred years of social psychology quantitatively described. Review of General Psychology, 7(4), 331-363. doi:10.1037/1089-2680.7.4.331

Ridley, M. (2003). The agile gene. how nature turns on nurture. New York: Perennial.

Riese, H., Ormel, J., Aleman, A., Servaas, M.N., Jeronimus, B.F. (2015). Don't throw the baby out with the bathwater: Depressive traits are part and parcel of neuroticism. Neuroimage, 15(125), 1103. doi:10.1016/j.neuroimage.2015.11.012

Riese, H., Snieder, H., Jeronimus, B. F., Korhonen, T., Rose, R. J., Kaprio, J., \& Ormel, J. (2014). Timing effects stressful life events on stability and change of neuroticism scores. European Journal of Personality, 28(2), 193-200. doi:10.1002/per.1929 
Roberts, B. W., \& Chapman, C. N. (2000). Change in dispositional well-being and its relation to role quality: A 30-year longitudinal study. Journal of Research in Personality, 34(1), 26-41. doi:10.1006/jrpe.1999.2259

Roberts, B. W., Kuncel, N. R., Shiner, R., Caspi, A., \& Goldberg, L. R. (2007). The power of personality the comparative validity of personality traits, socioeconomic status, and cognitive ability for predicting important life outcomes. Perspectives on Psychological Science, 2(4), 313-345. doi:10.1111/j.1745-6916.2007.00047.x

Roberts, B. W., \& Robins, R. W. (2000). Broad dispositions, broad aspirations: The intersection of personality traits and major life goals. Personality and Social Psychology Bulletin, 26(10), 1284-1296. doi:10.1177/0146167200262009

Roberts, B. W., \& Robins, R. W. (2004). Person-environment fit and its implications for personality development: A longitudinal study. Journal of Personality, 72(1), 89-110. doi:10.1111/j.0022-3506.2004.00257.x

Roberts, B. W., Walton, K. E., \& Viechtbauer, W. (2006). Personality traits change in adulthood: Reply to costa and McCrae (2006). Psychological Bulletin, 132(1), 29-32. doi:10.1037/0033-2909.132.1.29

Roberts, B. W., Wood, D., \& Smith, J. L. (2005). Evaluating five factor theory and social investment perspectives on personality trait development. Journal of Research in Personality, 39(1), 166-184. doi:10.1016/j.jrp.2004.08.002

Roberts, B. W., Caspi, A., \& Moffitt, T. E. (2003). Work experiences and personality development in young adulthood. Journal of Personality and Social Psychology, 84(3), 582-593. doi:10.1037/0022-3514.84.3.582

Roberts, B. W., Chernyshenko, O. S., Stark, S., \& Goldberg, L. R. (2005). The structure of conscientiousness: An empirical investigation based on seven major personality questionnaires. Personnel Psychology, 58(1), 103-139. doi:10.1111/j.17446570.2005.00301.x

Roberts, B. W., \& DelVecchio, W. F. (2000). The rank-order consistency of personality traits from childhood to old age: A quantitative review of longitudinal studies. Psychological Bulletin, 126(1), 3-25. doi:10.1037/0033-2909.126.1.3

Roberts, B. W., \& Jackson, J. J. (2008). Sociogenomic personality psychology. Journal of Personality, 76(6), 1523-1544. doi:10.1111/j.1467-6494.2008.00530.x

Roberts, B. W., \& Mroczek, D. (2008). Personality trait change in adulthood. Current Directions in Psychological Science, 17(1), 31-35. doi:10.1111/j.14678721.2008.00543.x

Roberts, B. W., Smith, J., Jackson, J. J., \& Edmonds, G. (2009). Compensatory conscientiousness and health in older couples. Psychological Science, 20(5), 553-559. doi:10.1111/j.1467-9280.2009.02339.x

Roberts, B. W., Walton, K. E., \& Viechtbauer, W. (2006). Patterns of mean-level change in personality traits across the life course: A meta-analysis of longitudinal studies. Psychological Bulletin, 132(1), 1-25. doi:10.1037/0033-2909.132.1.1 
Roberts, B. W., Walton, K., Bogg, T., \& Caspi, A. (2006). De-investment in work and nonnormative personality trait change in young adulthood. European Journal of Personality, 20(6), 461-474. doi:10.1002/per.607

Robins, R. W., Caspi, A., \& Moffitt, T. E. (2002). It's not just who you're with, it's who you are: Personality and relationship experiences across multiple relationships. Journal of Personality, 70(6), 925-964.

Robins, R. W., Noftle, E. E., Trzesniewski, K. H., \& Roberts, B. W. (2005). Do people know how their personality has changed? correlates of perceived and actual personality change in young adulthood. Journal of Personality, 73(2), 489-522. doi:10.1111/j.14676494.2005.00317.x

Rogosa, D. (1980). A critique of cross-lagged correlation. Psychological Bulletin, 88(2), 245258.

Rönkä, A., Oravala, S., \& Pulkkinen, L. (2003). Turning points in adults' lives: The effects of gender and the amount of choice. Journal of Adult Development, 10(3), 203-215. doi:10.1023/A:1023418414709

Rook, K. S., Catalano, R., \& Dooley, D. (1989). The timing of major life events - effects of departing from the social clock. American Journal of Community Psychology, 17(2), 233-258. doi:10.1007/BF00931009

Rose, R. J., Kaprio, J., Williams, C. J., Viken, R., \& Obremski, K. (1990). Social contact and sibling similarity - facts, issues, and red herrings. Behavior Genetics, 20(6), 763-778.

Rosenquist, J. N., Lehrer, S. F., O’Malley, A. J., Zaslavsky, A. M., Smoller, J. W., \& Christakis, N. A. (2015). Cohort of birth modifies the association between FTO genotype and BMI. Proceedings of the National Academy of Sciences, 112(2), 354-359. doi:10.1073/pnas.1411893111

Rothbart, M. K. (2011). Becoming who we are. New York, NY: Guilford Press.

Rothbart, M. K., \& Bates, J. E. (2007). Temperament. In W. Damon, R. Lerner \& N. Eisenberg (Eds.), Handbook of child psychology (6th ed., pp. 99-166) John Wiley \& Sons, Inc. doi:10.1002/9780470147658.chpsy0303

Rubin, D. C., Berntsen, D., \& Hutson, M. (2009). The normative and the personal life: Individual differences in life scripts and life story events among USA and danish undergraduates. Memory, 17(1), 54-68. doi:10.1080/09658210802541442

Ruiz-Caballero, J. A., \& Bermudez, J. (1995). Neuroticism, mood, and retrieval of negative personal memories. Journal of General Psychology, 122(1), 29-35.

Russell, J. A. (2003). Core affect and the psychological construction of emotion. Psychological Review, 110(1), 145-172. doi:10.1037/0033-295X.110.1.145

Rusting, C. L., \& Larsen, R. J. (1998). Personality and cognitive processing of affective information. Personality and Social Psychology Bulletin, 24(2), 200-213.

doi:10.1177/0146167298242008 
Rutter, M. (2000). Psychosocial influences: Critiques, findings, and research needs. Development and Psychopathology, 12(3), 375-405.

Rutter, M., \& Silberg, J. (2002). Gene-environment interplay in relation to emotional and behavioral disturbance. Annual Review of Psychology, 53, 463-490. doi:10.1146/annurev.psych.53.100901.135223

Rutter, M. (1987). Psychosocial resilience and protective mechanisms. American Journal of Orthopsychiatry, 57(3), 316-331. doi:10.1111/j.1939-0025.1987.tb03541.x

Rutter, M. (2012). Achievements and challenges in the biology of environmental effects. Proceedings of the National Academy of Sciences, 109(Supplement 2), 17149-17153. doi:10.1073/pnas.1121258109

Sacco, D. F., Young, S. G., Brown, C. M., Bernstein, M. J., \& Hugenberg, K. (2012). Social exclusion and female mating behavior: Rejected women show strategic enhancement of short-term mating interest. Evolutionary Psychology : An International Journal of Evolutionary Approaches to Psychology and Behavior, 10(3), 573-587.

Sacco, D. F., Brown, C. M., Young, S. G., Bernstein, M. J., \& Hugenberg, K. (2011). Social inclusion facilitates risky mating behavior in men. Personality and Social Psychology Bulletin, 37(7), 985-998. doi:10.1177/0146167211405063

Sackett, P. R. (2002). The structure of counterproductive work behaviors: Dimensionality and relationships with facets of job performance. International Journal of Selection and Assessment, 10(1-2), 5-11. doi:10.1111/1468-2389.00189

Salgado, J. (2002). The big five personality dimensions and counterproductive behaviors. International Journal of Selection and Assessment, 10(1-2), 117-125. doi:10.1111/14682389.00198

Sameroff, A. (2010). A unified theory of development: A dialectic integration of nature and nurture. Child Development, 81(1), 6-22. doi:10.1111/j.1467-8624.2009.01378.x

Sanderman, R. (1988). Life events, mediating variables and psychological distress: A longitudinal study. Groningen: University of Groningen.

Sarason, I. G., Sarason, B. R., \& Shearin, E. N. (1986). Social support as an individual difference variable: Its stability, origins, and relational aspects. Journal of Personality and Social Psychology, 50(4), 845.

Saudino, K. J. (2005). Behavioral genetics and child temperament. Journal of Developmental \& Behavioral Pediatrics, 26(3), 214-223. doi:10.1097/00004703-200506000-00010

Saudino, K. J., Pedersen, N. L., Lichtenstein, P., McClearn, G. E., \& Plomin, R. (1997). Can personality explain genetic influences on life events? Journal of Personality and Social Psychology, 72(1), 196-206. doi:10.1037/0022-3514.72.1.196

Scarr, S., \& McCartney, K. (1983). How people make their own environments: A theory of genotype $\rightarrow$ environment effects. Child Development, 54(2), 424-435. 
Schmidt, L. A., Miskovic, V., Boyle, M. H., \& Saigal, S. (2008). Shyness and timidity in young adults who were born at extremely low birth weight. Pediatrics, 122(1), E181E187. doi:10.1542/peds.2007-3747

Schmitt, D. P., Allik, J., McCrae, R. R., Benet-Martinez, V., Alcalay, L., Ault, L., . . . Zupaneic, A. (2007). The geographic distribution of big five personality traits - patterns and profiles of human self-description across 56 nations. Journal of Cross-Cultural Psychology, 38(2), 173-212. doi:10.1177/0022022106297299

Schmitt, D. P., Realo, A., Voracek, M., \& Allik, J. (2008). Why can't a man be more like a woman? sex differences in big five personality traits across 55 cultures. Journal of Personality and Social Psychology, 94(1), 168-182. doi:10.1037/0022-3514.94.1.168

Schmitt, D. P., \& Shackelford, T. K. (2008). Big five traits related to short-term mating: From personality to promiscuity across 46 nations. Evolutionary Psychology, 6(2), 246282.

Schuett, W., Tregenza, T., \& Dall, S. R. X. (2010). Sexual selection and animal personality. Biological Reviews, 85(2), 217-246. doi:10.1111/j.1469-185X.2009.00101.x

Schwarz, N. (2007). Cognitive aspects of survey methodology. Applied Cognitive Psychology, 21(2), 277-287. doi:10.1002/acp.1340

Scollon, C. N., \& Diener, E. (2006). Love, work, and changes in extraversion and neuroticism over time. Journal of Personality and Social Psychology, 91(6), 1152-1165. doi:10.1037/0022-3514.91.6.1152

Seery, M. D., Holman, E. A., \& Silver, R. C. (2010). Whatever does not kill us: Cumulative lifetime adversity, vulnerability, and resilience. J Pers Soc Psychol, 99(6), 1025-1041.

Shankman, S. A., \& Klein, D. N. (2003). The relation between depression and anxiety: An evaluation of the tripartite, approach-withdrawal and valence-arousal models. Clinical Psychology Review, 23(4), 605-637. doi:10.1016/S0272-7358(03)00038-2

Shiner, R. L., Masten, A. S., \& Tellegen, A. (2002). A developmental perspective on personality in emerging adulthood: Childhood antecedents and concurrent adaptation. Journal of Personality and Social Psychology, 83(5), 1165-1177. doi:10.1037//00223514.83.5.1165

Shiner, R. L., \& Masten, A. S. (2012). Childhood personality as a harbinger of competence and resilience in adulthood. Development and Psychopathology, 24(2), 507-528. doi:10.1017/S0954579412000120

Simmons, J. P., Nelson, L. D., \& Simonsohn, U. (2011). False-positive psychology. Psychological Science, 22(11), 1359-1366. doi:10.1177/0956797611417632

Singleton Jr., R. A., Straits, B. C., \& Straits, M. M. (1993). Approaches to social research (2nd ed.). New York, NY, US: Oxford University Press.

Smoller, J., \& Tsuang, M. (1998). Panic and phobic anxiety: Defining phenotypes for genetic studies. American Journal of Psychiatry, 155(9), 1152-1162. 
Sobolewski, A., Strelau, J., \& Zawadzki, B. (2001). The temperamental determinants of stressors as life changes. European Psychologist, 6(4), 287-295. doi:10.1027//10169040.6.4.287

Specht, J., Egloff, B., \& Schmukle, S. C. (2011). Stability and change of personality across the life course: The impact of age and major life events on mean-level and rank-order stability of the big five. Journal of Personality and Social Psychology, 101(4), 862-882.

Spijker, J., De Graaf, R., Bijl, R. V., Beekman, A. T. F., Ormel, J., \& Nolen, W. A. (2002). Duration of major depressive episodes in the general population: Results from the netherlands mental health survey and incidence study (NEMESIS). The British Journal of Psychiatry, 181(3), 208-213. doi:10.1192/bjp.181.3.208

Spinhoven, P., Penelo, E., de Rooij, M., Penninx, B. W., \& Ormel, J. (2014). Reciprocal effects of stable and temporary components of neuroticism and affective disorders: Results of a longitudinal cohort study. Psychological Medicine, 44(2), 337-48. doi:10.1017/S0033291713000822

Stevenson, B., \& Wolfers, J. (2007). Marriage and divorce: Changes and their driving forces . Journal of Economic Perspectives, 21(2), 27.

Stewart, A., \& Ostrove, J. (1998). Women's personality in middle age - gender, history, and midcourse corrections. American Psychologist, 53(11), 1185-1194. doi:10.1037//0003066X.53.11.1185

Sturaro, C., Denissen, J. J. A., van Aken, M. A. G., \& Asendorpf, J. B. (2008). Personenvironment transactions during emerging adulthood: The interplay between personality characteristics and social relationships. European Psychologist, 13(1), 1-11. doi:10.1027/1016-9040.13.1.1

Suh, E., Diener, E., \& Fujita, F. (1996). Events and subjective well-being: Only recent events matter. Journal of Personality and Social Psychology, 70(5), 1091-1102.

Suls, J., \& Martin, R. (2005). The daily life of the garden-variety neurotic: Reactivity, stressor exposure, mood spillover, and maladaptive coping. Journal of Personality, 73(6), 1485-1510. doi:10.1111/j.1467-6494.2005.00356.x

Sutin, A. R., \& Costa, P. T., Jr. (2010). Reciprocal influences of personality and job characteristics across middle adulthood. Journal of Personality, 78(1), 257-288. doi:10.1111/j.1467-6494.2009.00615.x

Sutin, A. R., Costa, P. T., Jr., Miech, R., \& Eaton, W. W. (2009). Personality and career success: Concurrent and longitudinal relations. European Journal of Personality, 23(2), 71-84. doi:10.1002/per.704

Sutin, A. R., Costa, P. T., Jr., Wethington, E., \& Eaton, W. (2010). Turning points and lessons learned: Stressful life events and personality trait development across middle adulthood. Psychology and Aging, 25(3), 524-533. doi:10.1037/a0018751 
Sutin, A. R., Ferrucci, L., Zonderman, A. B., \& Terracciano, A. (2011). Personality and obesity across the adult life span. Journal of Personality and Social Psychology, 101(3), 579-592. doi:10.1037/a0024286

Tamagawa, R., Lobb, B., \& Booth, R. (2007). Tolerance of shift work. Applied Ergonomics, 38(5), 635-642. doi:10.1016/j.apergo.2006.05.003

Tambs, K., Sundet, J. M., Eaves, L., \& Hornberg, M. (1991). Pedigree analysis of eysenck personality questionnaire (EPQ) scores in monozygotic (MZ) twin families. Behavior Genetics, 21(4), 369-382. doi:10.1007/BF01065973

Tang, T. Z., DeRubeis, R. J., Hollon, S. D., Amsterdam, J., Shelton, R., \& Schalet, B. (2009). Personality change during depression treatment: A placebo-controlled trial. Archives of General Psychiatry, 66(12), 1322-1330.

Taylor, S., Klein, L., Lewis, B., Gruenewald, T., Gurung, R., \& Updegraff, J. (2000). Biobehavioral responses to stress in females: Tend-and-befriend, not fight-or-flight. Psychological Review, 107(3), 411-429. doi:10.1037/0033-295X.107.3.411

Tellegen, A. (1985). Structures of mood and personality and their relevance to assessing anxiety, with an emphasis on self-report. In J. D. Maser (Ed.), Anxiety and the anxiety disorders. (pp. 681-706). Hillsdale, NJ England: Lawrence Erlbaum Associates, Inc.

ten Have, M., Iedema, J., Ormel, J., \& Vollebergh, W. (2006). Explaining service use for mental health problems in the dutch general population: The role of resources, emotional disorder and functional impairment. Social Psychiatry and Psychiatric Epidemiology, 41(4), 285-293. doi:10.1007/s00127-005-0028-9

Terracciano, A., McCrae, R. R., Brant, L. J., \& Costa, P. T. (2005). Hierarchical linear modeling analyses of the NEO-PI-R scales in the baltimore longitudinal study of aging. Psychology and Aging, 20(3), 493-506. doi:10.1037/0882-7974.20.3.493

Thapar, A., \& McGuffin, P. (1996). Genetic influences on life events in childhood. Psychological Medicine, 26(4), 813-820.

Theriault, J. (1994). Retirement as a psychological transition - process of adaptation to change. International Journal of Aging \& Human Development, 38(2), 153-170.

Trivers, R. (1972). Parental investment and sexual selection. In B. Campbell (Ed.), Sexual selection and the descent of man: 1871-1971 (pp. 136-179). Chicago: Aldine Publishing Company.

Turkheimer, E., Haley, A., Waldron, M., D'Onofrio, B., \& Gottesman, I. I. (2003). Socioeconomic status modifies heritability of IQ in young children. Psychological Science, 14(6), 623-628. doi:10.1046/j.0956-7976.2003.psci_1475.x

Twenge, J. M. (2000). The age of anxiety? birth cohort change in anxiety and neuroticism, 1952-1993. Journal of Personality and Social Psychology, 79(6), 1007-1021. doi:10.1037//0022-3514.79.6.1007 
Umberson, D., \& Williams, C. L. (1993). Divorced fathers - parental role strain and psychological distress. Journal of Family Issues, 14(3), 378-400.

doi: $10.1177 / 019251393014003003$

Vaidya, J. G., Gray, E. K., Haig, J., \& Watson, D. (2002). On the temporal stability of personality: Evidence for differential stability and the role of life experiences. Journal of Personality and Social Psychology, 83(6), 1469-1484. doi:10.1037//00223514.83.6.1469

van Aken, M. A. G., Denissen, J. J. A., Branje, S. J. T., Dubas, J. S., \& Goossens, L. (2006). Midlife concerns and short-term personality change in middle adulthood. European Journal of Personality, 20(6), 497-513. doi:10.1002/per.603

van der Krieke, L., Jeronimus, B.F., Blaauw, F.J., Wanders, R.B.K., Emerencia, A.C., Schenk, H.M., de Vos, S., Snippe, E., Wichers, M., Wigman, J.T.W., Bos, E.H., Wardenaar, K.J., de Jonge, P. (2015). HowNuts AreTheDutch (HoeGekIsNL): A crowdsourcing study of mental symptoms and strengths. International journal of methods in psychiatric research, 25(2), 123-44. doi:10.1002/mpr.1495

van der Krieke, L., Blaauw, F.J., Emerencia, A.C., Schenk, H.M., Slaets, J.P.J., Bos, E.H., de Jonge, P., Jeronimus, B.F. (2016). Temporal dynamics of health and well-being: a crowdsourcing approach to momentary assessments and automated generation of personalized feedback. Psychosomatic medicine, 79(2), 213-223. doi:10.1097/PSY.0000000000000378

Van Os, J., \& Jones, P. B. (1999). Early risk factors and adult person-environment relationships in affective disorder. Psychological Medicine, 29(5), 1055-1067.

van Os, J., Park, S. B. G., \& Jones, P. B. (2001). Neuroticism, life events and mental health: Evidence for person-environment correlation. British Journal of Psychiatry, 178, S72S77.

van Valen, L. (1973). A new evolutionary law. Evolutionary Theory, 1, 1-30.

VanderZee, K., Buunk, B., \& Sanderman, R. (1996). The relationship between social comparison processes and personality. Personality and Individual Differences, 20(5), 551. doi:10.1016/0191-8869(96)00007-4"

Vennum, A., Lindstrom, R., Monk, J. K., \& Adams, R. (2014). "It's complicated": The continuity and correlates of cycling in cohabiting and marital relationships. Journal of Social and Personal Relationships, 31(3), 410-430. doi:10.1177/0265407513501987

Verduyn, P., \& Lavrijsen, S. (2014). Which emotions last longest and why: The role of event importance and rumination. Motivation and Emotion, 39(1), 119-127. doi:10.1007/s11031-014-9445-y

Verduyn, P., Van Mechelen, I., \& Tuerlinckx, F. (2011). The relation between event processing and the duration of emotional experience. Emotion, 11(1), 20-28. doi:10.1037/a0021239

Verhaeghe, P. (2013). Identiteit. Amsterdam: De Bezige Bij. 
Vigil, J. M. (2007). Asymmetries in the friendship preferences and social styles of men and women. Human Nature-an Interdisciplinary Biosocial Perspective, 18(2), 143-161. doi:10.1007/s12110-007-9003-3

Viken, R. J., Rose, R. J., Kaprio, J., \& Koskenvuo, M. (1994). A developmental genetic analysis of adult personality: Extraversion and neuroticism from 18 to 59 years of age. Journal of Personality and Social Psychology, 66(4), 722-730. doi:10.1037/00223514.66.4.722

Vines, A. I., Ta, M., Esserman, D., \& Baird, D. D. (2009). A comparison of the occurrence and perceived stress of major life events in black and white women. Women \& Health, 49(5), 368-380. doi:10.1080/03630240903238743

Vinkhuyzen, A. A. E., Sluis, S. v. d., Geus, E. J. C. d., Boomsma, D. I., \& Posthuma, D. (2009). Genetic influences on 'environmental' factors. Genes, Brain and Behavior, 9(3), 276-287.

Wardenaar, K. J., van Veen, T., Giltay, E. J., Zitman, F. G., \& Penninx, B. W. J. H. (2014). The use of symptom dimensions to investigate the longitudinal effects of life events on depressive and anxiety symptomatology. Journal of Affective Disorders, 156(0), 126133. doi:10.1016/j.jad.2013.12.004

Watson, C., \& Casillas, A., (Eds.). (2003). Neuroticism: Adaptive and maladaptive features. Washington DC.: American Psychological Association.

Watson, D., Beer, A., \& McDade-Montez, E. (2014). The role of active assortment in spousal similarity. Journal of Personality, 82(2), 116-129. doi:10.1111/jopy.12039

Watson, D., \& Clark, L. A. (1984). Negative affectivity: The disposition to experience aversive emotional states. Psychological Bulletin, 96(3), 465-490. doi:10.1037/00332909.96.3.465

Wayne, J., Musisca, N., \& Fleeson, W. (2004). Considering the role of personality in the work-family experience: Relationships of the big five to work-family conflict and facilitation. Journal of Vocational Behavior, 64(1), 108-130. doi:10.1016/S00018791(03)00035-6

Weibel, D., Wissmath, B., \& Stricker, D. (2011). The influence of neuroticism on spatial presence and enjoyment in films. Personality and Individual Differences, 51(7), 866869. doi:10.1016/j.paid.2011.07.011

Weisberg, Y. J., DeYoung, C. G., \& Hirsh, J. B. (2011). Gender differences in personality across the ten aspects of the big five. Frontiers in Psychology, 2(Article 178) doi:10.3389/fpsyg.2011.00178

Weiss, A., King, J. E., Inoue-Murayama, M., Matsuzawa, T., \& Oswald, A. J. (2012). Evidence for a midlife crisis in great apes consistent with the U-shape in human wellbeing. Proceedings of the National Academy of Sciences, 109(49), 19949-19952. doi:10.1073/pnas.1212592109 
Whisman, M. A., Gordon, K. C., \& Chatav, Y. (2007). Predicting sexual infidelity in a population-based sample of married individuals. Journal of Family Psychology, 21(2), 320-324. doi:10.1037/0893-3200.21.2.320

Widiger, T. A. (2009). Neuroticism. In M. R. Leary, \& R. H. Hoyle (Eds.), Handbook of individual differences in social behavior (pp. 129-146). New York: The Guilford Press.

Wierzbicki, M. (1989). Twins responses to pleasant, unpleasant, and life events. Journal of Genetic Psychology, 150(2), 135-145.

Wiesner-Hanks, M. (2006). Early modern europe, 1450-1789 (5th print 2010 ed.). Cambridge: Cambridge University Press.

Wille, B., De Fruyt, F., \& De Clercq, B. (2013). Expanding and reconceptualizing aberrant personality at work: Validity of five-factor model aberrant personality tendencies to predict career outcomes. Personnel Psychology, 66(1), 173-223. doi:10.1111/peps.12016

Willemsen, G., \& Boomsma, D. I. (2007). Religious upbringing and neuroticism in dutch twin families. Twin Research and Human Genetics, 10(2), 327-333.

doi:10.1375/twin.10.2.327

Williams, D. G. (1993). Are personality effects upon average mood due to personality effects upon mood variation. Personality and Individual Differences, 14(1), 199-208. doi:10.1016/0191-8869(93)90190-E

Williams, D. G. (1990). Effects of psychoticism, extraversion, and neuroticism in current mood: A statistical review of six studies. Personality and Individual Differences, 11(6), 615-630. doi:10.1016/0191-8869(90)90045-S

Wolf, M., \& Weissing, F. J. (2012). Animal personalities: Consequences for ecology and evolution. Trends in Ecology \& Evolution, 27(8), 452-461. doi:10.1016/j.tree.2012.05.001

Wolfensberger, S. P. A., Veltman, D. J., Hoogendijk, W. J. G., Boomsma, D. I., \& de Geus, E. J. C. (2008). Amygdala responses to emotional faces in twins discordant or concordant for the risk for anxiety and depression. NeuroImage, 41(2), 544-552. doi:DOI: 10.1016/j.neuroimage.2008.01.053

Wood, D., \& Denissen, J. A. (2014). A functional perspective on personality trait development. In K. Reynolds, \& N. R. Branscombe (Eds.), The psychology of change: Life contexts, experiences, and identities (). New York: Psychology Press.

Wood, D., Hensler, M., \& Harms, P. D. (2014). How a functionalist understanding of behavior can explain trait covariation without the use of structural factors. Psychological Review, 122(1), 84-111. doi: 10.1037/a0038423.

Wood, D., \& Roberts, B. W. (2006a). Cross-sectional and longitudinal tests of the personality and role identity structural model (PRISM). Journal of Personality, 74(3), 779-809. doi:10.1111/j.1467-6494.2006.00392.x 
Wood, D., \& Roberts, B. W. (2006b). The effect of age and role information on expectations for big five personality traits. Personality and Social Psychology Bulletin, 32(11), 14821496. doi:10.1177/0146167206291008

Woods, N. F., Dery, G. K., \& Most, A. (1982). Stressful life events and perimenstrual symptoms. Journal of Human Stress, 8(2), 23-31.

Wray, N. R., Birley, A. J., Sullivan, P. F., Visscher, P. R. M., \& Martin, N. G. (2007). Genetic and phenotypic stability of measures of neuroticism over 22 years. Twin Research and Human Genetics, 10(5), 695-702.

Wright, M. H., Zautra, A. J., \& Braver, S. L. (1985). Distortion in control attributions for real life events. Journal of Research in Personality, 19(1), 54-71. doi:10.1016/00926566(85)90037-6

Wrzus, C., Hänel, M., Wagner, J., \& Neyer, F. J. (2013). Social network changes and life events across the life span: A meta-analysis. Psychological Bulletin, 139(1), 53-80. doi:10.1037/a0028601

Zautra, A. J., Affleck, G. G., Tennen, H., Reich, J. W., \& Davis, M. C. (2005). Dynamic approaches to emotions and stress in everyday life: Bolger and zuckerman reloaded with positive as well as negative affects. Journal of Personality, 73(6), 1511-1538. doi:10.1111/j.1467-6494.2005.00357.x

Zhao, H., \& Seibert, S. (2006). The big five personality dimensions and entrepreneurial status: A meta-analytical review. Journal of Applied Psychology, 91(2), 259-271. doi:10.1037/0021-9010.91.2.259

Zinbarg, R. E., Uliaszek, A. A., \& Adler, J. M. (2008). The role of personality in psychotherapy for anxiety and depression. Journal of Personality, 76(6), 1649-1688. doi:10.1111/j.1467-6494.2008.00534.x

Zuckerman, M. (1999). Diathesis-stress models. In M. Zuckerman (Ed.), Vulnerability to psychopathology: A biosocial model. (pp. 3-23). Washington, DC US: American Psychological Association. doi:10.1037/10316-001 
Table 3.

Environmental influences that prospectively predict change in neuroticism scores, or are a source of discordance for neuroticism in studies of twin pairs

\begin{tabular}{|c|c|c|c|c|c|c|c|c|c|c|c|}
\hline $\begin{array}{l}\text { First } \\
\text { Author }\end{array}$ & Year & Sample & $\mathbf{N}$ & $\%$ 우 & $\begin{array}{l}\text { Age range (R) or } \\
\text { Mean }(\mathrm{M}, \mathrm{SD}) \text { at } T_{1}\end{array}$ & $\begin{array}{l}\text { Years } \\
T_{1}-T x\end{array}$ & $\begin{array}{l}\text { Neuroticism and } \\
\text { (and adjustments) }\end{array}$ & Predictor (higher/more) & $\begin{array}{l}\text { Result } \\
\text { Effect size }\end{array}$ & $\begin{array}{c}\text { Cohen's d } \\
\left.(+,]^{1}\right)\end{array}$ & $\begin{array}{l}\Delta \mathbf{N} \\
90 \\
\end{array}$ \\
\hline \multirow[t]{6}{*}{ Jeronimus } & 2014 & Population & 296 & 47 & $R=16-63$ & 16 & $\mathrm{ABV}$ & Endogenous long-term difficulties & & 0.49 & $\uparrow$ \\
\hline & & Netherlands & & & $\mathrm{M}=34.3(11.8)$ & & & Exogenous long-term difficulties & & 0.19 & $\uparrow$ \\
\hline & & & & & & & & Negative life events & & & - \\
\hline & & & & & & & & Positive Life events & & & - \\
\hline & & & & & & & & Deterioration of life quality & & 0.46 & $\uparrow$ \\
\hline & & & & & & & & Improvement of life quality & & 0.25 & $\downarrow$ \\
\hline \multirow[t]{15}{*}{ Mund } & 2014 & Population & 654 & 54 & $\mathrm{M}=24.4(3.7)$ & 15 & NEO-FFI & Relationship conflict (over 7 years) & $\gamma=-.36^{b}$ & 0.67 & $\uparrow$ \\
\hline & & German & & & & & & Negative affect facet & & & - \\
\hline & & & & & & & & Self-reproach facet & & & - \\
\hline & & & & & & & & Relationship insecurity (over 7 years) & & & - \\
\hline & & & & & & & & Negative affect facet & & & - \\
\hline & & & & & & & & Self-reproach facet & & & - \\
\hline & & & & & & & & Conflict with friends (over 7 years) & $\gamma=-.36^{b}$ & 0.67 & $\uparrow$ \\
\hline & & & & & & & & Negative affect facet & $\gamma=-.42^{b}$ & 0.76 & $\uparrow$ \\
\hline & & & & & & & & Self-reproach facet & $\gamma=-.29^{b}$ & 0.55 & $\uparrow$ \\
\hline & & & & & & & & Decrease in closeness with friends (over 7 years) & & & - \\
\hline & & & & & & & & Negative affect facet & & & - \\
\hline & & & & & & & & Self-reproach facet & $\gamma=-.26^{\mathrm{b}}$ & 0.49 & $\uparrow$ \\
\hline & & & & & & & & Insecurity with kin (over 7 years) & & & - \\
\hline & & & & & & & & Negative affect facet & & & - \\
\hline & & & & & & & & Self-reproach facet & & & - \\
\hline Hutteman & 2013 & $\begin{array}{l}\text { Population } \\
\text { Croatia }\end{array}$ & 1008 & 54 & $\begin{array}{l}42.6(6) \\
R=27-65\end{array}$ & 3 & $\begin{array}{l}\text { IPIP-pool } \\
\text { Emotional stability }\end{array}$ & Parent-child conflict & $B=-.08^{\mathrm{b}}$ & 0.26 & $\bar{\uparrow}$ \\
\hline \multirow[t]{10}{*}{ Jeronimus } & 2012 & Population & 2981 & 67 & $R=18-65$ & 2 & NEO-FFI & Negative life events & $b$ & $0.19^{\mathrm{a}}$ & $\uparrow$ \\
\hline & & Netherlands & & & $\mathrm{M}=42(13.1)$ & & Neuroticism & Positive life events & $\mathrm{c}$ & $-0.23^{\mathrm{a}}$ & $\downarrow$ \\
\hline & & & & & & & & Family member seriously ill, wounded, or victim of violence & $\mathrm{c}$ & 0.15 & $-\uparrow$ \\
\hline & & & & & & & & Separation of partner & $\mathrm{c}$ & 0.15 & $\uparrow-$ \\
\hline & & & & & & & $(\Delta$ anxiety and & Broke up longstanding relationship with a friend/relative & $\mathrm{c}$ & 0.20 & $\uparrow-$ \\
\hline & & & & & & & depression) & Family member recovered from serious illness & $\mathrm{c}$ & 0.15 & $\downarrow-$ \\
\hline & & & & & & & & Befriended new people & $\mathrm{c}$ & 0.17 & $-\downarrow$ \\
\hline & & & & & & & & Started a new job or was promoted & $\mathrm{c}$ & 0.13 & $\downarrow-$ \\
\hline & & & & & & & & Formally finished school/course & $\mathrm{c}$ & 0.19 & $-\downarrow$ \\
\hline & & & & & & & & Holiday & c & 0.17 & $\downarrow-$ \\
\hline \multirow[t]{3}{*}{ Kandler } & 2012 & Twins & 338 & & $\mathrm{R}=22-74$ & 10 & NEO-PI-R & Controllable positive life events & $r=.02$ & & - \\
\hline & & Germany & & & $\mathrm{M}=39.6(\mathrm{SD}=13.5)$ & & & Controllable negative life events & $r=.15^{\mathrm{c}}$ & 0.30 & $\uparrow$ \\
\hline & & & & & & & & Uncontrollable negative life events & $r=.09$ & & - \\
\hline \multirow[t]{2}{*}{ Lüdtke } & 2011 & Population & 1908 & 62 & $\mathrm{M}=19.5(0.8)$ & 4 & NEO-FFI & Sexual problems & $r=.15^{\mathrm{a}}$ & 0.30 & $\uparrow$ \\
\hline & & Germany & & & & & Neuroticism $(\Delta N)$ & Started new job (neg.) & $r=.13^{\mathrm{a}}$ & 0.26 & $\uparrow$ \\
\hline
\end{tabular}




\begin{tabular}{|c|c|c|c|c|c|c|c|c|c|c|c|}
\hline $\begin{array}{l}\text { First } \\
\text { Author }\end{array}$ & Year & Sample & $\mathbf{N}$ & $\%$ & $\begin{array}{l}\text { Age range }(\mathbf{R}) \text { or } \\
\text { Mean }(\mathrm{M}, \mathrm{SD}) \text { at } T_{1}\end{array}$ & $\begin{array}{l}\text { Years } \\
T_{1}-T x \\
\end{array}$ & $\begin{array}{l}\begin{array}{l}\text { Neuroticism and } \\
\text { (and adjustments) }\end{array} \\
\end{array}$ & Predictor (higher/more) & $\begin{array}{l}\text { Result } \\
\text { Effect size } \\
\end{array}$ & $\begin{array}{c}\text { Cohen's d } \\
\left(+, 0^{7}\right)\end{array}$ & $\begin{array}{l}\Delta \mathbf{N} \\
+0^{\lambda}\end{array}$ \\
\hline & & (students) & & & & & & $\begin{array}{l}\text { Change in university studies (neg.) } \\
\text { Changed accommodation (neg.) } \\
\text { Increased working hours (neg.) } \\
\text { Failed important exam } \\
\text { Negative change in financial situation } \\
\text { Started psychotherapy (neg.) } \\
\text { Started psychotherapy (pos.) } \\
\text { Own injury or illness } \\
\text { Illness or injury of a friend } \\
\text { Death of a family member } \\
\text { Death of a friend } \\
\text { Went abroad (pos.) } \\
\text { Got promoted at work } \\
\text { Began regular work (pos.) } \\
\text { Quit a job (neutral). } \\
\text { Joined a student association } \\
\text { Moved out of home (pos.) } \\
\text { Broke off a relationship with boyfriend/girlfriend } \\
\text { Entered a new relationship (of at least } 1 \text { month) } \\
\text { Parents broke up or divorced } \\
\text { Got married } \\
\text { Failed the high school diploma } \\
\text { Got pregnant (self or partner) } \\
\text { Had an abortion (self or partner) } \\
\text { Change in sleeping habits } \\
\text { Change in eating habits }\end{array}$ & $\begin{array}{l}r=.12^{\mathrm{a}} \\
r=.12^{\mathrm{a}} \\
r=.09^{\mathrm{a}} \\
r=.09^{\mathrm{a}} \\
r=.09^{\mathrm{a}} \\
r=.08^{\mathrm{a}} \\
r=.17^{\mathrm{a}} \\
r=.08^{\mathrm{a}} \\
r \\
r \\
r \\
r=-.11^{\mathrm{a}} \\
r=-.08^{\mathrm{a}} \\
r=.07^{\mathrm{a}} \\
r \\
r \\
r \\
r \\
r \\
r \\
r \\
r \\
r \\
r \\
r=.17^{\mathrm{a}} \\
r=.15^{\mathrm{a}}\end{array}$ & $\begin{array}{l}0.22 \\
0.16 \\
0.14 \\
\\
\\
\\
\\
\\
\\
0.35 \\
0.30\end{array}$ & $\begin{array}{l}\uparrow \\
\uparrow \\
\uparrow \\
\uparrow \\
\uparrow \\
\uparrow \\
\downarrow \\
\uparrow \\
- \\
- \\
- \\
\downarrow \\
\downarrow \\
\downarrow \\
- \\
- \\
- \\
- \\
- \\
- \\
- \\
- \\
- \\
- \\
\uparrow \\
\uparrow\end{array}$ \\
\hline Specht & 2011 & $\begin{array}{l}\text { Population } \\
\text { Germany }\end{array}$ & 14718 & 52 & $\begin{array}{l}\mathrm{R}=16-96 \\
\mathrm{M}=47.21\end{array}$ & 4 & $\begin{array}{l}\text { BFI-S (3 N-items) } \\
\text { Emotional stability } \\
\text { Adj. for } \\
\text { demographic } \\
\text { variables }\end{array}$ & $\begin{array}{l}\text { Slope (mean) } \\
\text { Marriage } \\
\text { Sex*marriage } \\
\text { Moved in with partner } \\
\text { Divorce } \\
\text { Separation of partner } \\
\text { Sex*separation from partner } \\
\text { Death of a spouse } \\
\text { Sex*death of a spouse } \\
\text { Leaving parental home } \\
\text { Sex*leaving parental home } \\
\text { Child that leaves home } \\
\text { Birth of a child } \\
\text { Death of a parent } \\
\text { Unemployment } \\
\text { Retirement } \\
\text { First job } \\
\text { Positive LEs } \\
\text { Negative LEs }\end{array}$ & $\begin{array}{l}b=0.101^{\mathrm{a}} \\
b=-0.68^{\text {ns }} \\
b=-0.182^{\text {ns }} \\
b=-0.054^{\text {ns }} \\
b=0.035^{\text {ns }} \\
b=0.070^{\text {ns }} \\
\text { nescio } \\
b=0.018^{\text {ns }} \\
\text { nescio } \\
b=0.089^{\text {ns }} \\
b=-0.468^{\text {b }} \\
b=-0.002^{\text {ns }} \\
b=0.023^{\text {ns }} \\
b=-0.018^{\text {ns }} \\
b=0.021^{\text {ns }} \\
b=-0.025^{\text {ns }} \\
b=0.089^{\text {ns }} \\
b=-0.006^{\text {ns }} \\
b=0.020^{\text {ns }}\end{array}$ & & $\begin{array}{l}\uparrow \\
- \\
-- \\
- \\
- \\
- \\
-- \\
- \\
-- \\
- \\
\downarrow- \\
- \\
- \\
- \\
- \\
- \\
- \\
-\end{array}$ \\
\hline
\end{tabular}




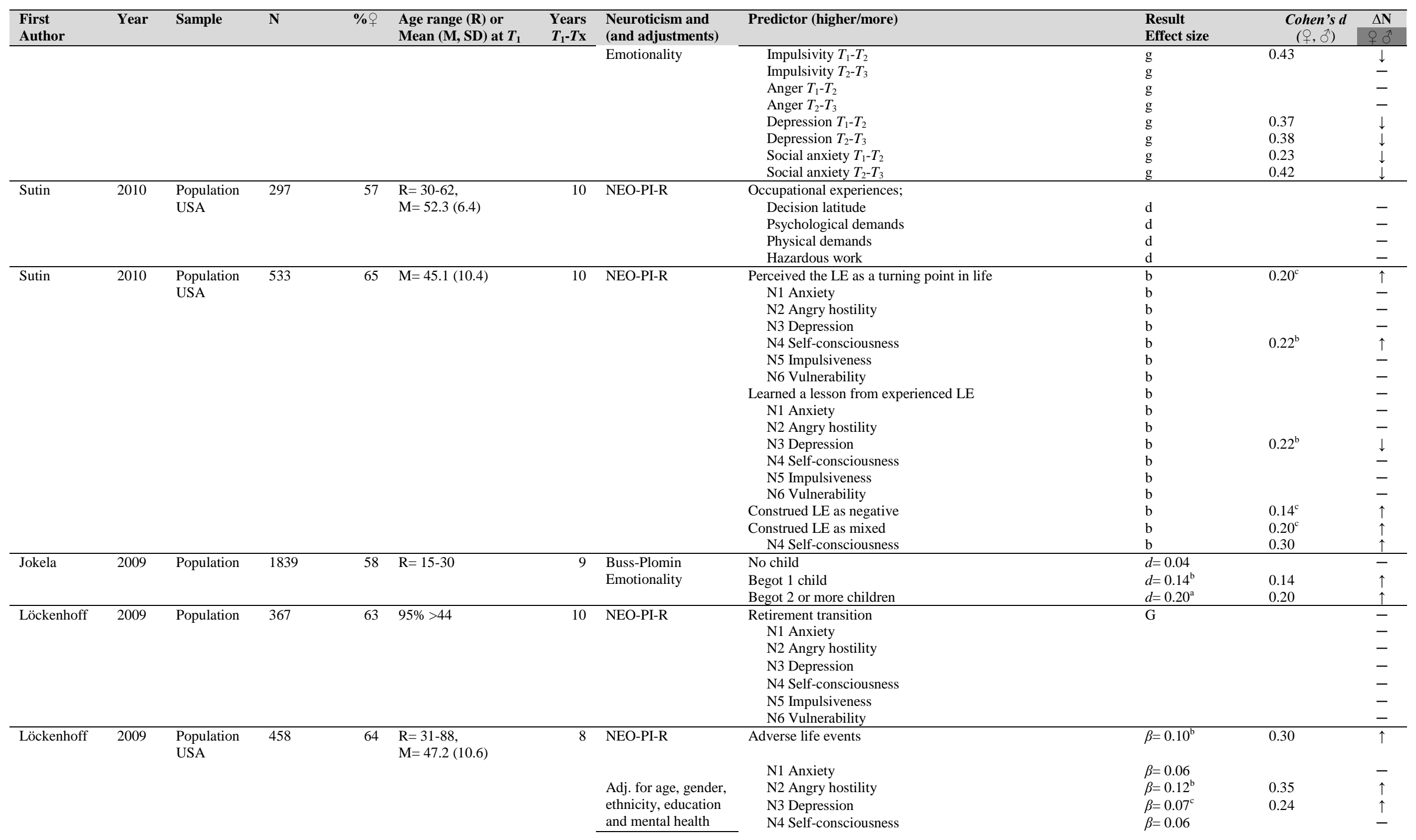




\begin{tabular}{|c|c|c|c|c|c|c|c|c|c|c|c|}
\hline $\begin{array}{l}\text { First } \\
\text { Author }\end{array}$ & Year & Sample & $\mathbf{N}$ & $\%$ & $\begin{array}{l}\text { Age range }(\mathbf{R}) \text { or } \\
\text { Mean }(\mathrm{M}, \mathrm{SD}) \text { at } T_{1}\end{array}$ & $\begin{array}{l}\text { Years } \\
T_{1}-T x\end{array}$ & $\begin{array}{l}\text { Neuroticism and } \\
\text { (and adjustments) }\end{array}$ & Predictor (higher/more) & $\begin{array}{l}\text { Result } \\
\text { Effect size }\end{array}$ & $\begin{array}{c}\text { Cohen's d } \\
\left(+,{ }^{\prime}\right)\end{array}$ & $\begin{array}{l}\Delta \mathbf{N} \\
q^{2}\end{array}$ \\
\hline & & & & & & & (GHQ) & $\begin{array}{l}\text { N5 Impulsiveness } \\
\text { N6 Vulnerability }\end{array}$ & $\begin{array}{l}\beta=-0.03 \\
\beta=0.05\end{array}$ & & - \\
\hline \multirow[t]{18}{*}{ Sutin } & 2009 & Population & 302 & 59 & $\mathrm{M}=52.4(6.4)$ & 10 & NEO-PI-R & $\begin{array}{l}\text { Personal income } \\
\text { N1 Anxiety }\end{array}$ & d & $0.39^{\mathrm{b}}$ & $\stackrel{\downarrow}{-}$ \\
\hline & & & & & & & Neuroticism & N2 Angry hostility & $\mathrm{d}$ & $0.37^{\mathrm{c}}$ & $\downarrow$ \\
\hline & & & & & & & & N3 Depression & $\mathrm{d}$ & $0.32^{\mathrm{c}}$ & $\downarrow$ \\
\hline & & & & & & & & N4 Self-consciousness & $\mathrm{d}$ & & - \\
\hline & & & & & & & & N5 Impulsiveness & $\mathrm{d}$ & $0.37^{\mathrm{c}}$ & $\downarrow$ \\
\hline & & & & & & & & N6 Vulnerability & $\mathrm{d}$ & & - \\
\hline & & & & & & & & Higher occupational prestige & $\mathrm{d}$ & $0.22^{\mathrm{b}}$ & $\downarrow$ \\
\hline & & & & & & & & N1 Anxiety & $\mathrm{d}$ & & - \\
\hline & & & & & & & & N2 Angry hostility & $\mathrm{d}$ & & - \\
\hline & & & & & & & & N3 Depression & d & & - \\
\hline & & & & & & & & N4 Self-consciousness & $\mathrm{d}$ & & - \\
\hline & & & & & & & & N5 Impulsiveness & d & & - \\
\hline & & & & & & & & N6 Vulnerability & $\mathrm{d}$ & $0.35^{\mathrm{c}}$ & $\downarrow$ \\
\hline & & & & & & & & Job satisfaction & $\mathrm{d}$ & & - \\
\hline & & & & & & & & N1 Anxiety & $\mathrm{d}$ & & - \\
\hline & & & & & & & & N2 Angry hostility & $\mathrm{d}$ & & - \\
\hline & & & & & & & & N3 Depression & $\mathrm{d}$ & & - \\
\hline & & & & & & & & N4 Self-consciousness & $\mathrm{d}$ & & - \\
\hline Middeldorp & 2008 & Twins & 5782 & 67 & $\mathrm{R}=18-65$ & 5 & $\mathrm{ABV}$ & Life events (general) & $\mathrm{g}$ & 0.38 & $\uparrow$ \\
\hline \multirow[t]{8}{*}{ Sturaro } & 2008 & Population & 174 & 47 & $\mathrm{M}=17$ & 6 & at age 17: Big Five & Perceived conflict with mother & $\mathrm{b}$ & 0.30 & $\uparrow$ \\
\hline & & & & & & & Emotional stability & Perceived conflict with mother & $\mathrm{b}$ & & - \\
\hline & & & & & & & at age 23: NEO-FFI & Perceived conflict with father & $\mathrm{b}$ & 0.56 & $\uparrow$ \\
\hline & & & & & & & & Perceived conflict with father & $\mathrm{b}$ & 0.47 & $\uparrow$ \\
\hline & & & & & & & & Perceived conflict with best friend & $\mathrm{b}$ & & - \\
\hline & & & & & & & & Perceived support from mother & $\mathrm{b}$ & & - \\
\hline & & & & & & & & Perceived support from father & $\mathrm{b}$ & & - \\
\hline & & & & & & & & Perceived support from best friend & $\mathrm{b}$ & & - \\
\hline \multirow[t]{10}{*}{ Neyer } & 2007 & Population & 339 & 55 & $\mathrm{R}=18-30$ & 8 & NEO-FFI & Insecurity with peers & $\mathrm{b}$ & 1.32 & $\uparrow$ \\
\hline & & & & & $M=24.4(3.7)$ & & Correlated change & Insecurity with family & $\mathrm{b}$ & 2.87 & $\uparrow$ \\
\hline & & & & & & & slope & Closeness to peers & $\mathrm{b}$ & & - \\
\hline & & & & & & & & Closeness to family & $\mathrm{b}$ & & - \\
\hline & & & & & & & & Conflict with peers & $\mathrm{b}$ & & - \\
\hline & & & & & & & & Conflict with family & $\mathrm{b}$ & & - \\
\hline & & & & & & & & Contact with peers & $\mathrm{b}$ & 1.46 & $\downarrow$ \\
\hline & & & & & & & & Contact with family & $\mathrm{b}$ & & - \\
\hline & & & & & & & & Transition into a first partnership $T_{1}-T_{2}$ & & 0.45 & $\downarrow$ \\
\hline & & & & & & & & Transition into a first partnership $T_{2}-T_{3}$ & & 0.54 & $\downarrow$ \\
\hline \multirow{2}{*}{ Lehnart } & 2007 & Twins & 4369 & 67 & $\mathrm{R}=>25$ & 11 & $\mathrm{ABV}$ & Religious upbringing & $\mathrm{g}$ & $0.13,0.21$ & $\downarrow$ \\
\hline & 2006 & Population & 253 & 61 & $\mathrm{R}=18-29$ & 8 & NEO-FFI & Relationship status; continuers & $d=-0.36$ & 0.36 & $\downarrow$ \\
\hline
\end{tabular}




\begin{tabular}{|c|c|c|c|c|c|c|c|c|c|c|c|}
\hline $\begin{array}{l}\text { First } \\
\text { Author }\end{array}$ & Year & Sample & $\mathbf{N}$ & $\%$ \% & $\begin{array}{l}\text { Age range }(\mathrm{R}) \text { or } \\
\text { Mean }(\mathrm{M}, \mathrm{SD}) \text { at } T_{1}\end{array}$ & $\begin{array}{l}\text { Years } \\
T_{1}-T \mathbf{x} \\
\end{array}$ & $\begin{array}{l}\begin{array}{l}\text { Neuroticism and } \\
\text { (and adjustments) }\end{array} \\
\end{array}$ & Predictor (higher/more) & $\begin{array}{l}\text { Result } \\
\text { Effect size }\end{array}$ & $\begin{array}{c}\text { Cohen's d } \\
\left(\begin{array}{c}0 \\
(+,\end{array}\right)\end{array}$ & $\begin{array}{l}\Delta \mathbf{N} \\
q 0^{\lambda}\end{array}$ \\
\hline & & & & & & & & Relationship security $T_{2}-T_{3} ;$ same partner & $r=-0.14$ & 0.28 & $\downarrow$ \\
\hline & & & & & & & & Relationship security $T_{1}-T_{2}$; changed partner & & n.a. & n.a. \\
\hline & & & & & & & & Relationship security $T_{2}-T_{3}$; changed partner & $r=-0.22$ & 0.45 & $\downarrow$ \\
\hline & & & & & & & & Relationship dependency $T_{1}-T_{2} ;$ same partner & $r=-0.14$ & 0.28 & $\downarrow$ \\
\hline & & & & & & & & Relationship dependency $T_{2}-T_{3}$; changed partner & n.s. & n.s. & - \\
\hline & & & & & & & & Relationship satisfaction $T_{1}-T_{2}$; same partner & $r=-0.15$ & 0.30 & $\downarrow$ \\
\hline & & & & & & & & Relationship satisfaction $T_{2}-T_{3}$; same partner & $r=-0.13$ & 0.26 & $\downarrow$ \\
\hline & & & & & & & & Relationship satisfaction $T_{1}-T_{2}$; changed partner & n.a. & n.a. & n.a. \\
\hline & & & & & & & & Relationship satisfaction $T_{2}-T_{3} ;$ changed partner & $r=-0.23$ & 0.47 & $\downarrow$ \\
\hline \multirow{3}{*}{ Roberts } & & & & & & & & Stress reaction & $\mathrm{b}$ & 0.27 & $\uparrow$ \\
\hline & & & & & & & & Aggression & $\mathrm{b}$ & 0.38 & $\uparrow$ \\
\hline & & & & & & & & Alienation & $\mathrm{b}$ & -- & - \\
\hline \multirow[t]{2}{*}{ Scollon } & 2006 & Population & 1130 & 52 & $\mathrm{R}=16-70$ & 8 & EPI & Work satisfaction & $r=-.64^{\mathrm{b}}(\mathrm{a})$ & 1.66 & $\downarrow$ \\
\hline & & Australia & & & $\mathrm{M}=37.2(13.3)$ & & & Relationship satisfaction & $r=-.42^{\mathrm{c}}(\mathrm{a})$ & 0.92 & $\downarrow$ \\
\hline \multirow[t]{3}{*}{ Van Aken } & 2006 & Families & 1152 & mixed & Fathers $\mathrm{M}=43.9$ & 3 & Big Five Factors & Life satisfaction & $\mathrm{b}$ &,$--- 0.24^{\mathrm{b}}$ & $-\downarrow$ \\
\hline & & & (s) & & (3.27) & & (30 adjectives) & Work stress & $\mathrm{b}$ & $0.20^{\mathrm{a}}, 0.41^{\mathrm{a}}$ & $\uparrow \uparrow$ \\
\hline & & & & & $\begin{array}{l}\text { Mothers } M=41.7 \\
\text { (3.71) }\end{array}$ & & Emotional stability & Father: Perceived partner support & $\mathrm{b}$ & $0.14^{\mathrm{c}},--$ & $\downarrow-$ \\
\hline \multirow[t]{2}{*}{ Robins } & 2005 & Population & & 59 & $\mathrm{M}=18$ & 4 & NEO-FFI & Higher college grades & $\mathrm{b}$ & & - \\
\hline & & of students & & & & & & Feeling positively about grades & $\mathrm{b}$ & 0.77 & $\downarrow$ \\
\hline \multirow[t]{3}{*}{ Steunenberg } & 2005 & Population & 2117 & 51 & $\mathrm{R}=55-85, \mathrm{M}=69.5$ & 6 & DPQ & Physical health related variables & & & - \\
\hline & & & & & & & & Presence chronic disease & & & - \\
\hline & & & & & & & & Cognitive functioning & & & - \\
\hline \multirow[t]{12}{*}{ Branje } & 2004 & Families & 1152 & 50 & Fathers $\mathrm{M}=43.9$, & 2 & Big Five Factors & Youngest child - perceived decrease social support father & $\mathrm{b}$ & 0.12 & $\uparrow$ \\
\hline & & & (s) & & $\mathrm{R}=34-56$ & & (30 adjectives) & Youngest child - perceives decrease social support mother & $\mathrm{b}$ & & - \\
\hline & & & & & Mothers $\mathrm{M}=41.7$, & & Emotional Stability & Youngest child - perceives decrease social support sibling & $\mathrm{b}$ & 0.12 & $\uparrow$ \\
\hline & & & & 53 & $\mathrm{R}=34-51$ & & & Oldest child - perceives decrease social support father & $\mathrm{b}$ & & - \\
\hline & & & & & Oldest children & & & Oldest child - perceives decrease social support mother & $\mathrm{b}$ & & - \\
\hline & & & & & $\mathrm{M}=14.5$ & & & Oldest child - perceives decrease social support sibling & $\mathrm{b}$ & & - \\
\hline & & & & & Youngest child & & & Mother - perceives decrease social support husband & $\mathrm{b}$ & & - \\
\hline & & & & & $\mathrm{M}=12.4$ & & & Mother - perceives decrease social support youngest child & $\mathrm{b}$ & & - \\
\hline & & & & & & & & Mother - perceives decrease social support oldest child & $\mathrm{b}$ & & - \\
\hline & & & & & & & & Father - perceives decrease social support husband & $\mathrm{b}$ & & - \\
\hline & & & & & & & & Father - perceives decrease social support youngest child & $\mathrm{b}$ & & - \\
\hline & & & & & & & & Father - perceives decrease social support oldest child & $\mathrm{b}$ & & - \\
\hline Möller & 2004 & Population & 2212 & 43 & $R=15-37$ & 15 & $\begin{array}{l}\text { Age } 15 \mathrm{HSPQ} \\
\text { Age } 37 \mathrm{EPO}-\mathrm{I}\end{array}$ & Stable partnership in mid-life & & & - \\
\hline Roberts & 2004 & $\begin{array}{l}\text { Population } \\
\text { USA }\end{array}$ & 305 & 56 & $\mathrm{R}=\geq 18$ & 4 & $\begin{array}{l}\text { NEO-FFI } \\
\text { Adj. for } \mathrm{N} \text { at } T_{1}\end{array}$ & $\begin{array}{l}\text { Person-Environment fit: Alpha fit (p) } \\
\text { Person-Environment fit: Beta fit (p) }\end{array}$ & $r=-.14^{\mathrm{c}}$ & 0.28 & $\stackrel{\downarrow}{-}$ \\
\hline & 2003 & Twins & 1914 & 0 & R: 14-54 & 10 & EPQ & Family Dysfunction & $\mathrm{k}$ & 0.33 & $\uparrow$ \\
\hline Maiden & 2003 & population & 74 & 100 & $\mathrm{M}=74$ & 6 & NEO-PI & Greater unmet needs in resources (i) & $\mathrm{b}$ & 0.67 & $\uparrow$ \\
\hline
\end{tabular}




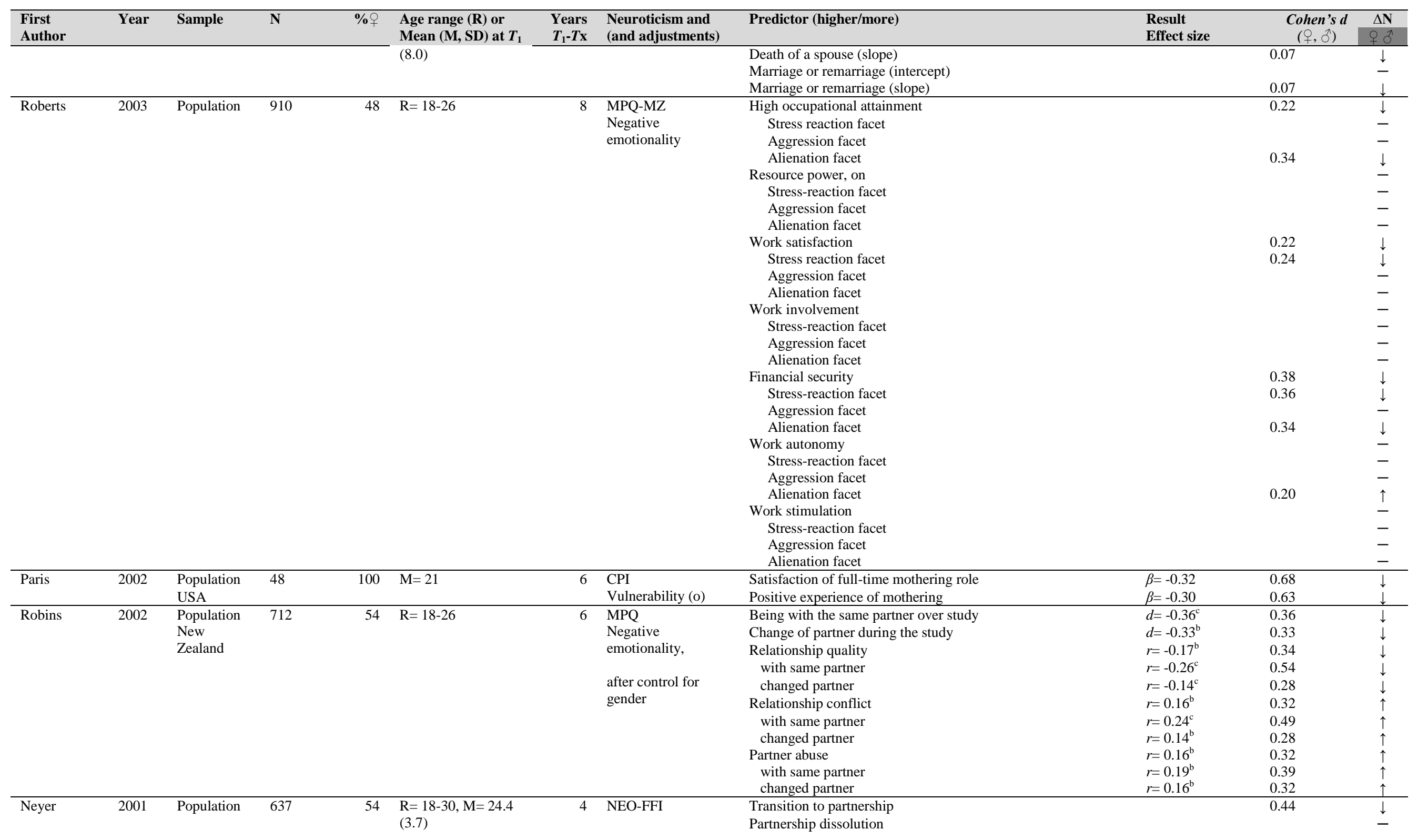




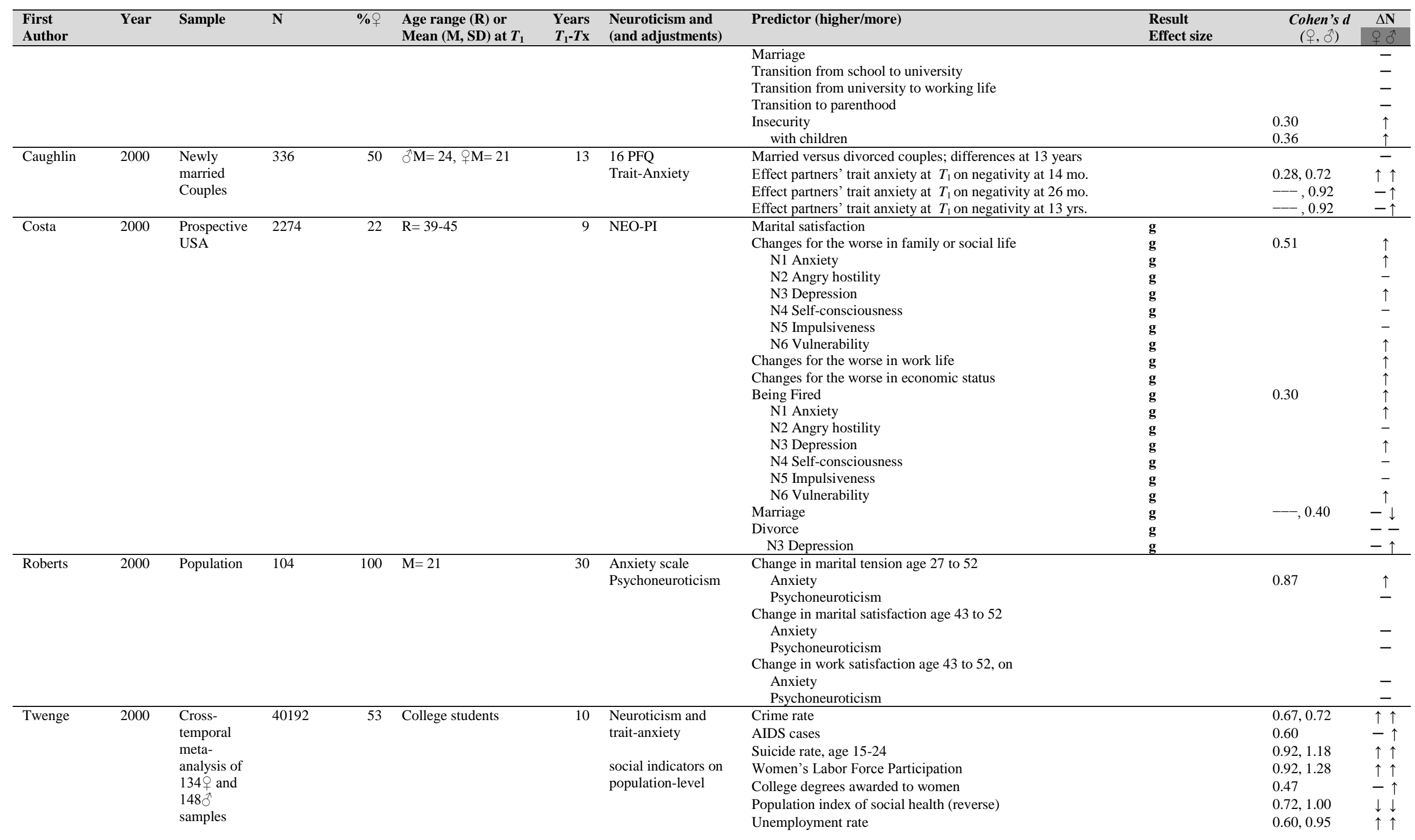




\begin{tabular}{|c|c|c|c|c|c|c|c|c|c|c|c|}
\hline $\begin{array}{l}\text { First } \\
\text { Author }\end{array}$ & Year & Sample & $\mathbf{N}$ & $\%$ \% & $\begin{array}{l}\text { Age range }(\mathrm{R}) \text { or } \\
\text { Mean }(\mathrm{M}, \mathrm{SD}) \text { at } T_{1}\end{array}$ & $\begin{array}{l}\text { Years } \\
T_{1}-T \mathrm{x} \\
\end{array}$ & $\begin{array}{l}\text { Neuroticism and } \\
\text { (and adjustments) }\end{array}$ & Predictor (higher/more) & $\begin{array}{l}\text { Result } \\
\text { Effect size }\end{array}$ & $\begin{array}{c}\text { Cohen's d } \\
\left(\begin{array}{l}0 \\
\left(+, 0^{-1}\right)\end{array}\right.\end{array}$ & $\begin{array}{l}\Delta \mathbf{N} \\
90 \\
0\end{array}$ \\
\hline & & & & & & & & Divorce rate & & $0.84,1.09$ & $\uparrow \uparrow$ \\
\hline & & & & & & & & Percentage of people living alone & & $0.74,1.03$ & $\uparrow \uparrow$ \\
\hline & & & & & & & & Women's age at first marriage & & $0.72,0.98$ & $\uparrow \uparrow$ \\
\hline & & & & & & & & Birth rate (reverse, in population & & $0.65,0.87$ & $\downarrow \downarrow$ \\
\hline & & & & & & & & Social connectedness + other threats & & $1.71,2.33$ & $\uparrow \uparrow$ \\
\hline Vollrath & 2000 & Students & 119 & 55 & $\mathrm{M}=22.6(3.6)$ & 3 & NEO-FFI & Concerns about academic capabilities & $\mathrm{d}$ & 0.39 & $\uparrow$ \\
\hline \multirow[t]{4}{*}{ Asendorpf } & 1998 & Prospective & 132 & 70 & $\mathrm{R}=18-22$ & 1.5 & NEO-FFI & Change in \# peer relations & $\mathrm{b}$ & & - \\
\hline & & Case- & & & $+\mathrm{M}=20$ & & & Conflict with parents/ peers & $\mathrm{b}$ & & - \\
\hline & & control & & & $\mathrm{M}=20.4$ & & & Falling in love & $\mathrm{b}$ & & - \\
\hline & & & & & & & & Perceived support parents/peers & $\mathrm{b}$ & & - \\
\hline Dunne & 1997 & $\begin{array}{l}\text { Twins } \\
\text { Australia }\end{array}$ & 6463 & 66 & $\mathrm{R}=17-88$ & 8 & EPQ & $\begin{array}{l}\text { Maintained versus decreased church attendance to twice a year } \\
\text { Increased from yearly to at least monthly }\end{array}$ & $\begin{array}{l}\mathrm{F}=16.47 * * * \\
\mathrm{~F}=1.46\end{array}$ & 0.22 & $\stackrel{\uparrow}{-}$ \\
\hline Santor & 1997 & & & & & & & & & & \\
\hline \multirow[t]{7}{*}{ Suh } & 1996 & Population & 115 & 63 & $R=20-23$ & 2 & $T_{1}:$ NEO-PI & Negative life events past 3 month & & & $\uparrow \uparrow$ \\
\hline & & & & & & & $T_{2}:$ NEI-FFI & Negative life events past 6 months & & & - \\
\hline & & & & & & & $T_{1}:$ NEO-PI & Negative life events past 12 months & & & - \\
\hline & & & & & & & $T_{2}:$ NEI-FFI & Negative life events 24 months & & & - \\
\hline & & & & & & & & Negative life events 36 & & & - \\
\hline & & & & & & & & Negative life events $>48$ months before $\mathrm{T} 2$ & & & $\uparrow$ \\
\hline & & & & & & & & Positive life events & & & - \\
\hline Barnett & 1995 & & & & & & & & & & \\
\hline Andrews & 1993 & $\begin{array}{l}\text { Prospective } \\
\text { case-control }\end{array}$ & 1042 & Nescio & $\begin{array}{l}\mathrm{M}=17.12 \\
17.2 \text { for controls }\end{array}$ & 1.5 & $\begin{array}{l}\text { Personality } \\
\text { vulnerability } \\
\text { index }(\mathrm{m})\end{array}$ & Exchange students after 12 months abroad & & 0.28 & $\downarrow$ \\
\hline Kurdek & 1993 & Population & 1076 & 50 & & 5 & $\begin{array}{l}\text { Symptom checklist } \\
90-\mathrm{R}\end{array}$ & Unstable marriage (husband) & $\begin{array}{l}F_{(1,183)}=0.63 \\
F_{(1,183)}=0.13\end{array}$ & & $\begin{array}{l}\uparrow_{\uparrow} \\
\uparrow\end{array}$ \\
\hline Magnus & 1993 & $\begin{array}{l}\text { Population } \\
\text { USA }\end{array}$ & 136 & 63 & $R=22-26$ & 4 & NEO-PI-R & $\begin{array}{l}\text { Objective positive events } \\
\text { Objective negative events }\end{array}$ & & & - \\
\hline \multirow[t]{4}{*}{ Duggan } & 1991 & Prospective & 34 & 70 & $R=16-67$ & 18 & EPI & Good vs. poor outcome groups (4 cat.) & & & - \\
\hline & & case-control & & & & & & Length of admission (short, long) & & 3.94 & $\downarrow$ \\
\hline & & & & & & & & Number of weeks in hospital (few, many) & & & - \\
\hline & & & & & & & & Amount of depressive episodes (few, many) & & & - \\
\hline \multirow[t]{3}{*}{ Kaprio } & 1990 & Twins & 1078 & 52 & $\mathrm{R}=18-25$ & 6 & EPI & Cohabiting at $T_{1}$ and still so at $T_{2}$ (vs. twins who separated) & & $0.40,0.43$ & $\uparrow \uparrow$ \\
\hline & & & & & & & Co-twin & Cohabiting at $T_{1, \text { separated but in frequent contact at } T_{2}}$ & & $0.40,0.19$ & $\downarrow \downarrow$ \\
\hline & & & & & & & resemblance & Cohabiting at $T_{1}$, separated but rare contact at $T_{2}$ & & $0.92,0.29$ & $\downarrow \downarrow$ \\
\hline \multirow[t]{2}{*}{ Rabins } & 1990 & $\begin{array}{l}\text { Prospective } \\
\text { case-control }\end{array}$ & 62 & 68 & $\mathrm{M}=60.8$ & 2 & NEO & $\begin{array}{l}\text { Caregiver whose relative with dementia is placed in a } \\
\text { nursing home during the study vs. caregivers whose } \\
\text { relatives stayed home. }\end{array}$ & & & \\
\hline & & & & & & & & $\begin{array}{l}\text { Negative mood } \\
\text { Guilt }\end{array}$ & & & - \\
\hline Kiernan & 1986 & $\begin{array}{l}\text { Population } \\
\text { Britain }\end{array}$ & 1857 & 100 & $\mathrm{M}=16$ & 10 & MPI & Divorced/separated vs. lasting marriages (at age 32) (q) & $\mathrm{M}(\mathrm{SD})$ & 0.63 & $\stackrel{\uparrow}{\imath}$ \\
\hline
\end{tabular}




\begin{tabular}{|c|c|c|c|c|c|c|c|c|c|c|c|}
\hline $\begin{array}{l}\text { First } \\
\text { Author }\end{array}$ & Year & Sample & $\mathbf{N}$ & $\%$ \% & $\begin{array}{l}\text { Age range }(\mathbf{R}) \text { or } \\
\text { Mean }(\mathrm{M}, \mathrm{SD}) \text { at } T_{1}\end{array}$ & $\begin{array}{l}\text { Years } \\
T_{1}-T x \\
\end{array}$ & $\begin{array}{l}\text { Neuroticism and } \\
\text { (and adjustments) }\end{array}$ & Predictor (higher/more) & $\begin{array}{l}\text { Result } \\
\text { Effect size }\end{array}$ & $\begin{array}{c}\text { Cohen's d } \\
\left(\begin{array}{l}\left(+, 0^{-1}\right) \\
\end{array}\right.\end{array}$ & $\begin{array}{l}\Delta \mathbf{N} \\
00^{\pi} \\
\end{array}$ \\
\hline Sagy & 1986 & $\begin{array}{l}\text { Population } \\
\text { Israel }\end{array}$ & 418 & 49 & $\mathrm{R}=14-18$ & 0.3 & $\begin{array}{l}\text { STAI } \\
\text { Trait anxiety }\end{array}$ & Severe stress situation ; evacuation of one's home & $\mathrm{M}(\mathrm{SD})$ & & - \\
\hline Kessler & 1984 & $\begin{array}{l}\text { Population } \\
\text { USA }\end{array}$ & 6919 & mixed & $\mathrm{R}=>18$ & 1 & $\begin{array}{l}\text { Psychological } \\
\text { distress }\end{array}$ & $\begin{array}{l}\text { Income loss } \\
\text { Separation and divorce } \\
\text { Other Love Loss } \\
\text { Death of a loved one } \\
\text { Ill Health } \\
\text { Negative network event } \\
\end{array}$ & $\begin{array}{l}b=0.330,0.342 \\
b=0.263,0.143 \\
b=0.354,0.374 \\
b=0.193,-0.003 \\
b=0.245,0.176 \\
b=0.129,-0.028\end{array}$ & $\begin{array}{l}0.24,0.41 \\
0.15,0.09 \\
0.23,0.22 \\
0.12 \\
0.27,0.22 \\
0.25 \\
\end{array}$ & 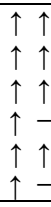 \\
\hline Koskenvuo & 1984 & Twins & 9912 & 0 & $\mathrm{R}=>18$ & - & $\begin{array}{l}\text { Eysenck's N-scale, } \\
\text { modified by } \\
\text { Floderus. } \\
\text { Adj. for age }\end{array}$ & $\begin{array}{l}\text { Years of education } \\
\text { Income } \\
\text { Unemployment vs. working } \\
\text { Heavy physical work vs. sedentary work } \\
\text { Divorce } \\
\text { Changes of workplace for negative reasons } \\
\text { Changes of place of residence for negative reasons } \\
\text { Night- and shift-work schedules vs. day work } \\
\text { Service work vs. farming work } \\
\text { Monotony of work } \\
\text { Chronic bronchitis vs. no chronic bronchitis } \\
\text { Illness or disability pension vs. at work } \\
\text { Swedish speaking vs. Finnish } \\
\text { Heavy drinking } \\
\text { Stress of daily activities }\end{array}$ & $\begin{array}{ll}\mathrm{c} \\
\mathrm{c} \\
\mathrm{f} \\
\mathrm{f} \\
\mathrm{c} \\
\mathrm{c} \\
\mathrm{c} \\
\mathrm{f} \\
\mathrm{f} \\
\mathrm{c} \\
\mathrm{f} \\
\mathrm{f} \\
\mathrm{f} \\
\mathrm{c} \\
\mathrm{c}\end{array}$ & $\begin{array}{l}0.12 \\
0.08 \\
0.14 \\
0.07 \\
0.14 \\
0.24 \\
0.22 \\
0.09 \\
0.16 \\
0.28 \\
0.37 \\
0.24 \\
0.18 \\
0.46 \\
0.95 \\
\end{array}$ & $\begin{array}{l}\downarrow \\
\downarrow \\
\uparrow \\
\uparrow \\
\uparrow \\
\uparrow \\
\uparrow \\
\uparrow \\
\uparrow \\
\uparrow \\
\uparrow \\
\uparrow \\
\uparrow \\
\uparrow \\
\downarrow \\
\uparrow \\
\uparrow \\
\uparrow\end{array}$ \\
\hline Brousseau & 1981 & Population & 176 & 0 & $\mathrm{R}=25-45$ & 7.44 & $\begin{array}{l}\text { GZTS } \\
\text { Emotional stability } \\
\text { (n) }\end{array}$ & $\begin{array}{l}\text { Job characteristics: } \\
\text { Skill variety } \\
\text { Task identity } \\
\text { Task significance } \\
\text { Autonomy } \\
\text { Feedback } \\
\end{array}$ & & $\begin{array}{l}0.34 \\
0.30 \\
0.56 \\
\\
0.36\end{array}$ & $\begin{array}{l}\uparrow \\
\downarrow \\
\downarrow \\
\frac{\downarrow}{\downarrow}\end{array}$ \\
\hline Brousseau & 1978 & $\begin{array}{l}\text { Population } \\
\text { USA }\end{array}$ & 116 & 0 & $\mathrm{R}=25-45$ & 6 & $\begin{array}{l}\text { GZTS , Freedom } \\
\text { from Depression } \\
\text { Scale (n) }\end{array}$ & $\begin{array}{l}\text { Job characteristics }(\mathrm{r}) \\
\text { Skill variety } \\
\text { Task identity } \\
\text { Task significance } \\
\text { Autonomy } \\
\text { Feedback } \\
\end{array}$ & $\begin{array}{l}r=.23^{\mathrm{b}} \\
r=.21^{\mathrm{c}} \\
r=.07^{\mathrm{ns}} \\
r=.24^{\mathrm{b}} \\
r=.07^{\mathrm{ns}} \\
r=.19^{\mathrm{c}}\end{array}$ & $\begin{array}{l}0.47^{\mathrm{b}} \\
0.43^{\mathrm{c}} \\
0.49^{\mathrm{b}} \\
0.38^{\mathrm{c}}\end{array}$ & $\begin{array}{l}\downarrow \\
\downarrow \\
\frac{\downarrow}{\downarrow} \\
\frac{\downarrow}{\downarrow}\end{array}$ \\
\hline
\end{tabular}

Note adj.= adjusted; 16PFQ= 16 personality factors questionnaire; $\mathbf{A B V}=$ Amsterdamse Biografische Vragenlijst; $\mathbf{C P I}=$ California Psychological Inventory; $\mathbf{D 5 D}=$ Système de Description en Cinq Dimensions; EPI= Eysenck Personality Inventory; EPQ= Eysenck Personality Questionnaire; GZTS= Guilford-Zimmerman Temperament Survey; $\mathbf{M D}=$ major depression; $\mathbf{N}=$ neuroticism; $\mathbf{N E}=$ negative emotionality; $\boldsymbol{r}=$ correlation coefficient; $\mathbf{S T A I}=$ State-Trait Anxiety Index; $\boldsymbol{T}_{\mathbf{1}}=$ baseline; $\boldsymbol{T}_{\mathbf{2}}=$ follow-up; $\mathbf{U S A}=$ united states of America. (a) Correlated change (of slopes); (b) standardized regression coefficient beta, (c) partial correlation; (d) cross-lagged coefficient; (f) Odds-ratios of means; (g) t- or f-tests; (h) Valence-ratings were made on a 5-point scale with 1=high negative impact till 5=very positive impact; (i) For example, income, health care, housing,

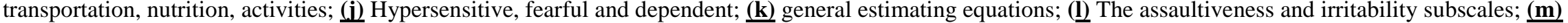
Personality Vulnerability index: $0.6 *$ EPI-N-scale (=trait-anxiety index) $+0.2 *$ locus of control (LCB) $+0.3 *$ Defense Style; (n) emotional stability is the low pole of neuroticism, and reported effects are therefore presented in reverse i.e. applied to neuroticism; $\underline{(\mathbf{0})}$ Depressed mood and Psychophysiological distress scales; perceptions or 
bodily feelings associated with anxiety and depression; (p) person-environment fit is the match between subjective values and desires of the individual and for Alpha fit a consensus judgment of the resources provided by the environment, and for Beta fit the subjective resources of the environment; (q) the effect must be strongly inflated

because the initial (pre-marriage) difference was already $d=0.57$, suggesting that the effect of divorce on neuroticism is merely $d=0.06$; $(\mathbf{r})$ the mean of the five other job dimension scores for each respondent; (s) 288 middle-class two-parent Dutch families with at least two adolescent children between age 11 and 15 from the Nijmegen Family and Personality Study; (t) Psycho-education, breathing and relaxation strategies, monitoring and challenging thoughts, and social skills training; (u) interaction term sex $*$ variable is used to examine gender-effects. Significance, ${ }^{\mathrm{a}}=p<.001,{ }^{\mathrm{b}}=p<01,{ }^{\mathrm{c}}=p<.05$ 